Florida International University

FIU Digital Commons

FIU Electronic Theses and Dissertations

University Graduate School

3-29-2019

\title{
Poly-tobacco Use Among Youth and Adults in the United States
}

Olatokunbo Osibogun

oosib002@fiu.edu

Follow this and additional works at: https://digitalcommons.fiu.edu/etd

Part of the Epidemiology Commons

\section{Recommended Citation}

Osibogun, Olatokunbo, "Poly-tobacco Use Among Youth and Adults in the United States" (2019). FIU Electronic Theses and Dissertations. 3968.

https://digitalcommons.fiu.edu/etd/3968

This work is brought to you for free and open access by the University Graduate School at FIU Digital Commons. It has been accepted for inclusion in FIU Electronic Theses and Dissertations by an authorized administrator of FIU Digital Commons. For more information, please contact dcc@fiu.edu. 


\title{
FLORIDA INTERNATIONAL UNIVERSITY
}

\author{
Miami, Florida
}

POLY-TOBACCO USE AMONG YOUTH AND ADULTS IN THE UNITED STATES

A dissertation submitted in partial fulfillment of the

requirements for the degree of

DOCTOR OF PHILOSOPHY

in

PUBLIC HEALTH

by

Olatokunbo Osibogun

2019 
To: Dean Tomás R. Guilarte

Robert Stempel College of Public Health and Social Work

This dissertation, written by Olatokunbo Osibogun, and entitled Poly-tobacco Use Among Youth and Adults in the United States, having been approved in respect to style and intellectual content, is referred to you for judgment.

We have read this dissertation and recommend that it be approved.

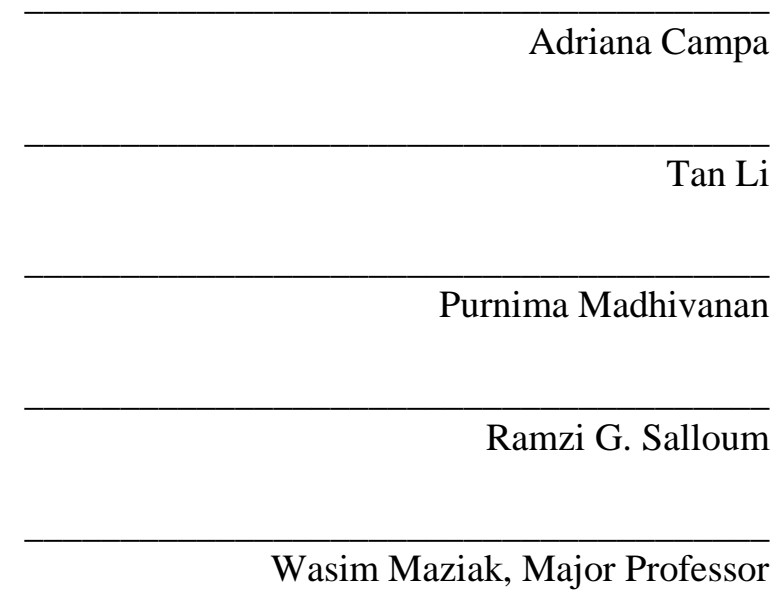

Date of Defense: March 29, 2019

The dissertation of Olatokunbo Osibogun is approved.

Dean Tomás R. Guilarte Robert Stempel College of Public Health and Social Work

Andrés G. Gil

Vice President for Research and Economic Development and Dean of the University Graduate School

Florida International University, 2019 
(C) Copyright 2019 by Olatokunbo Osibogun

All rights reserved. 


\section{DEDICATION}

This dissertation is dedicated to my family. Their unconditional love and support made this work possible. 


\section{ACKNOWLEDGMENTS}

I am indebted to God for His grace to complete this dissertation. I am sincerely thankful to my family for their constant support and unwavering love during this academic journey. I thank my major professor Dr. Wasim Maziak for his unending patience, support and critical feedback towards ensuring the success of this dissertation. I also thank Drs. Li and Bursac for entertaining my constant analytical questions and providing me with the appropriate analytical guidance. For the critical feedback and continual encouragement from Drs. Campa, Madhivanan and Salloum, I am also grateful.

This work was supported by the Epidemiology Departmental Graduate Assistantship, University Graduate School Dissertation Year Fellowship from Florida International University and U54MD012393-01 for the FIU-RCMI. The content is solely the responsibility of the authors and does not represent the views of Florida International University. 


\title{
ABSTRACT OF THE DISSERTATION
}

\section{POLY-TOBACCO USE AMONG YOUTH AND ADULTS IN THE UNITED STATES}

by

\section{Olatokunbo Osibogun}

Florida International University, 2019

\author{
Miami, Florida
}

\section{Professor Wasim Maziak, Major Professor}

This dissertation 1) described prevalence and correlates of poly-tobacco use among US youth and young adults; 2) addressed positive and negative transitions of e-cigarettes among US youth and adults and 3) examined the 2-year transition of dual e-cigarette/cigarette use among US adults in relation to nicotine dependence (ND) symptoms, interest in quitting, and cardiovascular disease (CVD) factors. Data from 2013-2016 of the Population Assessment of Tobacco and Health Study were used.

In the first study, $3.6 \%$ of youth (12-17years) and $18.3 \%$ of young adults (18-34years) were current poly-tobacco users between 2013-2014. Common poly-tobacco products combination was cigarettes and e-cigarettes for youth and young adults. Among youth, heavy drinking was associated with higher odds of poly-tobacco use. Factors associated with higher odds of poly-tobacco use among young adults included males, younger adults (18-24years), those with lower levels of educational attainment, residing in the South, heavy drinking, and marijuana use.

In the second study, between 2013-2016, e-cigarette use increased only in youth. Young e-cigarette users were more likely to be never cigarette smokers compared to older users. Among 
youth e-cigarette users at each wave, the proportion of never cigarette smokers rose from $24.1 \%$ in Wave 1 to $42.6 \%$ in Wave 3 ( $p=0.0001$ for trends). Among adult e-cigarette dual users in Wave $1,8.8 \%$ transitioned to no tobacco use at Wave 3, 6.2\% to mono e-cigarette use, while $85 \%$ either relapsed to cigarettes $(53.5 \%)$ or continued dual use $(31.5 \%)$.

In the final study, among 1,870 adult dual tobacco users from Wave 1, 25.8\% (95\% CI $23 \cdot 5-28 \cdot 3)$ remained dual users 2 years later, $11 \cdot 9 \%(95 \%$ CI 10.5-13.5) reported no tobacco use (cessation transition), 7.0\% (95\% CI 5.5-8·7) reported e-cigarette mono use (harm reduction transition), and 55.3\% (95\% CI 52-6-58.0) reported cigarette mono use (relapse transition). In the adjusted regression analysis, ND severity was associated with lower odds of cessation (OR $0 \cdot 36$; 95\% CI 0.15-0.88) and harm reduction (OR 0.18; 95\% CI 0.04-0.82) transitions. Interest in quitting and CVD factors were not associated with cessation or harm reduction.

Collectively, our study findings emphasize the need for stricter tobacco regulatory policies to prevent another tobacco epidemic. 


\section{TABLE OF CONTENTS}

CHAPTER

PAGE

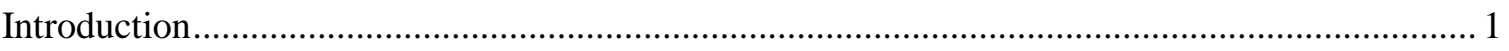

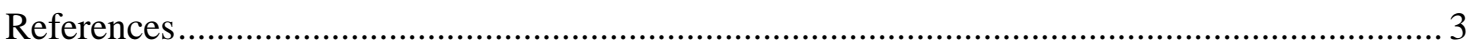

Manuscript 1 .

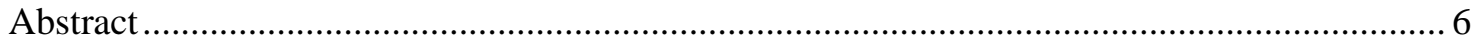

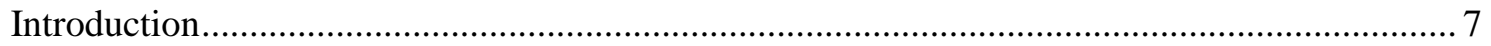

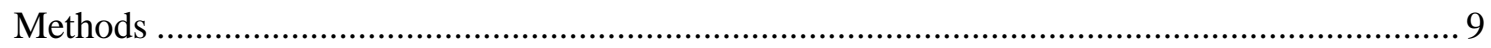

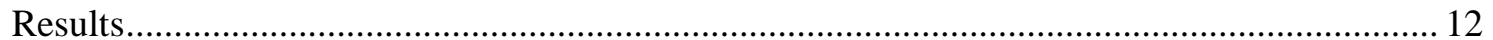

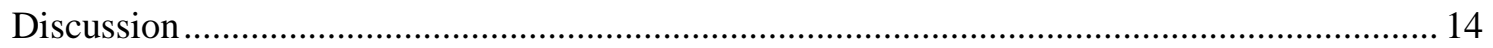

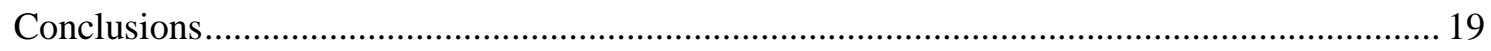

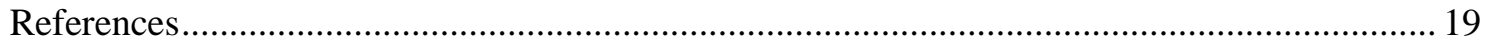

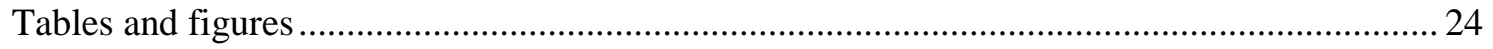

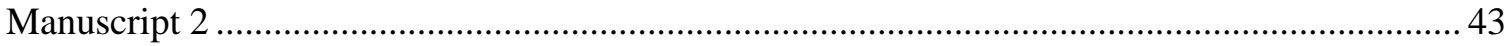

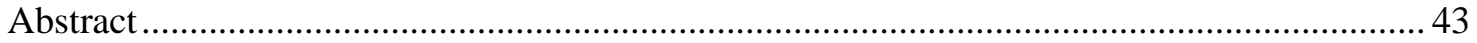

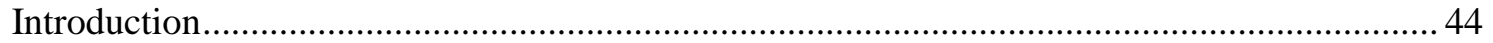

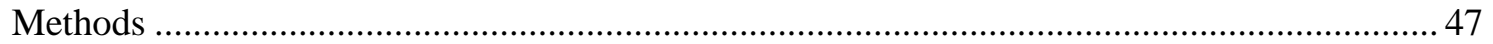

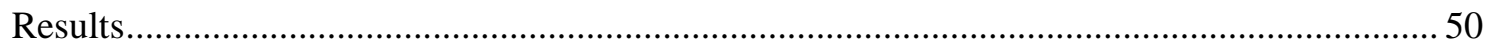

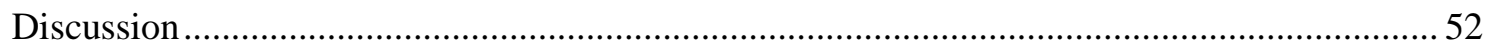

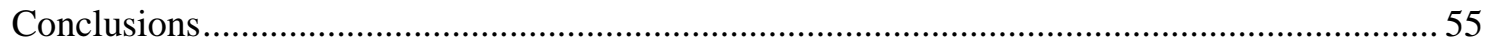

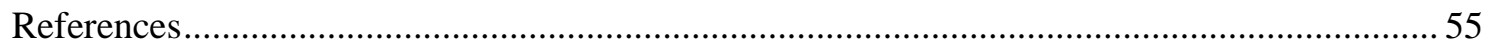

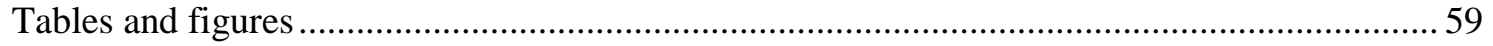

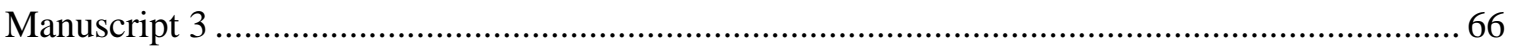

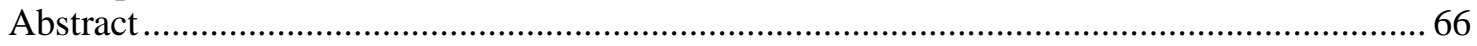

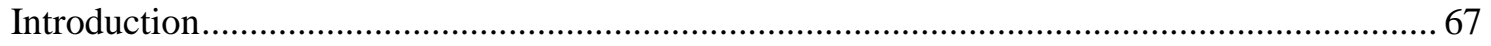

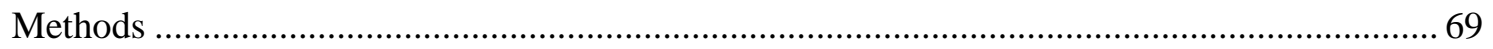

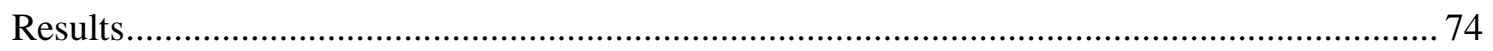

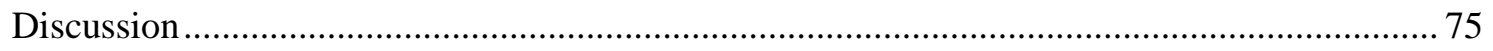

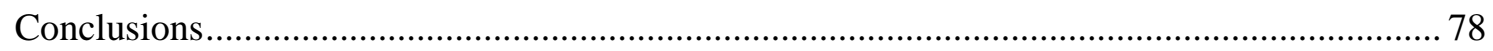

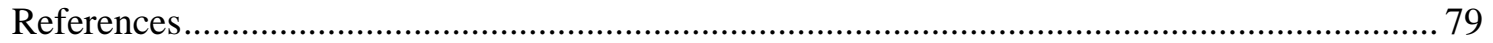

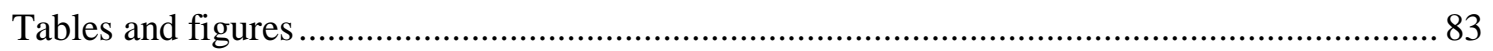

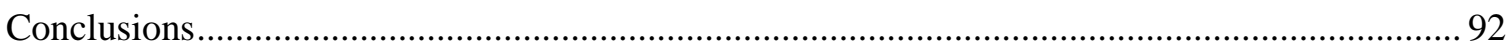

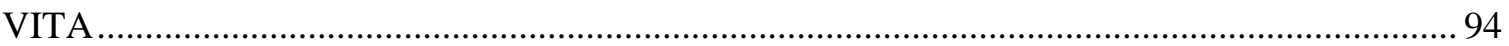




\section{LIST OF TABLES}

TABLES

PAGE

Manuscript 1

Table 1 Characteristics of Youth (12-17 years) by Tobacco Status: PATH Study,

2013-2014 (N=12,898)

Table 2 Characteristics of Young Adults (18-34 years) by Tobacco Status: PATH Study, 2013-2014 ( $\mathrm{N}=14,931)$

Table 3 Multivariable associations for poly-tobacco use compared to mono-tobacco use among youth (12-17 years) past 30 days tobacco users overall, and stratified by gender:

PATH Study, 2013-2014

Table 4 Multivariable associations for poly-tobacco use compared to mono-tobacco use among young adults (18-34 years) past 30 days tobacco users overall, and stratified by gender: PATH Study, 2013-2014

Supplementary table 1 Characteristics of Tobacco users among Youths (12-17 years):

PATH Study, 2013-2014

Supplementary table 2 Characteristics of Tobacco users among Young Adults

(18-34 years): PATH Study, 2013-2014

Manuscript 2

Table 1 Prevalence of current e-cigarette use among US youth (12-17 years) by cigarette

smoking history: PATH Cohort Study, 2013-2016.

Table 2 Prevalence of current e-cigarette use among US adults ( $\geq 18$ years) by cigarette smoking history: PATH Cohort Study, 2013-2016.

Table 3 Transition of current e-cigarette use among US youth (12-17 years) between Waves 1 and 3 of PATH Cohort Study, 2013-2016

Table 4 Transition of current e-cigarette use among US adults ( $\geq 18$ years) between

Waves 1 and 3 of PATH Cohort Study, 2013-2016

Manuscript 3

Table 1 Prevalence characteristics of adult ( $\geq 18$ years) dual e-cigarette/cigarette users according to main transitions at 2-year follow-up: PATH Cohort Study, 2013-2016.

Table 2 Nicotine dependence symptoms and interest in quitting among adult ( $\geq 18$ years) dual e-cigarette/cigarette users according to main transitions at 2-year follow-up: PATH Cohort Study, 2013-2016. 
Table 3 Clinical cardiovascular disease factors among adult ( $\geq 18$ years) dual ecigarette/cigarette users according to main transitions at 2-year follow-up: PATH Cohort Study, 2013-2016.

Table 4 Univariate predictors of dual use transitions at 2-year follow up among US adults

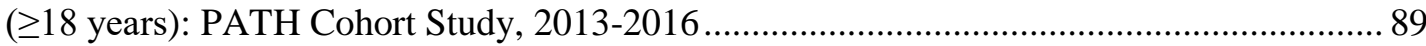

Table 5 Multivariate predictors of dual use transitions at 2-year follow up among US adults ( $\geq 18$ years): PATH Cohort Study, 2013-2016 ..................................................................... 91 


\section{ABBREVIATIONS AND ACRONYMS}

$\begin{array}{ll}\text { aOR } & \text { Adjusted odds ratio } \\ \text { CDC } & \text { Centers for Disease Control and Prevention } \\ \text { CI } & \text { Confidence interval } \\ \text { CVD } & \text { Cardiovascular disease } \\ \text { DM } & \text { Diabetes Mellitus } \\ \text { ENDS } & \text { Electronic nicotine delivery systems } \\ \text { FDA } & \text { Food and Drug Administration } \\ \text { MI } & \text { Myocardial infarction } \\ \text { NASEM } & \text { National Academies of Science, Engineering and Medicine } \\ \text { ND } & \text { Nicotine dependence } \\ \text { NIH } & \text { National Institutes of Health } \\ \text { PATH } & \text { Population Assessment of Tobacco and Health } \\ \text { THR } & \text { Tobacco harm reduction } \\ \text { US } & \text { United States }\end{array}$




\section{Introduction}

Poly-tobacco use (concurrent use of two or more tobacco products) is a common public health problem (McMillen et al., 2012; Lee et al., 2014), particularly with the emergence of alternate tobacco products such as electronic cigarettes (a.k.a. e-cigarettes, electronic nicotine delivery systems, ENDS) (Delnevo 2014; Maxwell 2010). These products are increasingly promoted as cigarette alternatives and potentially less harmful than traditional cigarettes (Mejia \& Ling 2010; Regan et al., 2012). Previous studies report that young adults are more likely to report the concurrent use of tobacco products compared to older adults (Backinger et al., 2008; Fix et al., 2014), which is a problematic issue as the use of a combination of tobacco products at the same time, may lead to an increased risk of tobacco-related illnesses, illicit drug use and nicotine dependence compared to a single tobacco product use (Everett et al., 2000; Bombard et al., 2007; O’Connor 2012).

The dramatic increase in e-cigarettes use among youth in the United States (US) has also necessitated a comprehensive examination of the regulatory implications of their spread in the society, despite the steady decline in cigarette smoking (Barrington-Trimis et al., 2016; Leventhal et al., 2015; Primack et al., 2015; Unger et al., 2016). This questions the role of e-cigarettes in tobacco harm reduction (THR) in the society, and the potential to increase smoking uptake among young people (US Department of Health and Human Services 2016; NASEM 2018). Findings from the National Youth Tobacco Survey that showed a 78\% increase in e-cigarette use among high school students in 2018 (Cullen et al., 2018) has raised concerns about the increasing number of tobacco naïve youth initiating e-cigarettes in the US, which may lead to cigarette smoking transitions (Aleyan et al., 2018; Soneji et al., 2017; Chapman et al., 2018).

A major argument of e-cigarette harm reduction is that harms related to smoking will reduce through cessations and reductions in smoking frequency, if e-cigarette use is encouraged. 
From this viewpoint, e-cigarettes' potential for tobacco control promises reduction in the global burden of disease caused by smoking (Abrams et al., 2018; McNeil et al., 2015; Hajek et al., 2014). This is based on the assumption that the overall net contribution of e-cigarette use across populations will be positive, i.e., the number of smokers who quit smoking using e-cigarettes will be more than the combined numbers of those who relapse to smoking, become dual users (i.e., using e-cigarettes and cigarettes), and naïve smokers who initiate smoking after first using ecigarettes (Warner \& Mendez 2018). In contrast, the increased popularity of e-cigarettes among youth, and their potential to lead to cigarette smoking are raising concerns on their role in expanding the nicotine addiction base among young people, and a subsequent perpetuation of the tobacco epidemic (Glantz \& Bareham 2018; Soneji et al., 2017; Chapman et al., 2018).

Like any new product gaining popularity, there is still a dearth of knowledge about ecigarettes. According to the Surgeon General's reports; "strategic, comprehensive research is critical to identify and characterize the potential risks from e-cigarette use" (US Department of Health and Human Services, 2016). A significant health consequence of tobacco or nicotine use is their tendency to lead to dependence, and tobacco smoking is reported to be the leading cause of premature morbidity and mortality in the US (Warren et al., 2014)

In conclusion, factors that affect poly-tobacco use among young people in the US, with regards to the current tobacco landscape warrants further research. Studies with a longitudinal design, lengthy follow up, and tobacco use focus in a real-world setting are also needed to examine e-cigarettes' THR potential at the population level. The Food and Drug Administration (FDA) and National Institutes of Health (NIH) initiated the Population Assessment of Tobacco and Health (PATH) study in 2011, the largest research effort since Congress gave FDA jurisdiction to regulate tobacco products in 2009 (US Department of Health and Human Services 2018; Hyland et al., 2017). The PATH is a longitudinal study that tracks tobacco use in a 
representative sample of youth and adults in the US using a detailed assessment of all tobacco products currently in the marketplace (Hyland et al., 2017).

This dissertation aimed to determine the prevalence and identify correlates of polytobacco use among young people (12-34 years) in the United States from Wave 1 (2013-2014) of the PATH study. It further aimed to examine over a period of 2 years; the trends in e-cigarette uptake among never cigarette smokers among youth, the transition from e-cigarette mono use to cigarette smoking among youth and adults; and the transition of dual (e-cigarette/cigarette) use to mono or no tobacco product use among youth and adults from the Wave 1 (2013-2014), Wave 2 (2014-2015) and Wave 3 (2015-2016) of the PATH study. Finally, this study examined the transition to sole e-cigarette use or total abstinence versus relapse to exclusive smoking among adult dual e-cigarette/cigarette users who are nicotine dependent, interested in quitting and reported a history of a clinical condition such as cardiovascular disease (CVD).

\section{References}

Abrams DB, Glasser AM, Pearson JL, Villanti AC, Collins LK, Niaura RS. Harm Minimization and Tobacco Control: Reframing Societal Views of Nicotine Use to Rapidly Save Lives. Annu Rev Public Health. 2018;39:193-213.

Aleyan S, Cole A, Qian W, Leatherdale ST. Risky business: a longitudinal study examining cigarette smoking initiation among susceptible and non-susceptible e-cigarette users in Canada. BMJ Open. 2018;8(5):e021080.

Backinger C, Fagan P, O'Connell M, Grana R, Lawrence D, Bishop J, et al. Use of other tobacco products among US adult cigarette smokers: Prevalence, trends and correlates. Addict Behav. 2008;33(3):472-489.

Barrington-Trimis JL, Urman R, Berhane K, Unger JB, Cruz TB, Pentz MA, et al., E-cigarettes and future cigarette use. Pediatrics. 2016;138 (1).

Bombard JM, Pederson LL, Nelson DE, Malarcher AM. 2007. Are smokers only using cigarettes? Exploring current polytobacco use among an adult population. Addict Behav. 2007;32(10):2411-9.

Chapman S, Bareham D, Maziak W. The Gateway Effect of e-cigarettes; Reflections on main Criticisms. Nicotine Tob Res. 2018. 
Cullen KA, Ambrose BK, Gentzke AS, Apelberg BJ, Jamal A, King BA. Notes from the Field: Use of Electronic Cigarettes and Any Tobacco Product Among Middle and High School Students - United States, 2011-2018. MMWR Morb Mortal Wkly Rep. 2018;67(45):12767.

Delnevo CD, Wackowski OA, Giovenco DP, Manderski MT, Hrywna M, Ling PM. Examining market trends in the United States smokeless tobacco use: 2005-2011. Tob Control. 2014;23(2):107-12.

Everett SA, Malarcher AM, Sharp DJ, Husten CG, Giovino GA. 2000. Relationship between cigarette, smokeless tobacco, and cigar use, and other health risk behaviors among U.S. high school students. J Sch Health. 2000;70(6):234-40.

Fix BV, O'Connor RJ, Vogl L, Smith D, Bansal-Travers M, Conway KP, et al. Patterns and correlates of polytobacco use in the United States over a decade: NSDUH 2002-2011. Addict Behav. 2014;39(4):768-81.

Glantz SA, Bareham DW. E-Cigarettes: Use, Effects on Smoking, Risks, and Policy Implications. Annu Rev Public Health. 2018;39:215-35.

Hajek P, Etter JF, Benowitz N, Eissenberg T, McRobbie H. Electronic cigarettes: review of use, content, safety, effects on smokers and potential for harm and benefit. Addiction. 2014;109(11):1801-10.

Hyland A, Ambrose BK, Conway KP, Borek N, Lambert E, Carusi C et al. Design and methods of the Population

Assessment of Tobacco and Health (PATH) Study. Tob Control 2017;26:371-8.

Lee Y, Hebert C, Nonnemaker J, Kim A. Multiple tobacco product use among adults in the United States: Cigarettes, cigars, electronic cigarettes, hookah, smokeless tobacco, and snus. Prev Med. 2014;62:14-19.

Leventhal AM, Strong DR, Kirkpatrick MG, Unger JB, Sussman S, Riggs NR, et al., Association of electronic cigarette use with initiation of combustible tobacco product smoking in early adolescence. JAMA. 2015;314 (7):700-707.

Maxwell JC. The Maxwell Report: Cigar industry in 2009. In. Richmond, VA; 2010.

McMillen R, Maduka J, Winickoff J. Use of emerging tobacco products in the United States. $J$ Environ Public Health 2012:989474.

McNeill A, Brose LS, Calder R, Hitchman SC, Hajek P, McRobbie H. E-cigarettes: an evidence update. A report commissioned by Public Health England. In; 2015. Available at https://assets.publishing.service.gov.uk/government/uploads/system/uploads/attachment_ data/file/733022/Ecigarettes_an_evidence_update_A_report_commissioned_by_Public_ Health_England_FINAL.pdf. Accessed October 2018

Mejia AB, Ling PM. Tobacco industry consumer research on smokeless tobacco users and product development. Am J Public Health. 2010;100(1):78-87. 
National Academies of Sciences, Engineering and Medicine. Public health consequences of ecigarette. Washington, DC: National Academies Press, 2018. Available at https://doi.org/10.17226/24952. Accessed October 2018.

O'Connor RJ. 2012. Non-cigarette tobacco products: what have we learnt and where are we headed? Tob Control. 2012;21(2):181-90.

Primack, B.A., Soneji, S., Stoolmiller,M., Fine, M.J., Sargent, J.D. Progression to traditional cigarette smoking after electronic cigarette use among US adolescents and young adults. JAMA Pediatr. 2015;169 (11):1018-1023.

Regan AK, Dube SR, Arrazola R. Smokeless and flavored tobacco products in the U.S.: 2009 Styles survey results. Am J Prev Med. 2012;42(1):29-36.

Soneji S, Barrington-Trimis JL, Wills TA, et al. Association Between Initial Use of e-Cigarettes and Subsequent Cigarette Smoking Among Adolescents and Young Adults: A Systematic Review and Meta-analysis. JAMA Pediatr. 2017;171(8):788-797.

Unger JB, Soto DW, Leventhal A. E-cigarette use and subsequent cigarette and marijuana use among Hispanic young adults. Drug Alcohol Depend. 2016;163:261-264.

US Department of Health and Human Services. E-cigarette Use Among Youth and Young Adults: A Report of the Surgeon General-Executive Summary. 2016

United States Department of Health and Human Services. National Institutes of Health. National Institute on Drug Abuse, and United States Department of Health and Human Services. Food and Drug Administration. Center for Tobacco Products. Population Assessment of Tobacco and Health (PATH) Study [United States] Public-Use Files. Ann Arbor, MI: Inter-university Consortium for Political and Social Research [distributor], 2018-05-01. https://doi.org/10.3886/ICPSR36498.v7. Last accessed October 2018.

Warner KE, Mendez D. E-cigarettes: Comparing the Possible Risks of Increasing Smoking Initiation with the Potential Benefits of Increasing Smoking Cessation. Nicotine Tob Res. 2018 .

Warren GW, Alberg AJ, Kraft AS, Cummings KM. The 2014 surgeon general's report: "the health consequences of smoking-50 years of progress": a paradigm shift in cancer care. Cancer. 2014;120 (13):1914-1916. 


\title{
MANUSCRIPT 1
}

\section{(C) Copyright 2019}

\section{Correlates of Poly-tobacco use Among Youth and Young adults: Findings from the Population Assessment of Tobacco and Health Study, 2013-2014.}

\begin{abstract}
Introduction: Poly-tobacco use is increasing among youth and young adults. This study examined sociodemographic, tobacco-related, and substance use characteristics of poly-tobacco use compared to mono-tobacco use among youth and young adults aged 12-34 years in the United States (U.S). Methods: We conducted a descriptive analysis of 12,898 youth (12-17 years) and 14,931 young adults (18-34 years) from the 2013-2014 Population Assessment of Tobacco and Health study. Multiple logistic regression modeling was conducted to assess the sociodemographic, tobacco-related and substance use associations with current (past 30 days) tobacco product use on a binary scale (poly- versus mono-tobacco use) among tobacco users. Results: Between 2013 and 2014, 3.6\% of youth and 18.3\% of young adults were current polytobacco users. Approximately $43 \%$ of youth and $48 \%$ of young adult tobacco users were polytobacco users, with cigarettes and e-cigarettes being the most common combination. Among youth and young adult tobacco users, preferred tobacco flavor, heavy drinking, and marijuana use had higher proportions of poly-tobacco use compared to mono-tobacco use. In the multiple logistic regression, youth heavy drinkers had statistically significant higher odds of poly-tobacco use relative to mono-tobacco use. For young adults, males, younger adults (18-24 years), those with lower levels of educational attainment, those residing in the south, heavy drinkers, and marijuana users had statistically significant higher odds of poly-tobacco use. Conclusions: Polytobacco use is common among US youth and young adults. Intervention methods explicitly
\end{abstract}


designed to address factors associated with poly-tobacco use among youth and young adults are warranted.

KEYWORDS: alcohol, drug use, heavy drinking, marijuana, poly-tobacco use, tobacco use, youth, young adults

\section{Introduction}

Poly-tobacco use, the concurrent use of two or more tobacco products, is increasingly common among youth and young adults (Harrell et al., 2016; Richardson et al., 2014) who are more likely to be poly users of emerging tobacco products such as hookah, little cigars, cigarillos, and electronic cigarettes (e-cigarettes) (Kasza et al., 2017; Lee et al., 2014; Lee et al., 2015; Soneji et al., 2016). The increased use of emerging tobacco products can be partially attributable to the aggressive marketing practices of the tobacco industry (Mejia and Ling, 2010; Regan et al., 2012), capitalizing on the misperception of lower harm of these products relative to cigarettes (Braun et al., 2012; Pearson et al., 2012; Sterling KL et al., 2013). Additionally, the increased availability, reduced cost, and attractiveness of flavored options are likely contributing to the popularity of these products among youth in the United States (U.S) (Saunders and Geletko, 2012).

Epidemiological studies in the U.S. show that the use of tobacco products is established primarily in adolescence, with 9 out of 10 daily cigarette smokers reporting first smoking by age 18 and $99 \%$ by age 26 years (USDHHS, 2014). The continued use of these tobacco products can predispose young people to prolonged nicotine exposure and subsequently nicotine addiction (USDHHS, 2014), because their developing brain's reward system is altered, thereby making

them more vulnerable to dependence (McQuown et al., 2007). Studies already suggest that youth poly-tobacco users have increased symptoms of nicotine dependence compared to mono-tobacco users (Apelberg et al., 2014). This nicotine dependence may increase the likelihood of young 
poly-tobacco users maturing into adult poly-tobacco users who delay quitting tobacco in comparison to adult mono-tobacco users (Henningfield et al., 2002; Soneji et al., 2016). Furthermore, compared to mono-tobacco use, the concurrent use of multiple tobacco products may also provide challenges for those willing to quit (Bombard et al., 2007; Wetter et al., 2002), most especially because smoking cessation programs are usually tailored to deal mainly with cigarettes.

Because of the evolving landscape of tobacco products, coupled with the easy availability and accessibility of emerging tobacco products; it is particularly necessary to understand the characteristics of young poly-tobacco users. The increasing diversity of these tobacco products also highlights the importance of considering the totality of all the tobacco products available to consumers. Therefore, characterizing young tobacco users who are more likely to be poly-tobacco users is essential for targeted prevention efforts, as well as for research into the evolution of tobacco use among poly-tobacco users and challenges they may present to cessation.

Previous research has examined the use of multiple tobacco products using different definitions ranging from the use of cigarettes and any other tobacco product, the use of 3 or more tobacco products, whereas some did not include e-cigarettes and hookah among tobacco products (Bombard et al., 2009; Bombard et al., 2007; Bombard et al., 2008; Lee et al., 2014; Lee et al., 2015). This study applied an inclusive definition of concurrent use of 2 or more tobacco products to show the significance of poly-tobacco use regardless of tobacco product type, and emphasize the epidemic of poly-tobacco use among young people in the U.S. This study used the Population Assessment of Tobacco and Health (PATH) dataset to investigate the prevalence of poly-tobacco use among youth and young adults across the range of tobacco products currently available. We also examined the characteristics of poly-tobacco use compared to mono-tobacco use among youth (12-17 years) and young adult (18-34 years) tobacco users. 


\section{Methods}

$\underline{\text { Study sample }}$

Study data were from the restricted use files of the PATH study, an ongoing longitudinal study of tobacco use trajectories and health outcomes, with an overall purpose to inform the Food and Drug Administration (FDA)'s regulatory policies on tobacco products (USDHHS, 2017).

A detailed methodology for the PATH study is described elsewhere (Hyland et al., 2016; Kasza et al., 2017). Briefly, the PATH study is a nationally representative sample of 45,971 youth and adults aged $\geq 12$ years. The PATH study employs a multistage sampling design to produce a nationally representative sample of the U.S. population. Wave 1 assessment conducted between 2013 and 2014 had a participant response rate among 32,320 adults of 74\% and 78.4\% among 13,621 youth. Data were collected using audio computer-assisted self-interview (ACASI), available in English and Spanish. Adult tobacco users, young adults (aged 18-24 years), and African-Americans were oversampled to make results nationally representative of the general population (USDHHS, 2017). Survey responses were weighted to adjust for nonresponse, varying selection probabilities, and oversampling to reflect national estimates.(USDHHS, 2017) This study was approved by the Institutional Review Board of Florida International University.

\section{$\underline{\text { Measures }}$}

\section{Outcome}

The PATH Study inquired about several tobacco products: Bidis and kreteks were also examined in the youth sample only. We classified subjects into current mono-tobacco users if they reported the use of only one tobacco product in the past 30 days, or current poly-tobacco users if they reported the concurrent use of two or more tobacco products in the past 30 days. A 
binary variable was derived to indicate respondents' tobacco status $(0=$ mono-tobacco use, $1=$ poly-tobacco use).

\section{Covariates}

Using the PATH's broad theoretical framework of the host, agent, vectors, and environment, (Hyland et al., 2016) the authors selected covariates most relevant to the study aim, and those well established in existing tobacco control literature related to tobacco use among young people (Ambrose et al., 2015; Cohn et al., 2015; Hinds et al., 2017). We classified the selected items into sociodemographic, tobacco-related and substance use variables.

Sociodemographic variables included in this study were age, sex, sexual orientation, race/ethnicity, education (young adults), grade (youth), household income (young adults only), employment status (young adults only) and census region. Self-perception of overall health was assessed on a 5-point Likert scale, but categorized into four for the current study: excellent, very good, good and fair/poor due to the small responses in the 'fair' and 'poor' categories.

Tobacco-related variables examined included; age at first exposure to a tobacco product regardless of the specific type first used. The variables, preferred tobacco flavor (tobacco products [come | came] in flavors I like | liked) and advert appeal (the advertising for tobacco product [appeals | appealed] to me) was assessed for all tobacco products except for cigarettes, and single binary variables were derived respectively for each $(0=$ no; $1=$ yes $)$.

Substance use variables assessed include; marijuana and other drug use (Ritalin, painkillers, cocaine, methamphetamine, and heroin). We also assessed excessive alcohol consumption. The variables used included: 1) heavy drinking derived from the number of days the respondent had one or more alcoholic drink in last 30 days $(<5 \geq 5$ days) and coded as no/yes, and 2$)$ high-risk drinking derived from the average number of drinks per day. The variable was coded as yes $(\geq 4$ 
drinks/day for females and $\geq 5$ drinks/day for males $)$, and no $(<4$ drinks/day for females and $<5$ drinks/day for males) (USDHHS \& USDA, 2015).

\section{$\underline{\text { Statistical analyses }}$}

Initial analysis included descriptive statistics for the overall sample by tobacco status (nontobacco use, mono-tobacco use, and poly-tobacco use) for youth and young adults individually, by assessing current (past 30 days) tobacco product use. Replicate weights provided by the PATH study were used to obtain variance estimates using Fay's Method of Balanced Repeated Replication (BRR), with the Fay coefficient value of 0.3, as recommended by the PATH Study (USDHHS, 2017) Weighted percentages for sociodemographic, tobacco-related and substance use characteristics were reported with their confidence intervals (CI). We reported the proportions of for mono-tobacco products and poly-tobacco use combinations among youth and young adults. Next, we examined the differences in the proportions of the characteristics and the current use of tobacco products (poly-tobacco and mono-tobacco) using the Pearson chi-square test. Factors (sociodemographic, tobacco-related and substance use variables) with $\mathrm{P}$ values $<0.10$ in the bivariate analyses were included in the binary logistic regression model to determine the relationship between each variable and poly-tobacco use. Additionally, gender stratification for the adjusted model was conducted to identify factors associated with poly-tobacco use. We calculated and reported the adjusted odds ratio (aOR) with the accompanying 95\% CI controlling for the sociodemographic, tobacco-related and substance use variables. A two-sided P value < 0.05 was considered statistically significant. Analyses were conducted using SAS version 9.4 statistical software procedures (SAS Institute Inc., Cary, NC, USA), -PROC SURVEYFREQ and PROC SURVEYLOGISTIC with BRR method and Fay's correction of 0.3 - that corrects for the complex survey design in the PATH study (USDHHS, 2017) 


\section{Results}

In the general population of the PATH study, the prevalence of poly-tobacco use was $3.6 \%$ among youth and $18.3 \%$ among young adults. Mono-tobacco use was $4.8 \%$ among youth, and $19.9 \%$ among young adults (Table 1). Among youth mono-tobacco users, current use of cigarettes was most prevalent at 39.6\%, followed by use of e-cigarettes $(24.1 \%)$, hookah (15.0\%), and cigarillos (9.0\%) (Supplementary figure 1). The most common combination of poly-tobacco use was cigarettes and e-cigarettes $(15.1 \%)$, followed by the combination of cigarettes and cigarillos (10.1\%) among youth poly-tobacco users. (Supplementary figure 2). The most prevalent single tobacco product use was current cigarette use (66.1\%) among young adult monotobacco users, followed by use of hookah (9.3\%), and e-cigarettes (7.5\%) (Supplementary figure 3). Similar to youth, the most common combination of poly-tobacco use was cigarettes and ecigarettes $(22.5 \%)$, followed by cigarettes and cigarillos (9.9\%) among young adult poly-tobacco users. (Supplementary figure 4). The characteristics of tobacco users only (mono- and polytobacco use) were also reported for youth (12-17 years, Supplementary Table 1), and young adults (18-34 years, Supplementary Table 2). The proportion of poly-tobacco use among youth tobacco users was $42.9 \%$, and $47.9 \%$ among young adult tobacco users, while for mono-tobacco use, the proportion was $57.1 \%$ among youth, and $52.1 \%$ among young adults. Among youth (1217 years), a higher proportion of poly-tobacco users were more likely to have a preferred tobacco flavor, be heavy and high-risk drinkers, and marijuana users compared to mono-tobacco users. (Supplementary Table 1). For young adults (18-34 years), a higher proportion of poly-tobacco users were more likely to be aged 18-24 years, males, have a preferred tobacco flavor, and be heavy drinkers and marijuana users compared to mono-tobacco users (Supplementary Table 2). Additional characteristics of youth and young adult current tobacco users are available in Supplementary tables $1 \& 2$. 
We presented the adjusted ORs for youth (12-17 years) poly-tobacco users relative to mono-tobacco users in Table 3. Overall, heavy drinkers had significantly higher odds of polytobacco use (aOR: 2.40; CI:1.39-4.16) compared to non-heavy drinkers. Those classified as other race, compared to non-Hispanic White had significantly lower odds of poly-tobacco use relative to mono-tobacco use (aOR: 0.40; CI:0.17-0.94). Further, the gender-based analysis shows that male heavy drinkers had higher odds for poly-tobacco use (aOR: 5.66; CI:1.67-19.18), and those classified as other race had lower odds for poly-tobacco use (aOR:0.33; CI:0.11-0.97) relative to mono-tobacco use (Table 3).

In table 4, the adjusted ORs for young adult (18-34 years) poly-tobacco users relative to mono-tobacco users were reported. Younger (18-24 years), compared to older (25-34 years) young adults were at higher odds of poly-tobacco use relative to mono-tobacco use (aOR:1.51; CI:1.13-2.02). Overall, males had higher odds than females of being a poly-tobacco user (aOR:1.42; CI:1.12-1.80) relative to a mono-tobacco user. Compared to those with a bachelor's or advanced degree, those with less than high school or GED (aOR:1.74; CI:1.22-2.49), high school graduate (aOR:1.85; CI:1.33-3.57), and some college or associate degree (aOR:1.39; CI:1.03-1.87) had higher odds of poly-tobacco use. Residing in the South was associated with higher odds of poly-tobacco use compared to those living in the Northeast (aOR:1.75; CI:1.342.23). Additional analysis showed that heavy drinking (aOR:1.43; CI:1.17-1.74), high-risk drinking (aOR:1.34; CI:1.09-1.66), and marijuana use in the past 30days (aOR:2.10; CI:1.752.51) had significantly higher odds of poly-tobacco use compared to mono-tobacco use. Further, among young adults, age at first exposure to tobacco product <18 years (aOR:0.41; CI:0.26-0.66); and age at first tobacco product 18-24 years (aOR:0.60; CI:0.44-0.83) compared to 25-34 years had lower odds of poly-tobacco use relative to mono-tobacco use. Finally, preferred tobacco flavor compared to non-preferred tobacco flavor (aOR:0.79; CI:0.65-0.96) also had significantly lower odds for poly-tobacco use relative to mono-tobacco use (Table 4). 
Following gender stratification, among females, those who identified as lesbian, gay, bisexual or other compared to heterosexuals (aOR:1.62; 1.16-2.27), and those with less than high school or GED compared to bachelor's or advanced degree (aOR:2.04; CI:1.08-3.88) had significantly higher odds of poly-tobacco use. Among males, younger age of 18-24 years (aOR:1.94; CI:1.40-2.70) compared to 25-34 years, and high-risk drinking (aOR:1.32; CI:1.031.69) compared to no high-risk drinking had significantly higher odds of poly-tobacco use. Also, age at first exposure to tobacco product of less than 18 years (aOR: 0.41; CI:0.26-0.66); 18-24 years (aOR:0.58; CI:0.41-0.82) compared to age 25-34 years, and those using a preferred tobacco flavor (aOR:0.78; CI:0.63-0.95) compared to non-preferred tobacco flavor had significantly lower odds of poly-tobacco use relative to mono-tobacco use. Additional details about the results of the multiple logistic regression for the factors associated with both male and female poly-tobacco use are available in table 4.

\section{Discussion}

This is the first study to describe and examine the factors associated with poly-tobacco use in a large, representative sample of US youth and young adults using the FDA-supported PATH study. Approximately $4 \%$ of youth and $18 \%$ of young adults were poly-tobacco users in the US general population between 2013 and 2014. Our results showed that the most common combination of poly-tobacco use among youth and young adults was cigarettes and e-cigarettes. Among current tobacco users, a high proportion of poly-tobacco use among youth (42.9\%) and young adults (47.9\%) was observed. We also demonstrated that heavy drinkers and those who were classified as other race were significantly associated with poly-tobacco use among youth (12-17 years). Among young adults (18-34 years), younger age, males, lower educational attainment, residing in the Southern part of the US, heavy- and high-risk drinking, and marijuana use were significantly associated with poly-tobacco use. Our results signify a shift in the tobacco 
epidemic among young people trending towards the use of multiple tobacco products (Fix et al., 2014), which is concerning because poly-tobacco use is found to increase the risk of illicit drug use, and nicotine addiction compared to the use of a single tobacco product (Bombard et al., 2009). Additionally, the distinct characteristics of poly-tobacco users compared to mono-tobacco users, suggest where interventions may be applied to address this particular issue.

Previous epidemiological research has consistently found males to have higher odds of tobacco use (Butler et al., 2016; Lee et al., 2014; Lee et al., 2015). The current study extends this observation to poly-tobacco use where males were at significantly higher odds (42\%) for polytobacco use among young adult tobacco users. Although in the current study males and females in both age groups had almost comparable proportions of mono-tobacco use, the proportion of polytobacco use was much higher among males. This interesting finding may follow the known stages of the cigarette smoking epidemic, as earlier stages of the epidemic found that males had higher prevalence rates of cigarette smoking compared to females (Thun et al., 2012). However, the rates of cigarette use between males and females narrowed as the epidemic advanced (Thun et al., 2012). The pattern of poly-tobacco use we observed may set up a new stage of another tobacco epidemic, where females eventually catch up with rates comparable to males in the future.

Using data from the National Adult Tobacco Survey, the Centers for Disease Control and Prevention (CDC) and the FDA, in 2013-2014, demonstrated that US young adults aged 18-24 years had the highest prevalence of emerging tobacco product use including hookah and ecigarettes (Hu et al., 2016). Moreover, there is evidence that young adulthood is increasingly becoming a time of initiation of multiple tobacco products, particularly new ones (Hu et al., 2016). In the current study, the high prevalence of poly-tobacco use among those aged 18-24 years may, in fact, have resulted from the increased use of these emerging tobacco products due to their attractiveness to youth, aggressive marketing by the industry, and the reduced harm 
perception associated with their use relative to cigarettes (Braun et al., 2012; Mejia and Ling, 2010; Pearson et al., 2012; Regan et al., 2012; Sterling KL et al., 2013).

Emerging research demonstrates that tobacco use is more prevalent among lesbians, gays, and bisexuals (LGB) compared to heterosexuals (Dilley et al., 2008; Hu et al., 2016; Lee et al., 2009). Our study extends this literature showing that young adult lesbian and bisexual female tobacco users have a $62 \%$ higher odd of poly-tobacco use compared to mono-tobacco use. It is posited that this finding may be due to a variety of psychosocial factors, ranging from higher levels of alcohol consumption, depression, discrimination, homophobia, low socioeconomic status, stigma, and stress (Blosnich et al., 2013; Lee et al., 2009; Pelster et al., 2015). Furthermore, they are more likely to be targeted by the tobacco industry's marketing strategies (Blosnich et al., 2013; Dilley et al., 2008; Lee et al., 2009; Pelster et al., 2015). LGBs are also more likely to be surrounded by smokers; which is associated with a higher likelihood of tobacco use, a barrier to cessation and leads to an increase in morbidity and mortality in these individuals (Cochran et al., 2013; Oberg et al., 2011; Perales et al., 2017). Research reports that lesbian and bisexual females are more likely to smoke cigarettes and use hookah compared to heterosexual females or gay males (Dilley et al., 2008; Emory et al., 2016; Gamarel et al., 2016). Reducing poly-tobacco use in this particular group of tobacco users should be a priority.

Our results also indicate that young adults residing in the South compared to the Northeast had a 75\% higher odd for poly-tobacco use relative to mono-tobacco use. A survey conducted in the US during 2013 - 2014 found that those residing in the South reported the highest prevalence of the use of any tobacco product (Hu et al., 2016). It has also been described that those living in the South tend to use multiple tobacco products, such as cigarettes and smokeless tobacco (USDHHS, 2014). The regional disparities observed in poly-tobacco use may be due to a variety of factors such as demographics, variations in tobacco control programs and 
policies, and regional differences in tobacco industry marketing and promotion practices (King et al., 2012)

Consistent with the literature (Cohn et al., 2017; Wetter et al., 2002), we also found that youth and young adults tobacco users who used alcohol had higher odds of poly-tobacco use relative to mono-tobacco use. Additionally, those aged 18-34 years had a 2-fold higher odds of marijuana use. Previous research demonstrated that young poly-tobacco users were more likely to engage in heavy drinking and marijuana use than mono-tobacco users (Cohn et al., 2017; Soneji et al., 2016). The utilization of alcohol and marijuana has been shown to contribute to greater nicotine dependence and increased difficulty with quitting in late adulthood (Cohn et al., 2015; Kahler et al., 2009). Studies suggest that tobacco, alcohol, and marijuana use are risk factors that co-occur among youth and young adults and have the potential to serve as "gateway drugs" to each other (Kandel and Kandel, 2014; Sosensky and Doyle, 2016). Given that substance use and tobacco use often co-occur, substance use may serve as a hindrance to tobacco control efforts, particularly among young people thereby contributing to the poly-tobacco use epidemic. Therefore, coping mechanisms for dealing with the bait of heavy alcohol consumption, and substance use should be incorporated into cessation interventions.

Although preferred tobacco flavor was associated with lower odds of poly-tobacco use in our study, the proportion of those who had a preferred tobacco product among tobacco users was much higher among youth and young adult poly-tobacco users. This finding contributes more evidence to the problem of the flavoring of unregulated tobacco products accessible to young people (Ambrose et al., 2015; Harrell et al., 2017). Flavor restrictions do not apply to cigars, ecigarettes, and hookah, and these may appeal to young people by concealing the harsh taste of tobacco for new and inexperienced smokers (Carpenter et al., 2005; Soneji et al., 2016), and 
incidentally lead to an increase in the use of tobacco products which may also be contributory to the prevalence of poly-tobacco use among young people.

Additionally, youth and young adults have the option of choosing from a wide array of tobacco products that can help with circumventing smoking bans or smoke-free laws. These tobacco products also have different routes of administration which may serve as a marker for increased nicotine dependence (Agaku and Ayo-Yusuf, 2014), thereby promoting increased polytobacco product use (Kaufman et al., 2015). It is disturbing for young persons, particularly those before the age of maturity, to become addicted to nicotine; and it is likely that this trend will continue (USDHHS, 2014; Kozlowski and Sweanor 2017) As a result, tobacco control efforts should be vigorously intensified to halt this public health burden. These findings suggest the need to develop targeted control policies responsive to the unique characteristics associated with polytobacco use among young people with the goal of reducing the prevalence of poly-tobacco use among this subpopulation in the US.

Major strengths of this study include the use of a large national sample of youth and young adults not restricted to high school or college students. An additional strength is the assessment of the new and emerging tobacco products such as e-cigarettes and hookah. There are however some limitations to be considered. First, the cross-sectional analysis does not allow the observation of causality of the factors associated with poly-tobacco use. Second, this study relied on participant self-reports of tobacco use and age at first exposure to a tobacco product, which predisposes to recall bias. However, studies show that self-reports on tobacco use are reliable and provide valid estimates in the US (Brener et al., 2003). Finally, due to the relatively small sample sizes for nonHispanic Asians, American Indian/Alaska Natives, Native Hawaiians, Pacific Islanders, and multi-racial groups; these were collapsed into one category. Hence estimates for these racial groups were not possible in the current study. 


\section{Conclusions}

Our results demonstrate that a significant proportion of youth and young adults are polytobacco users regardless of tobacco product type. Furthermore, the rates are even much higher among tobacco users. It is glaring that poly-tobacco use epidemic in the US poses a direct threat to tobacco control, both in prevention and cessation efforts, majorly because of the easy accessibility, and flavoring of some of these tobacco products. The current tobacco control framework is inadequate to address this epidemic due to their inconsistency with poly-tobacco use among young people for tobacco products that are not adequately regulated by the FDA. Population-level interventions directed at all forms of tobacco product use, including taxation of tobacco products, comprehensive smoke-free laws, reducing flavor appeal and access to tobacco products, in addition to the FDA's regulation of all tobacco products, will be particularly critical in reducing the burden of poly-tobacco use among young people in the US.

\section{References}

Agaku IT, Ayo-Yusuf OA. The Effect of Exposure to Pro-Tobacco Advertising on Experimentation With Emerging Tobacco Products Among U.S. Adolescents. Health Educ Behav. 2014;41(3):275-280.

Ambrose BK, Day HR, Rostron B, Conway, K.P., Borek, N., Hyland, A., Villanti, A.C., 2015. Flavored Tobacco Product Use Among US Youth Aged 12-17 Years, 2013-2014. JAMA 314(17):1871-1873. doi:10.1001/jama.2015.13802.

Apelberg BJ, Corey CG, Hoffman AC, Schroeder MJ, Husten CG, Caraballo RS, Backinger CL. Symptoms of tobacco dependence among middle and high school tobacco users: results from the 2012 National Youth Tobacco Survey. Am J Prev Med. 2014;47(2 Suppl 1):S414. doi:10.1016/j.amepre.2014.04.013.

Blosnich J, Lee JG, Horn K. A systematic review of the aetiology of tobacco disparities for sexual minorities. Tob Control. 2013;22(2):66-73. doi:10.1136/tobaccocontrol-2011050181 .

Bombard JM, Pederson LL, Koval JJ, O'Hegarty M. How are lifetime polytobacco users different than current cigarette-only users? Results from a Canadian young adult population. Addict Behav. 2009;34(12):1069-1072. doi: 10.1016/j.addbeh.2009.06.009. 
Bombard JM, Pederson LL, Nelson DE, Malarcher AM. Are smokers only using cigarettes? Exploring current polytobacco use among an adult population. Addict Behav. 2007;32(10):2411-2419. doi:10.1016/j.addbeh.2007.04.001.

Bombard JM, Rock VJ, Pederson LL, Asman KJ. Monitoring polytobacco use among adolescents: do cigarette smokers use other forms of tobacco? Nicotine Tob Res. 2008;10(11):1581-1589. doi: 10.1080/14622200802412887.

Braun R, Glassman T, Wohlwend J, Whewell A, Reindl D. Hookah Use Among College Students from a Midwest University. J Community Health. 2012;37(2):294-298. doi: 10.1007/s10900-011-9444-9.

Brener ND, Billy JO, Grady WR. Assessment of factors affecting the validity of self-reported health-risk behavior among adolescents: evidence from the scientific literature. J Adolesc Health. 2003;33(6):436-457. doi: http://dx.doi.org/10.1016/S1054-139X(03)00052-1

Butler KM, Ickes MJ, Rayens MK, Wiggins AT, Hahn EJ. Polytobacco Use Among College Students. Nicotine Tob Res. 2016;18(2), 163-169. doi: 10.1093/ntr/ntv056.

Carpenter CM, Wayne GF, Pauly JL, Koh HK, Connolly GN. New cigarette brands with flavors that appeal to youth: tobacco marketing strategies. Health Aff (Millwood). 2005;24(6):1601-1610. doi: 10.1377/hlthaff.24.6.1601.

Cochran SD, Bandiera FC, Mays VM. Sexual orientation-related differences in tobacco use and secondhand smoke exposure among US adults aged 20 to 59 years: 2003-2010 National Health and Nutrition Examination Surveys. Am J Public Health. 2013;103(10):18371844. doi: 10.2105/AJPH.2013.301423.

Cohn A, Villanti A, Richardson A, Rath JM, Williams V, Stanton C, Mermelstein R. The association between alcohol, marijuana use, and new and emerging tobacco products in a young adult population. Addict Behav. 2015;48:79-88. doi:10.1016/j.addbeh.2015.02.005.

Cohn AM, Ehlke SJ, Cobb CO, Soule EK. Hookah tobacco smoking in a large urban sample of adult cigarette smokers: Links with alcohol and poly-tobacco use. Addict Behav. 2017;68:1-5. doi:10.1016/j.addbeh.2016.12.012.

Dilley JA, Spigner C, Boysun MJ, Dent CW, Pizacani BA. Does tobacco industry marketing excessively impact lesbian, gay and bisexual communities? Tob Control. 2008;17(6):385390. doi:10.1136/tc.2007.024216.

Emory K, Kim Y, Buchting F, Vera L, Huang J, Emery SL. Intragroup Variance in Lesbian, Gay, and Bisexual Tobacco Use Behaviors: Evidence That Subgroups Matter, Notably Bisexual Women. Nicotine Tob Res. 2016;18(6):1494-1501. doi: 10.1093/ntr/ntv208.

Fix BV, O'Connor RJ, Vogl L, Smith D, Bansal-Travers M, Conway KP, Ambrose B, Yang L, Hyland A. Patterns and correlates of polytobacco use in the United States over a decade: NSDUH 2002-2011. Addict Behav. 2014;39(4):768-781. doi: 10.1016/j.addbeh.2013.12.015. 
Gamarel KE, Kahler CW, Lee JH, Reisner SL, Mereish EH, Matthews AK, Operario D. Sexual orientation disparities in smoking vary by sex and household smoking among US adults: Findings from the 2003-2012 National Health and Nutrition Examination Surveys. Prev Med. 2016;82:1-6. doi:10.1016/j.ypmed.2015.10.008.

Harrell MB, Loukas A, Jackson CD, Marti CN, Perry CL. Flavored Tobacco Product Use among Youth and Young Adults: What if Flavors Didn't Exist? Tob Regul Sci. 2017;3(2):168173. doi: 10.18001/TRS.3.2.4.

Harrell PT, Naqvi SM, Plunk AD, Ji M, Martins SS. Patterns of youth tobacco and polytobacco usage: The shift to alternative tobacco products. Am J Drug Alcohol Abuse. 2017;43(6):694-702. doi: 10.1080/00952990.2016.1225072.

Henningfield JE, Rose CA, Giovino GA. Brave new world of tobacco disease prevention: promoting dual tobacco-product use? Am J Prev Med. 2002;23(3):226-228.

Hinds JT, Li X, Loukas A, Pasch KE, Perry CL. Flavored Cigars Appeal to Younger, Female, and Racial/Ethnic Minority College Students. Nicotine Tob Res. 2017. doi:10.1093/ntr/ntx041

Hu SS, Neff L, Agaku IT, Cox S, Day HR, Holder-Hayes E, King BA. Tobacco Product Use Among Adults - United States, 2013-2014. MMWR Morb Mortal Wkly Rep. 2016;65(27):685-691. doi: 10.15585/mmwr.mm6527a1.

Hyland A, Ambrose BK, Conway KP, Borek N, Lambert E, Carusi, C, et al. Design and methods of the Population Assessment of Tobacco and Health (PATH) Study. Tob Control 26(4), 371-378.

Kahler CW, Borland R, Hyland A, McKee SA, Thompson ME, Cummings KM. Alcohol consumption and quitting smoking in the International Tobacco Control (ITC) Four Country Survey. Drug Alcohol Depend. 2009;100(3):214-220. doi: 10.1016/j.drugalcdep.2008.10.006.

Kandel DB, Kandel ER. A molecular basis for nicotine as a gateway drug. $N$ Engl J Med. 2014;371(21):2038-2039. doi: 10.1056/NEJMsa1405092.

Kasza KA, Ambrose BK, Conway KP, Borek N, Taylor K, Goniewicz ML, et al. TobaccoProduct Use by Adults and Youths in the United States in 2013 and 2014. N Engl J Med. 2017;376(4):342-353. DOI: 10.1056/NEJMsa1607538.

Kaufman A, Land S, Parascandola M, Augustson E, Backinger C. Tobacco use transitions in the United States: The National Longitudinal Study of Adolescent Health. Prev Med. 2015;81:251-257. doi: 10.1016/j.ypmed.2015.08.026.

King BA, Dube SR, Tynan MA. Current tobacco use among adults in the United States: findings from the National Adult Tobacco Survey. Am J Public Health. 2012:102(11), e93-e100. doi: 10.2105/AJPH.2012.301002.

Kozlowski LT, Sweanor DT. Young or adult users of multiple tobacco/nicotine products urgently need to be informed of meaningful differences in product risks. Addict Behav. 2017. doi10.1016/j.addbeh.2017.01.026. 
Lee JG, Griffin GK, Melvin CL. Tobacco use among sexual minorities in the USA, 1987 to May 2007: a systematic review. Tob Control. 2009;18(4):275-282. doi:

10.1136/tc.2008.028241.

Lee Y, Hebert C, Nonnemaker J, Kim A. Multiple tobacco product use among adults in the United States: Cigarettes, cigars, electronic cigarettes, hookah, smokeless tobacco, and snus. Prev Med. 2014;62:14-19. doi: 10.1016/j.ypmed.2014.01.014.

Lee YO, Hebert CJ, Nonnemaker JM, Kim AE. Youth tobacco product use in the United States. Pediatrics. 2015;135(3), 409-415. doi: 10.1542/peds.2014-3202.

McQuown SC, Belluzzi JD, Leslie FM. Low dose nicotine treatment during early adolescence increases subsequent cocaine reward. Neurotoxicol Teratol. 2007;29(1):66-73. DOI: 10.1016/j.ntt.2006.10.012.

Mejia AB, Ling PM., 2010. Tobacco industry consumer research on smokeless tobacco users and product development. Am J Public Health. 2010;100(1):78-87. doi: 10.2105/AJPH.2008.152603.

Oberg M, Jaakkola MS, Woodward A, Peruga A, Prüss-Ustün A. Worldwide burden of disease from exposure to second-hand smoke: a retrospective analysis of data from 192 countries. Lancet. 2011;377(9760):139-146.

Pearson JL, Richardson A, Niaura RS, Vallone DM, Abrams DB. e-Cigarette awareness, use, and harm perceptions in US adults. Am J Public Health. 2012; 102(9):1758-1766. doi: 10.2105/AJPH.2011.300526.

Pelster AD, Fisher CM, Irwin JA, Coleman JD, McCarthy MA. Tobacco Use and Its Relationship to Social Determinants of Health in LGBT Populations of a Midwestern State. LGBT Health. 2015;2(1):71-76. doi: 10.1089/lgbt.2014.0012.

Perales J, Checa I, Espejo B. Current active and passive smoking among adults living with same sex partners in Spain. Gac Sanit. 2017;pii: S0213-9111(17),30099-30097. doi: 10.1016/j.gaceta.2017.03.006.

Regan AK, Dube SR, Arrazola R. Smokeless and flavored tobacco products in the U.S.: 2009 Styles survey results. Am J Prev Med. 2012;42(1):29-36. doi: 10.1016/j.amepre.2011.08.019.

Richardson A, Williams V, Rath J, Villanti A, Vallone D. The Next Generation of Users: Prevalence and Longitudinal Patterns of Tobacco Use Among US Young Adults. Am J Public Health. 2014;104(8):1429-1436. doi: 10.2105/AJPH.2013.301802.

Saunders C, Geletko K. Adolescent cigarette smokers' and non-cigarette smokers' use of alternative tobacco products. Nicotine Tob Res. 2012;14(8):977-985. doi: $10.1093 / \mathrm{ntr} / \mathrm{ntr} 323$.

Soneji S, Sargent J, Tanski S. Multiple tobacco product use among US adolescents and young adults. Tob Control 25(2), 174-180. doi:10.1136/tobaccocontrol-2014-051638. 
Sosensky MM, Doyle EA. Polytobacco Use Among Adolescents. Pediatr Nurs. 2016;42(3):150154.

Sterling KL, Berg CJ, Thomas AN. Factors associated with little cigar and cigarillo use among college students. Am J Health Behav. 2013;37(3):325 - 333. doi: 10.5993/AJHB.37.3.5.

Thun M, Peto R, Boreham J, Lopez AD. Stages of the cigarette epidemic on entering its second century. Tob Control. 2012;21(2):96-101. doi: 10.1136/tobaccocontrol-2011-050294.

US Department of Health and Human Services, 2014. The Health Consequences of Smoking 50 years of progress: A report of the surgeon general. Atlanta, GA: U.S. Department of Health and Human Services, Centers for Disease Control and Prevention, National Center for Chronic Disease Prevention and Health Promotion, Office on Smoking and Health. (Accessed June 9, 2017).

U.S. Department of Health and Human Services and U.S. Department of Agriculture, 2015. Dietary Guidelines for Americans 2015 - 2020. Retrieved from https://health.gov/dietaryguidelines/2015/guidelines/acknowledgments/. (Accessed August 17 2017).

United States Department of Health and Human Services. National Institutes of Health. National Institute on Drug Abuse, and United States Department of Health and Human Services. Food and Drug Administration. Center for Tobacco Products. Population Assessment of Tobacco and Health (PATH) Study [United States] Restricted-Use Files. ICPSR36231v13. Ann Arbor, MI: Inter-university Consortium for Political and Social Research [distributor], 2017-06-19. https://doi.org/10.3886/ICPSR36231.v13.

Wetter DW, McClure JB, de Moor C, Cofta-Gunn L, Cummings S, Cinciripini PM, Gritz ER. Concomitant use of cigarettes and smokeless tobacco: prevalence, correlates, and predictors of tobacco cessation. Prev Med. 2002;34(6):638-648. https://doi.org/10.1006/pmed.2002.1032. 
Tables and figures

\begin{tabular}{|c|c|c|c|c|c|}
\hline \multicolumn{6}{|c|}{ Table 1 - Characteristics of Youths (12-17 years) by Tobacco Status ${ }^{\mathrm{T}}$ : PATH Study, 2013-2014 (N=12,898) } \\
\hline & $\begin{array}{c}\text { Total, weighted } \\
\%\end{array}$ & $\begin{array}{c}\text { Non-tobacco use, } \\
\text { weighted } \%(95 \% \mathrm{CI})\end{array}$ & $\begin{array}{c}\text { Mono-tobacco use, } \\
\text { weighted \% }(95 \% \mathrm{CI})\end{array}$ & $\begin{array}{c}\text { Poly-tobacco use, } \\
\text { weighted \% (95\% CI) }\end{array}$ & P value \\
\hline Total & $12898 *(100.0)$ & $91.6(90.9-92.1)$ & $4.8(4.4-5.3)$ & $3.6(3.3-4.0)$ & $<0.0001$ \\
\hline \multicolumn{6}{|l|}{$\begin{array}{l}\text { Sociodemographic } \\
\text { variables }\end{array}$} \\
\hline Age group (y) & & & & & $<0.0001$ \\
\hline $12-14$ & $6541(49.9)$ & $48.6(47.7-49.5)$ & $0.9(0.7-1.0)$ & $0.5(0.3-0.6)$ & \\
\hline $15-17$ & $6357(50.1)$ & $42.9(42.1-43.8)$ & $4.0(3.6-4.4)$ & $3.2(2.9-3.5)$ & \\
\hline Gender & & & & & $<0.0001$ \\
\hline Male & $6538(50.7)$ & $46.0(45.2-46.9)$ & $2.3(2.1-2.6)$ & $2.3(2.1-2.7)$ & \\
\hline Female & $6360(49.3)$ & $45.5(44.6-46.4)$ & $2.5(2.2-2.8)$ & $1.3(1.1-1.5)$ & \\
\hline Sexual Orientation & & & & & $<0.0001$ \\
\hline Heterosexual & $7846(93.1)$ & $82.7(81.7-83.6)$ & $5.8(5.2-6.4)$ & $4.6(4.2-5.2)$ & \\
\hline $\begin{array}{l}\text { Lesbian, } \\
\text { Bisexual, Other }\end{array}$ & $585(6.9)$ & $5.4(4.8-5.9)$ & $0.9(0.7-1.2)$ & $0.6(0.4-0.8)$ & \\
\hline Non-Hispanic White & $6150(54.7)$ & $49.3(48.4-50.2)$ & $2.9(2.5-3.3)$ & $2.5(2.2-2.8)$ & \\
\hline Non-Hispanic Black & $1697(13.6)$ & $12.7(12.1-13.2)$ & $0.7(0.6-0.9)$ & $0.3(0.2-0.4)$ & \\
\hline Other & $1164(9.3)$ & $8.7(8.2-9.2)$ & $0.3(0.2-0.4)$ & $0.3(0.2-0.4)$ & \\
\hline Hispanic & $3662(22.4)$ & $20.9(20.2-21.6)$ & $0.9(0.8-1.1)$ & $0.6(0.5-0.8)$ & \\
\hline Grade in school $^{b}$ & & & & & $<0.0001$ \\
\hline $5-8$ & $4856(37.8)$ & $37.1(36.3-38.0)$ & $0.5(0.4-0.6)$ & $0.2(0.2-0.4)$ & \\
\hline $9-12$ & $7524(60.2)$ & $53.0(52.1-53.8)$ & $4.1(3.7-4.5)$ & $3.1(2.8-3.5)$ & \\
\hline Other & $250(2.0)$ & $1.5(1.3-1.8)$ & $0.3(0.2-0.4)$ & $0.2(0.1-0.3)$ & \\
\hline $\begin{array}{l}\text { Money received per } \\
\text { week }\end{array}$ & & & & & $<0.0001$ \\
\hline None & 4195 (33.3) & $31.7(30.7-32.7)$ & $0.9(0.7-1.0)$ & $0.7(0.5-0.9)$ & \\
\hline
\end{tabular}




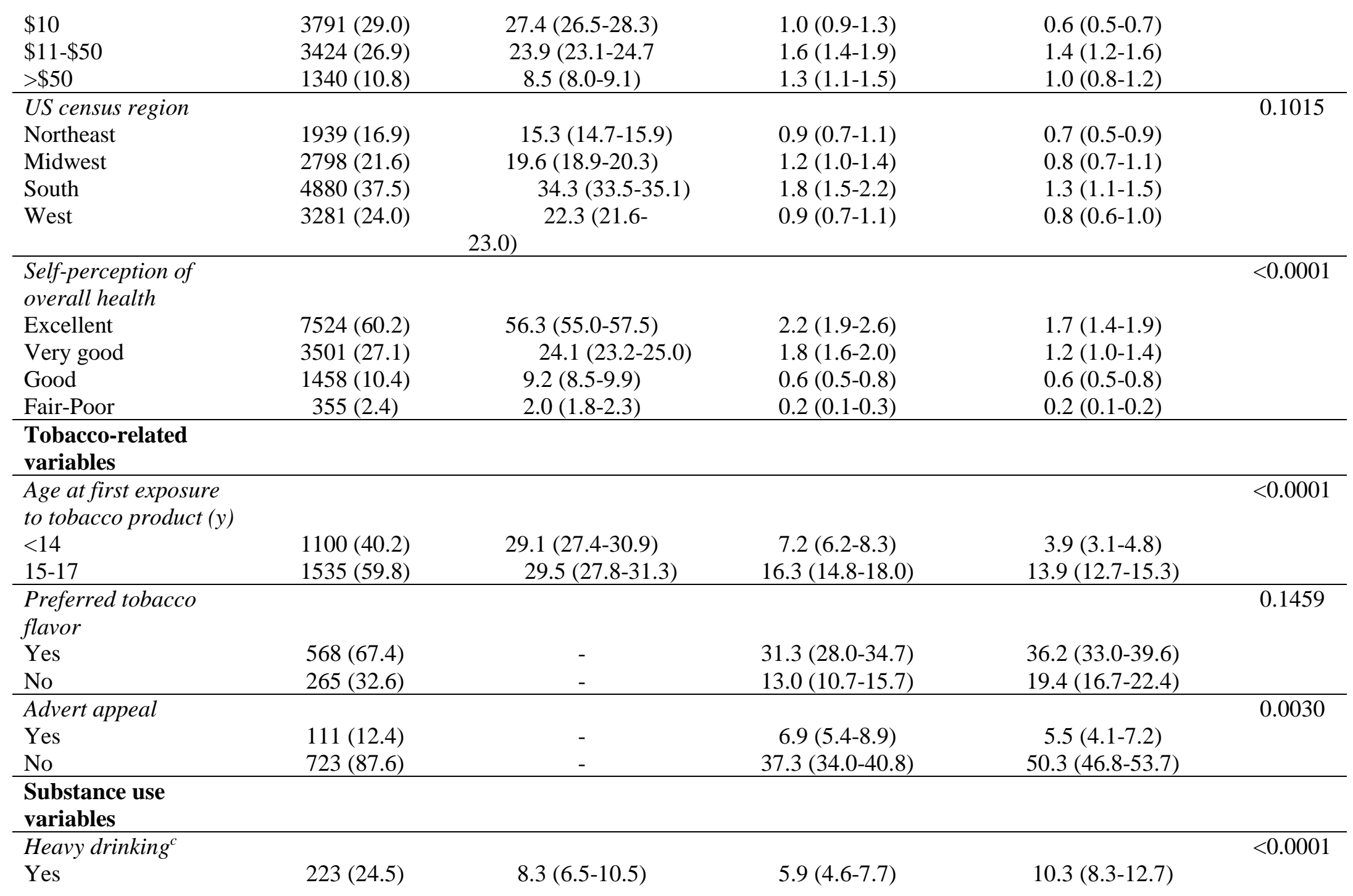




\begin{tabular}{|c|c|c|c|c|c|}
\hline No & $696(75.5)$ & $47.2(44.0-50.5)$ & $16.1(13.6-18.8)$ & $12.2(10.2-14.5)$ & \\
\hline High-risk drinking ${ }^{d}$ & & & & & $<0.0001$ \\
\hline Yes & $253(30.1)$ & $10.0(7.9-12.7)$ & $7.6(5.8-10.0)$ & $12.4(10.1-15.2)$ & \\
\hline No & $582(69.9)$ & $43.1(39.8-46.6)$ & $15.1(12.6-17.9)$ & $11.7(9.7-14.2))$ & \\
\hline Marijuana use $e^{e}$ & & & & & $<0.0001$ \\
\hline Within the past 30days & $631(38.1)$ & $14.5(12.6-16.6)$ & $11.2(9.8-12.8)$ & $12.3(10.6-14.3)$ & \\
\hline$>30$ days & $1065(61.9)$ & $43.6(41.3-46.0)$ & $9.8(8.4-11.4)$ & $8.5(7.2-9.9)$ & \\
\hline Other substance use $e^{e}$ & & & & & $<0.0001$ \\
\hline Within the past 30days & $493(39.6)$ & $33.9(31.1-36.9)$ & $2.8(1.9-3.9)$ & $2.9(2.1-4.0)$ & \\
\hline$>30$ days & $765(60.4)$ & $42.2(39.0-45.5)$ & $8.1(6.7-9.8)$ & $10.1(8.4-12.0)$ & \\
\hline \multicolumn{6}{|c|}{ 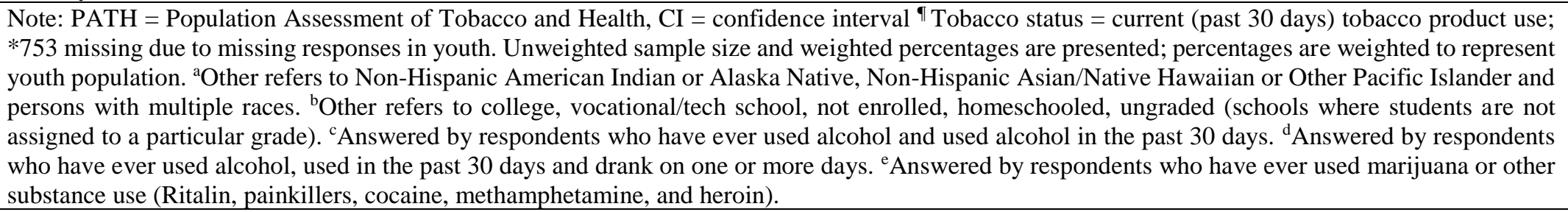 } \\
\hline
\end{tabular}


Table 2 - Characteristics of Young Adults (18-34 years) by Tobacco Status ${ }^{\mathrm{II}}$ PATH Study, 2013-2014 (N= 14,931)

\begin{tabular}{|c|c|c|c|c|c|}
\hline & $\begin{array}{c}\text { Total, } \\
\text { weighted } \%\end{array}$ & $\begin{array}{l}\text { Non-tobacco use, } \\
\text { weighted \% (95\% } \\
\text { CI) } \\
\end{array}$ & $\begin{array}{c}\text { Mono-tobacco use, } \\
\text { weighted \% (95\% CI) }\end{array}$ & $\begin{array}{c}\text { Poly-tobacco use, } \\
\text { weighted \% }(95 \% \\
\text { CI })\end{array}$ & P value \\
\hline Total & $14931 *(100.0)$ & $61.7(60.4-63.0)$ & $19.9(19.2-20.8)$ & $18.3(46.6-49.2)$ & \\
\hline \multicolumn{6}{|l|}{ Sociodemographic variables } \\
\hline Age group (y) & & & & & $<0.0001$ \\
\hline $18-24$ & $8843(42.6)$ & $25.5(24.6-26.4)$ & $7.9(7.4-8.3)$ & $9.3(8.7-9.9)$ & \\
\hline $25-34$ & $6081(57.4)$ & $36.2(35.2-37.3)$ & $12.1(11.5-12.7)$ & $9.1(8.6-9.6)$ & \\
\hline Gender & & & & & $<0.0001$ \\
\hline Male & $7521(49.8)$ & $26.7(25.6-27.9)$ & $10.9(10.3-11.4)$ & $12.3(11.6-13.0)$ & \\
\hline Female & $7410(50.2)$ & $35.0(34.2-35.8)$ & $9.1(8.6-9.6)$ & $6.1(5.7-6.5)$ & \\
\hline Sexual Orientation & & & & & $<0.0001$ \\
\hline Heterosexual & $13351(92.3)$ & $57.6(56.2-59.0)$ & $18.2(17.4-19.0)$ & $16.5(15.7-17.3)$ & \\
\hline Lesbian, Gay, Bisexual, Other & $1380(7.7)$ & $3.9(3.4-4.5)$ & $1.8(1.6-2.1)$ & $2.0(1.7-2.2)$ & \\
\hline Race/Ethnicity $^{a}$ & & & & & $<0.0001$ \\
\hline Non-Hispanic White & $8134(57.2)$ & $33.5(32.1-35.0)$ & $12.3(11.7-13.0)$ & $11.4(10.7-12.2)$ & \\
\hline Non-Hispanic Black & $2137(12.6)$ & $7.5(7.0-8.2)$ & $2.6(2.4-2.9)$ & $2.5(2.2-2.8)$ & \\
\hline Other & $1356(10.0)$ & $7.1(6.4-7.9)$ & $1.4(1.2-1.7)$ & $1.5(1.3-1.7)$ & \\
\hline Hispanic & $3196(20.1)$ & $13.5(12.7-14.4)$ & $3.6(3.3-3.9)$ & $3.0(2.7-3.3)$ & \\
\hline Education & & & & & $<0.0001$ \\
\hline Less than high school or GED & $2693(14.5)$ & $6.6(6.0-7.2)$ & $4.0(3.7-4.3)$ & $3.9(3.6-4.2)$ & \\
\hline High school graduate & $3810(24.0)$ & $13.8(13.1-14.5)$ & $5.2(4.8-5.5)$ & $5.0(4.6-5.4)$ & \\
\hline $\begin{array}{l}\text { Some college or associate's } \\
\text { degree }\end{array}$ & $5826(36.8)$ & $21.9(20.7-23.1)$ & $7.6(7.2-8.1)$ & $7.3(6.9-7.8)$ & \\
\hline $\begin{array}{l}\text { Bachelor's degree or advanced } \\
\text { degree }\end{array}$ & $2602(24.7)$ & $19.4(18.5-20.4)$ & $3.1(2.7-3.6)$ & $2.1(1.9-2.4)$ & \\
\hline Household income $e^{b}$ & & & & & $<0.0001$ \\
\hline$<\$ 25,000$ & $6686(38.5)$ & $20.7(19.5-21.8)$ & $8.8(8.3-9.4)$ & $9.0(8.4-9.6)$ & \\
\hline
\end{tabular}




\begin{tabular}{|c|c|c|c|c|c|}
\hline$\$ 25,000-\$ 74,999$ & $4561(32.9)$ & $20.7(19.6-21.8)$ & $6.6(6.2-7.1)$ & $5.6(5.2-6.1)$ & \\
\hline$\geq \$ 75,000$ & $2303(19.5)$ & $14.2(13.3-15.3)$ & $3.0(2.7-3.3)$ & $2.3(2.1-2.6)$ & \\
\hline Not reported & $1381(9.1)$ & $6.1(5.5-6.8)$ & $1.5(1.3-1.8)$ & $1.4(1.2-1.6)$ & \\
\hline Employment status & & & & & 0.0627 \\
\hline Full-time ( $\geq 35$ hours per week) & $6536(49.9)$ & $30.9(29.7-32.2)$ & $10.3(9.6-10.9)$ & $8.7(8.1-9.2)$ & \\
\hline $\begin{array}{l}\text { Part-time (15-24hours per } \\
\text { week) }\end{array}$ & $2846(17.0)$ & $10.4(9.5-11.4)$ & $3.2(2.9-3.6)$ & $8.8(8.2-9.5)$ & \\
\hline Part-time (<15hours per week) & $1027(6.3)$ & $4.0(3.5-4.6)$ & $1.1(0.9-1.3)$ & $3.1(2.7-3.5)$ & \\
\hline Don't currently work for pay & $4421(26.8)$ & $16.3(15.4-17.2)$ & $5.4(5.0-5.9)$ & $5.1(4.8-5.9)$ & \\
\hline US census region & & & & & $\begin{array}{c}{ }_{01}^{<} \\
0.00\end{array}$ \\
\hline Northeast & $2237(16.7)$ & $10.0(9.2-10.8)$ & $3.9(3.4-4.3)$ & $2.8(2.5-3.2)$ & \\
\hline Midwest & $3458(21.4)$ & $12.9(12.0-13.9)$ & $4.5(4.1-4.8)$ & $4.1(3.7-4.5)$ & \\
\hline South & $5691(37.5)$ & $22.4(20.8-24.1)$ & $7.6(7.1-8.2)$ & $7.5(6.9-8.0)$ & \\
\hline West & $3545(24.4)$ & $16.4(14.9-18.1)$ & $4.0(3.6-4.5)$ & $4.0(3.5-4.6)$ & \\
\hline $\begin{array}{l}\text { Self-perception of overall } \\
\text { health }\end{array}$ & & & & & $<0.0001$ \\
\hline Excellent & $2856(21.1)$ & $15.1(14.1-16.2)$ & $3.2(2.9-3.5)$ & $2.7(2.5-3.0)$ & \\
\hline Very good & $5508(38.7)$ & $25.8(24.6-27.0)$ & $6.9(6.5-7.3)$ & $6.0(5.6-6.5)$ & \\
\hline Good & $5052(31.6)$ & $17.0(16.0-18.0)$ & $7.4(6.9-7.8)$ & $7.3(6.8-7.7)$ & \\
\hline Fair-Poor & $1496(8.6)$ & $3.9(3.4-4.4)$ & $2.5(2.2-2.8)$ & $2.3(2.1-2.5)$ & \\
\hline \multicolumn{6}{|l|}{ Tobacco-related variables } \\
\hline $\begin{array}{l}\text { Age at first exposure to } \\
\text { tobacco product (y) }\end{array}$ & & & & & $<0.0001$ \\
\hline$<18$ & $1338(11.7)$ & $6.1(5.4-7.0)$ & $3.1(2.7-3.4)$ & $2.5(2.2-2.8)$ & \\
\hline $18-24$ & $7328(58.0)$ & $25.4(24.1-26.6)$ & $15.4(14.6-16.1)$ & $17.2(16.4-18.1)$ & \\
\hline $25-34$ & $2889(30.4)$ & $8.8(8.0-9.5)$ & $10.7(10.0-11.4)$ & $10.9(10.3-11.6)$ & \\
\hline Preferred tobacco flavor & & & & & 0.0023 \\
\hline Yes & $3960(62.1)$ & $7.7(6.9-8.7)$ & $20.4(19.2-21.7)$ & $33.9(32.4-35.5)$ & \\
\hline No & $2310(37.9)$ & $4.6(3.9-5.3)$ & $10.6(9.7-11.5)$ & $22.8(21.6-24.0)$ & \\
\hline
\end{tabular}




\begin{tabular}{|c|c|c|c|c|c|}
\hline Yes & $484(7.5)$ & $0.8(0.6-1.2)$ & $2.4(2.0-2.9)$ & $4.2(3.7-4.8)$ & \\
\hline No & $5785(92.5)$ & $11.4(10.3-12.6)$ & $28.6(27.3-30.0)$ & $52.5(51.1-53.8)$ & \\
\hline \multicolumn{6}{|l|}{ Substance use variables } \\
\hline Heavy drinking ${ }^{c}$ & & & & & 0.0001 \\
\hline Yes & $4601(51.6)$ & $25.1(23.7-26.5)$ & $12.3(11.6-13.1)$ & $14.2(13.4-15.0)$ & \\
\hline No & $4148(48.4)$ & $29.3(27.9-30.6)$ & $10.4(9.7-11.1)$ & $8.7(8.2-9.3)$ & \\
\hline High-risk drinking ${ }^{d}$ & & & & & $<0.0001$ \\
\hline Yes & $2362(22.5)$ & $7.4(6.6-8.4)$ & $6.8(6.3-7.4)$ & $8.3(7.7-8.9)$ & \\
\hline No & $6308(77.5)$ & $46.7(45.2-48.3)$ & $15.9(15.1-16.7)$ & $14.8(14.0-15.6)$ & \\
\hline Marijuana use $e^{e}$ & & & & & $<0.000$ \\
\hline Within the past 30days & $2912(30.8)$ & $6.1(5.4-6.8)$ & $8.9(8.2-9.6)$ & $15.8(15.1-16.7)$ & \\
\hline$>$ 30days & $5163(69.2)$ & $33.4(31.7-35.2)$ & $19.3(18.3-20.4)$ & $16.5(15.5-17.5)$ & \\
\hline Other substance use $e^{e}$ & & & & & 0.0114 \\
\hline Within the past 30days & $473(11.3)$ & $5.3(4.3-6.4)$ & $2.6(2.1-3.3)$ & $3.4(2.9-3.9)$ & \\
\hline$>30$ days & $3878(88.7)$ & $33.7(31.7-35.8)$ & $24.7(23.2-26.3)$ & $30.3(28.7-31.9)$ & \\
\hline
\end{tabular}

Note: PATH $=$ Population Assessment of Tobacco and Health, $\mathrm{CI}=$ confidence interval ${ }^{\mathbb{I}}$ Tobacco status $=$ current (past 30 days) tobacco product use;

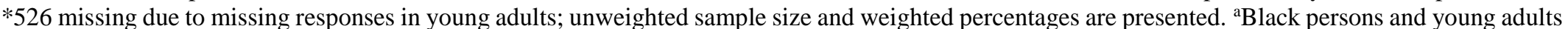
(18-24) were oversampled; percentages are weighted to represent young adult populations; Other refers to Non-Hispanic American Indian or Alaska Native, Non-Hispanic Asian/Native Hawaiian or Other Pacific Islander and persons with multiple races. ${ }^{b}$ Household income includes those who refused to report their income. ${ }^{\mathrm{c}}$ Answered by respondents who have ever used alcohol and used alcohol in the past 30 days. ${ }^{\mathrm{d}}$ Answered by respondents who have ever used alcohol, used in the past 30 days and drank on one or more days. ${ }^{\mathrm{e} A n s w e r e d ~ b y ~ r e s p o n d e n t s ~ w h o ~ h a v e ~ e v e r ~ u s e d ~ m a r i j u a n a ~ o r ~ o t h e r ~ s u b s t a n c e ~}$ use (Ritalin, painkillers, cocaine, methamphetamine, and heroin). 


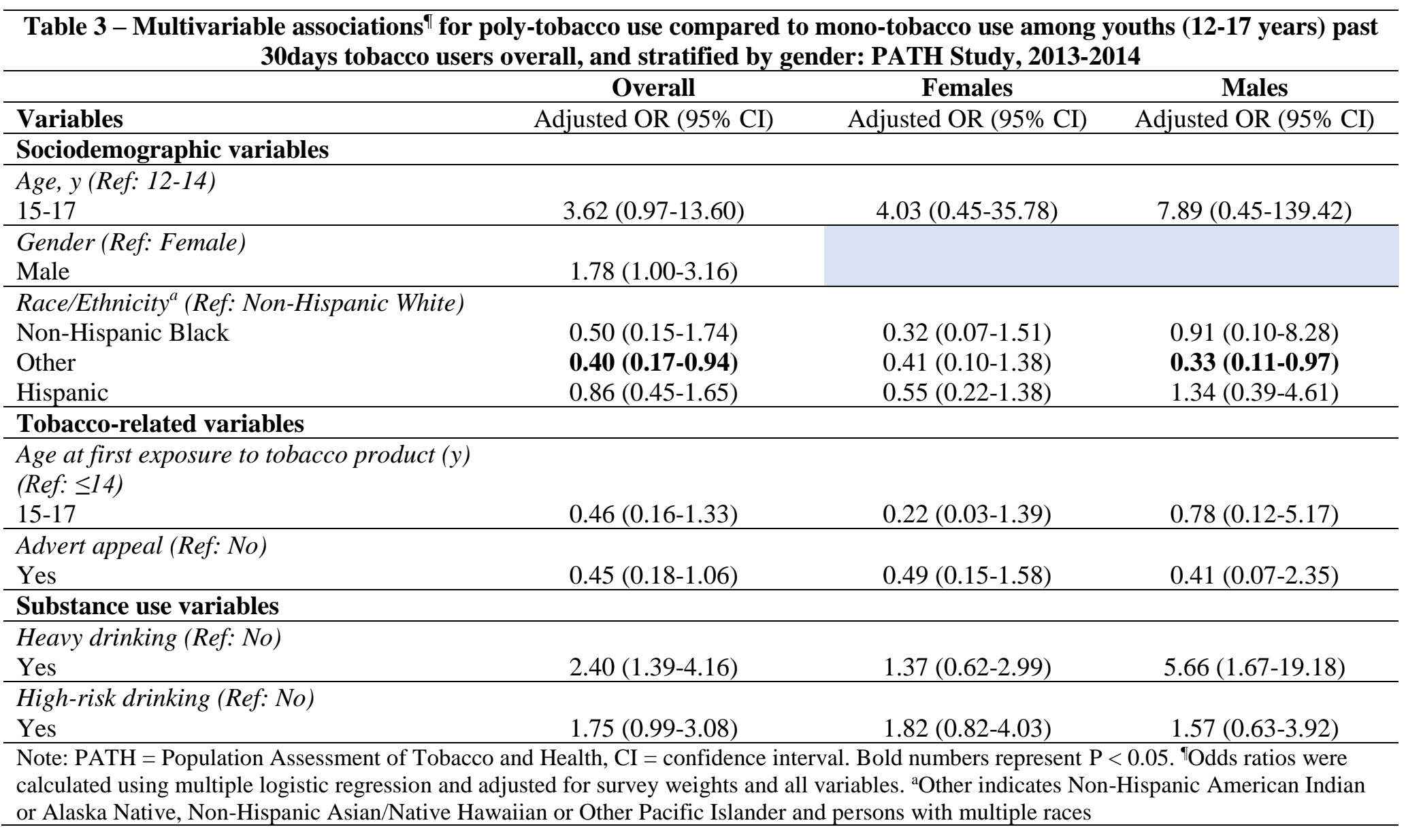




\begin{tabular}{|c|c|c|c|}
\hline & Overall & Females & Males \\
\hline Variables & Adjusted OR (95\% CI) & $\begin{array}{l}\text { Adjusted OR }(95 \% \\
\text { CI) }\end{array}$ & $\begin{array}{l}\text { Adjusted OR }(95 \% \\
\text { CI) }\end{array}$ \\
\hline \multicolumn{4}{|l|}{ Sociodemographic variables } \\
\hline $\begin{array}{l}\text { Age, y (Ref: } 25-34) \\
18-24\end{array}$ & $1.51(1.13-2.02)$ & $0.92(0.57-1.51)$ & $1.94(1.40-2.70)$ \\
\hline $\begin{array}{l}\text { Gender (Ref: Female) } \\
\text { Male }\end{array}$ & $1.42(1.12-1.80)$ & & \\
\hline $\begin{array}{l}\text { Sexual Orientation (Ref: Heterosexual) } \\
\text { Lesbian, Gay, Bisexual, Other }\end{array}$ & $1.26(0.90-1.77)$ & $1.62(1.16-2.27)$ & $0.63(0.34-1.16)$ \\
\hline $\begin{array}{l}\text { Education (Ref: Bachelor's or advanced degree) } \\
\text { Less than high school or GED } \\
\text { High school graduate } \\
\text { Some college or associate degree }\end{array}$ & $\begin{array}{l}1.74(1.22-2.49) \\
1.85(1.33-2.57) \\
1.39(1.03-1.87)\end{array}$ & $\begin{array}{l}\mathbf{2 . 0 4}(\mathbf{1 . 0 8 - 3 . 8 8}) \\
\mathbf{2 . 0 3}(\mathbf{1 . 0 7 - 3 . 8 3}) \\
1.43(0.85-2.40)\end{array}$ & $\begin{array}{l}1.51(0.96-2.38) \\
\mathbf{1 . 6 4}(\mathbf{1 . 0 7 - 2 . 5 3 )} \\
1.32(0.90-1.95)\end{array}$ \\
\hline $\begin{array}{l}\text { Household income (Ref: } \$ 75,000) \\
<\$ 25,000 \\
\$ 25,000-\$ 74,999 \\
\text { Not reported }\end{array}$ & $\begin{array}{l}1.24(0.77-1.98) \\
1.31(0.99-1.72) \\
1.39(1.03-1.87) \\
\end{array}$ & $\begin{array}{l}1.34(0.60-2.95) \\
1.32(0.77-2.25) \\
1.15(0.65-2.02) \\
\end{array}$ & $\begin{array}{l}1.32(0.76-2.29) \\
1.32(0.97-1.80) \\
1.34(0.97-1.86) \\
\end{array}$ \\
\hline $\begin{array}{l}\text { US census region (Ref: } \text { Northeast) } \\
\text { Midwest } \\
\text { South } \\
\text { West }\end{array}$ & $\begin{array}{l}1.32(0.99-1.74) \\
\mathbf{1 . 7 5}(\mathbf{1 . 3 4 - 2 . 2 3}) \\
1.24(0.92-1.68)\end{array}$ & $\begin{array}{l}1.09(0.69-1.71) \\
\mathbf{1 . 7 2}(\mathbf{1 . 0 8 - 2 . 7 5 )} \\
1.27(0.77-2.08)\end{array}$ & $\begin{array}{l}1.53(0.97-2.42) \\
\mathbf{1 . 8 4}(\mathbf{1 . 2 2 - 2 . 7 7 )} \\
1.28(0.85-1.94)\end{array}$ \\
\hline $\begin{array}{l}\text { Employment status (Ref: Full-time } \geq 35 \text { hours per } \\
\text { week } \\
\text { Part-time ( } 15-24 \text { hours per week) } \\
\text { Part-time }(<15 \text { hours per week) } \\
\text { Don't currently work for pay }\end{array}$ & $\begin{array}{l}0.82(0.62-1.08) \\
0.96(0.65-1.42) \\
0.97(0.77-1.23)\end{array}$ & $\begin{array}{l}0.82(0.55-1.24) \\
0.78(0.47-1.32) \\
0.86(0.60-1.24)\end{array}$ & $\begin{array}{l}0.78(0.56-1.10) \\
1.11(0.61-2.01) \\
0.98(0.71-1.37)\end{array}$ \\
\hline $\begin{array}{l}\text { Self-perception of health (Ref: Fair/Poor) } \\
\text { Excellent } \\
\text { Very good }\end{array}$ & $\begin{array}{l}0.84(0.57-1.24) \\
0.73(0.51-1.04)\end{array}$ & $\begin{array}{l}0.98(0.53-1.79) \\
0.85(0.52-1.41)\end{array}$ & $\begin{array}{l}0.70(0.41-1.21) \\
0.62(0.38-1.03)\end{array}$ \\
\hline
\end{tabular}




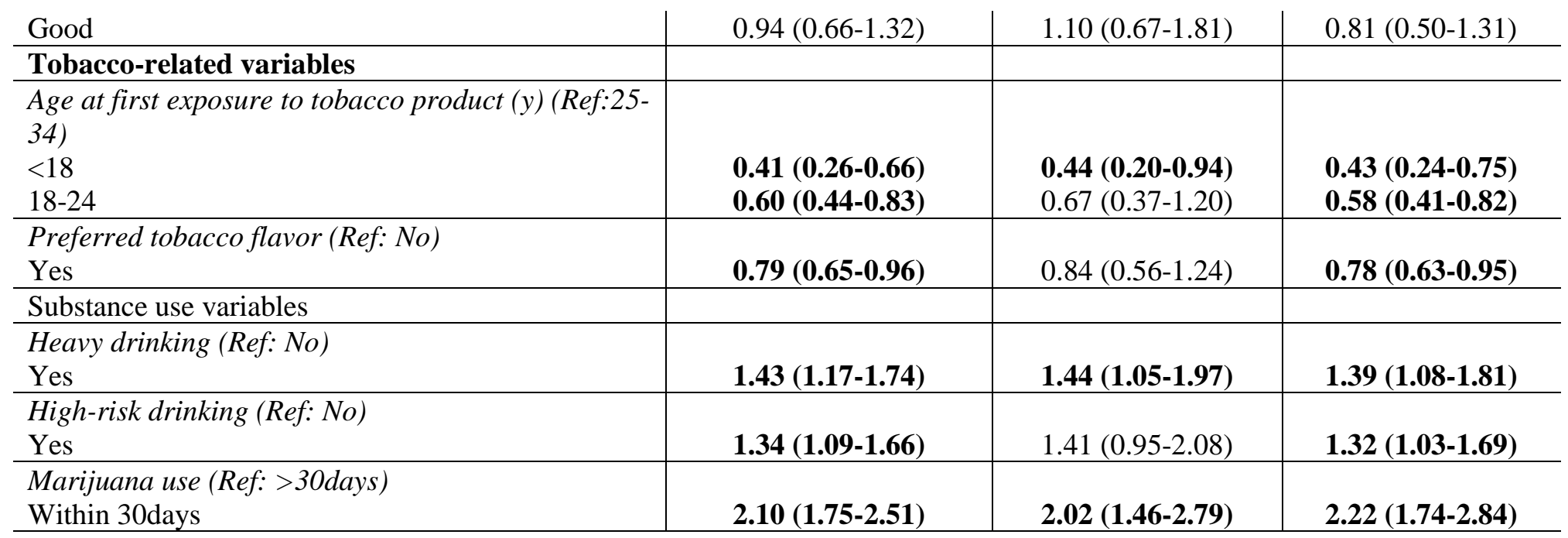

Note: PATH = Population Assessment of Tobacco and Health, $\mathrm{CI}=$ confidence interval. Bold numbers represent $\mathrm{P}<0.05$

${ }^{\pi}$ Odds ratios were calculated using multiple logistic regression and adjusted for survey weights and all variables 


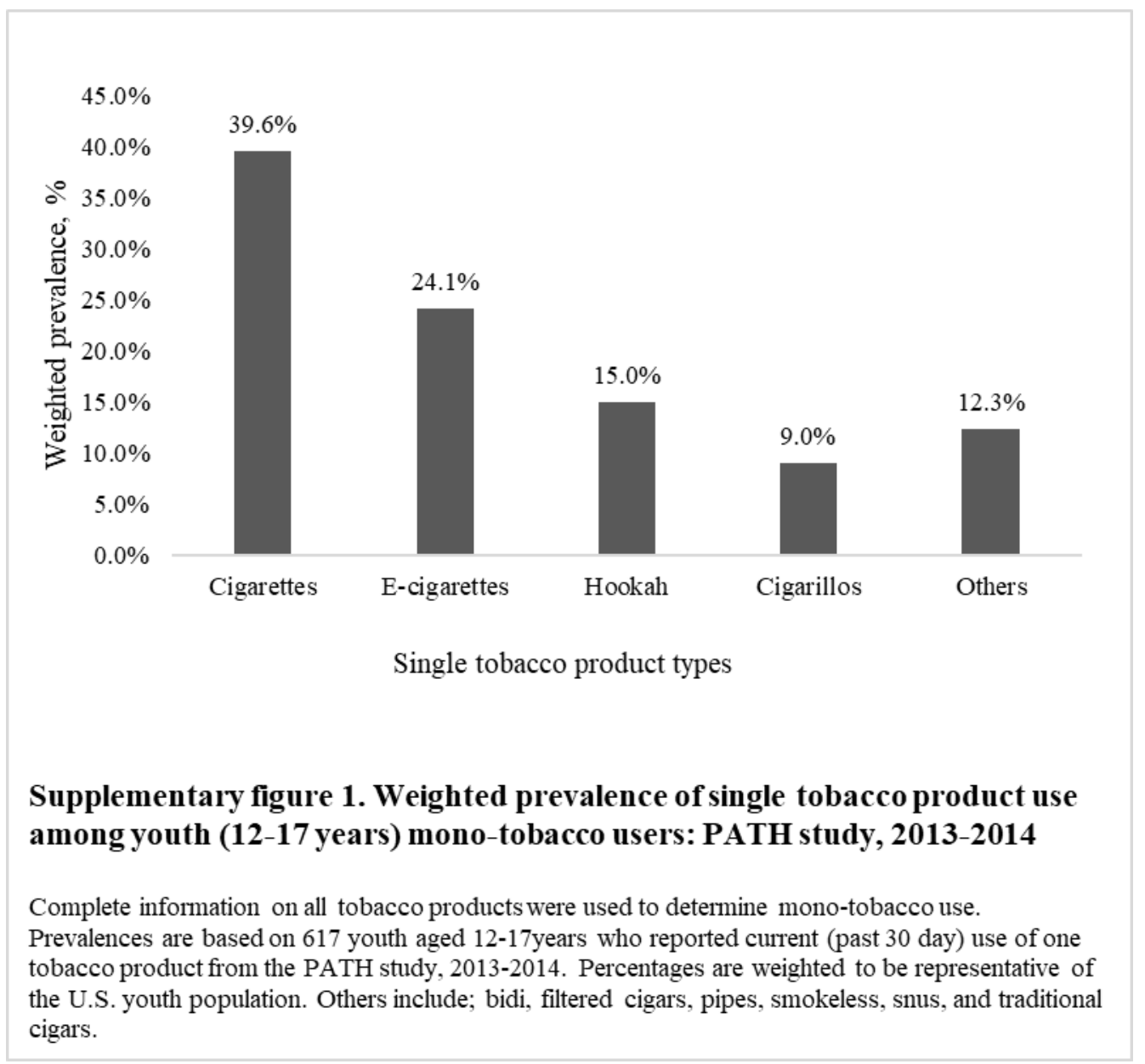




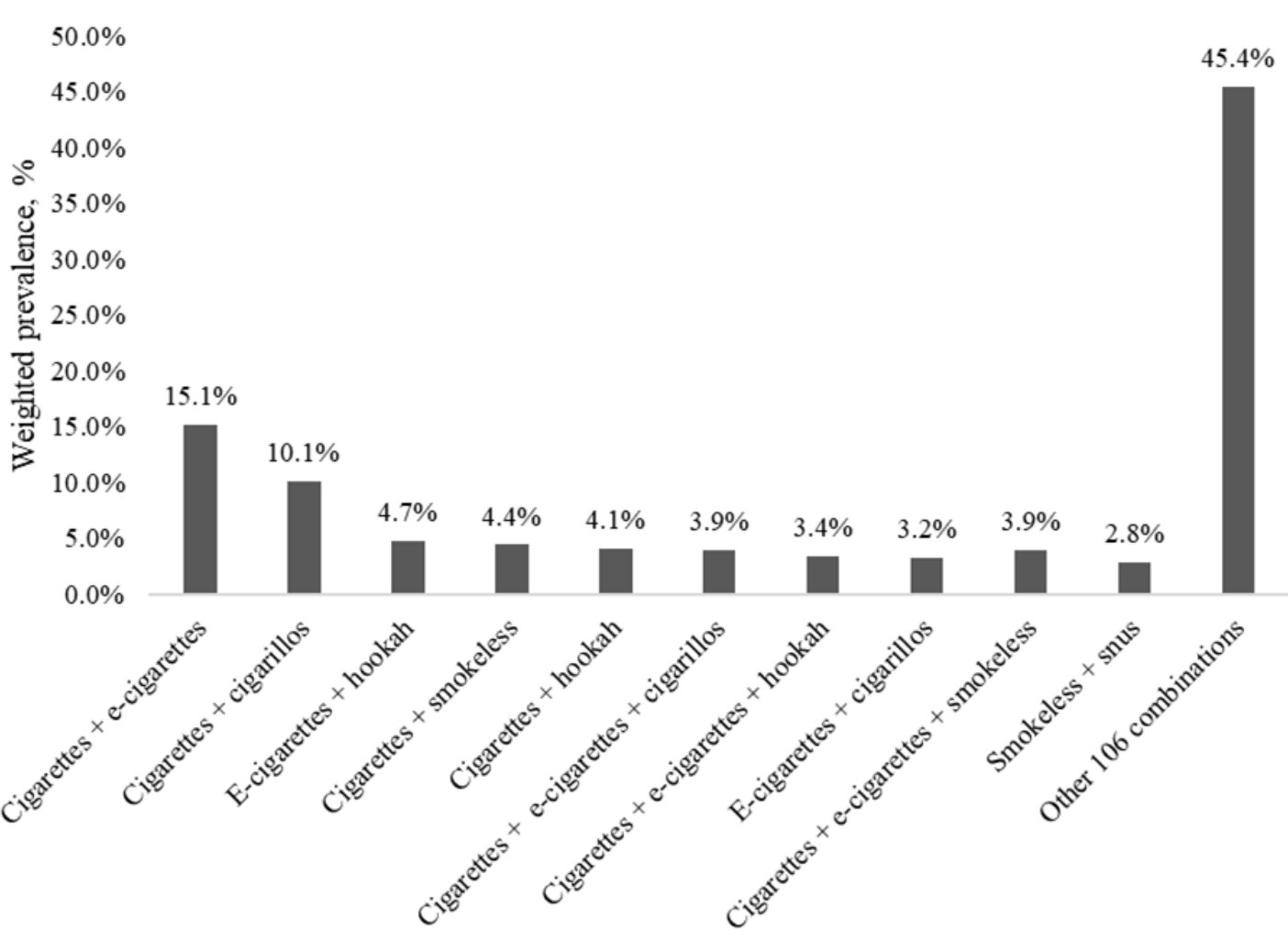

Tobacco product combination types

Supplementary figure 2 . Weighted prevalence of common multiple tobacco product combinations among youth (12-17 years) poly-tobacco users: PATH study, 2013-2014

Complete information on all tobacco products were used to determine poly-tobacco use. Prevalences are based on 467 youth aged 12-17years who reported current (past 30 day) use of two or more tobacco products from the PATH study, 2013-2014. Percentages are weighted to be representative of the U.S. youth population. 


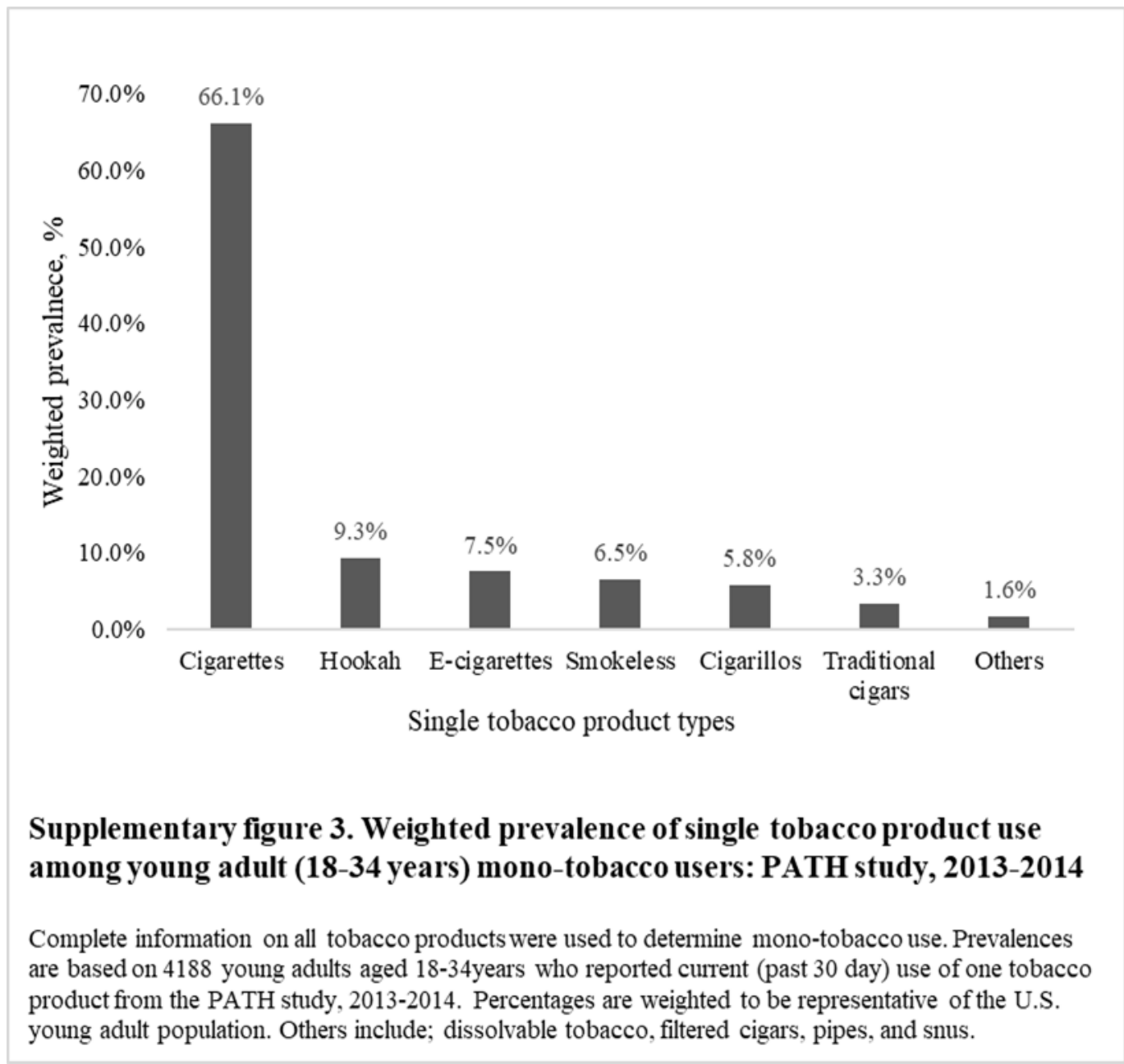




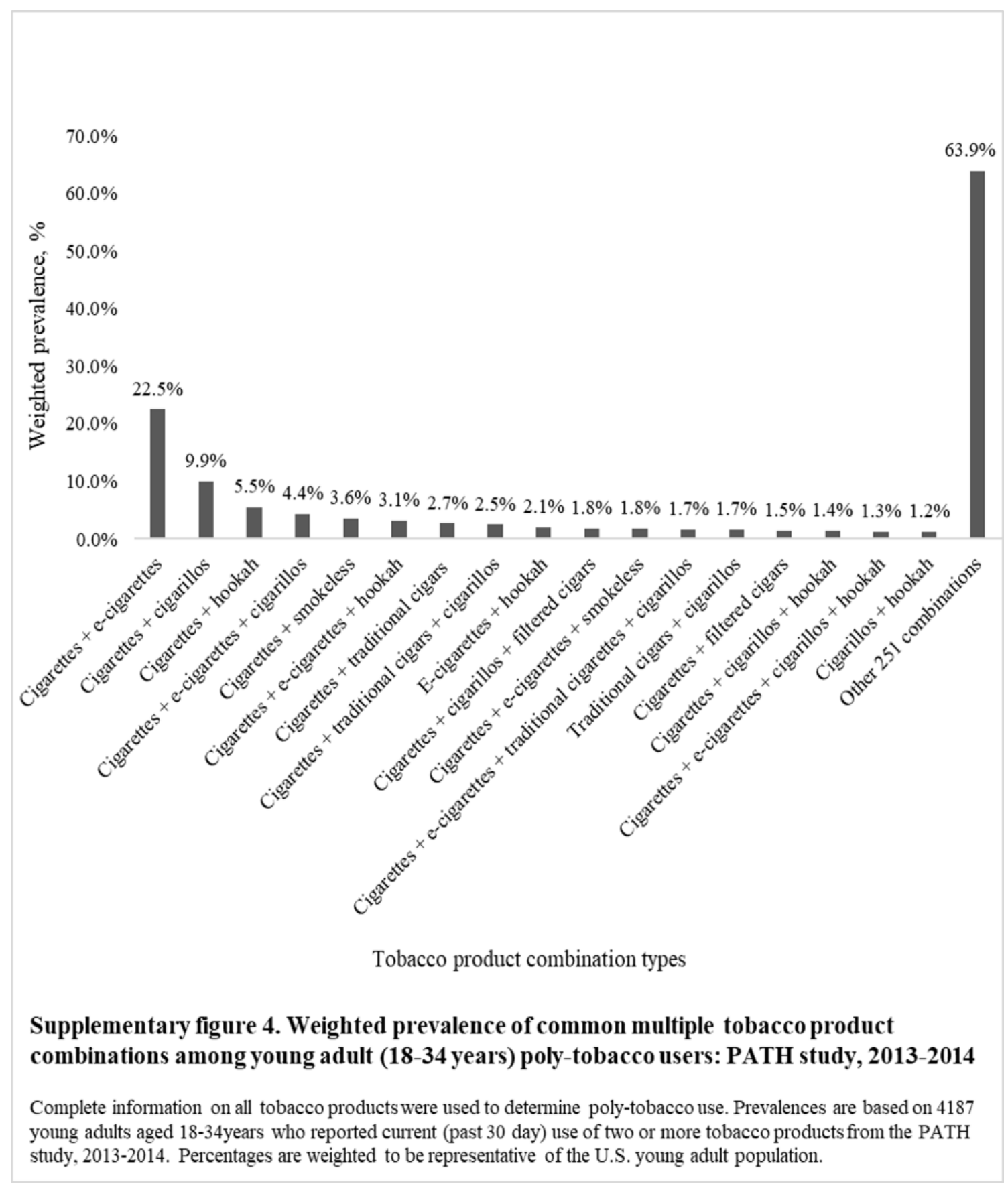




\begin{tabular}{|c|c|c|c|c|}
\hline \multicolumn{5}{|c|}{ Supplementary table 1 - Characteristics of Tobacco users among Youths (12-17 years): PATH Study, 2013-2014 } \\
\hline & Total, weighted \% & $\begin{array}{c}\text { Mono-tobacco use, } \\
\text { weighted \% (95\% CI) }\end{array}$ & $\begin{array}{c}\text { Poly-tobacco use, } \\
\text { weighted \% (95\% CI) }\end{array}$ & P value \\
\hline Total & $1082(100.0)$ & $57.1(53.9-60.2)$ & $42.9(39.8-46.1)$ & \\
\hline \multicolumn{5}{|l|}{ Sociodemographic variables } \\
\hline Age group (y) & & & & 0.0152 \\
\hline $12-14$ & $178(15.4)$ & $10.1(8.5-12.1)$ & $5.3(4.1-6.9)$ & \\
\hline $15-17$ & $904(84.6)$ & $47.0(43.9-50.0)$ & $37.6(34.6-40.7)$ & \\
\hline Gender & & & & $<0.0001$ \\
\hline Male & $588(55.3)$ & $27.6(24.9-30.5)$ & $27.7(24.9-30.8)$ & \\
\hline Female & $494(44.7)$ & $29.5(26.6-32.6)$ & $15.2(13.1-17.5)$ & \\
\hline Sexual Orientation & & & & 0.2980 \\
\hline Heterosexual & $880(87.1)$ & $48.5(44.9-52.0)$ & $38.6(35.3-42.0)$ & \\
\hline Lesbian, Gay, Bisexual, Other & $128(12.9)$ & $7.9(6.1-10.2)$ & $5.0(3.7-6.8)$ & \\
\hline Race/Ethnicity $^{a}$ & & & & 0.0058 \\
\hline Non-Hispanic White & $613(63.1)$ & $34.1(30.0-37.4)$ & $29.0(26.0-32.2)$ & \\
\hline Non-Hispanic Black & $116(11.5)$ & $8.2(6.6-10.1)$ & $3.3(2.4-4.6)$ & \\
\hline Other & $96(7.0)$ & $3.8(2.8-5.2)$ & $3.1(2.3-4.4)$ & \\
\hline Hispanic & $244(18.4)$ & $11.1(9.3-13.1)$ & $7.4(5.9-9.1)$ & \\
\hline 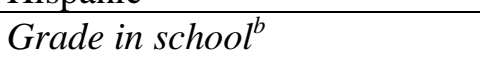 & & & & 0.1787 \\
\hline $5-8$ & $96(8.6)$ & $5.7(4.4-7.2)$ & $2.9(2.0-4.2)$ & \\
\hline $9-12$ & $886(86.0)$ & $48.9(45.8-52.0)$ & $37.1(34.0-40.3)$ & \\
\hline Other & $61(5.5)$ & $3.1(2.2-4.3)$ & $2.4(1.6-3.5)$ & \\
\hline Money received per week & & & & 0.1193 \\
\hline None & $195(18.1)$ & $10.1(8.5-12.1)$ & $8.0(6.3-10.1)$ & \\
\hline$\$ 10$ & $214(19.0)$ & $12.3(10.4-14.5)$ & $6.7(5.4-8.4)$ & \\
\hline$\$ 11-\$ 50$ & $381(35.8)$ & $19.4(17.0-22.0)$ & $16.4(14.3-18.8)$ & \\
\hline$>\$ 50$ & $286(27.0)$ & $15.1(12.8-17.7)$ & $11.9(9.9-14.2)$ & \\
\hline US census region & & & & 0.7559 \\
\hline Northeast & $186(18.7)$ & $10.5(8.8-12.5)$ & $8.1(6.3-10.4)$ & \\
\hline
\end{tabular}




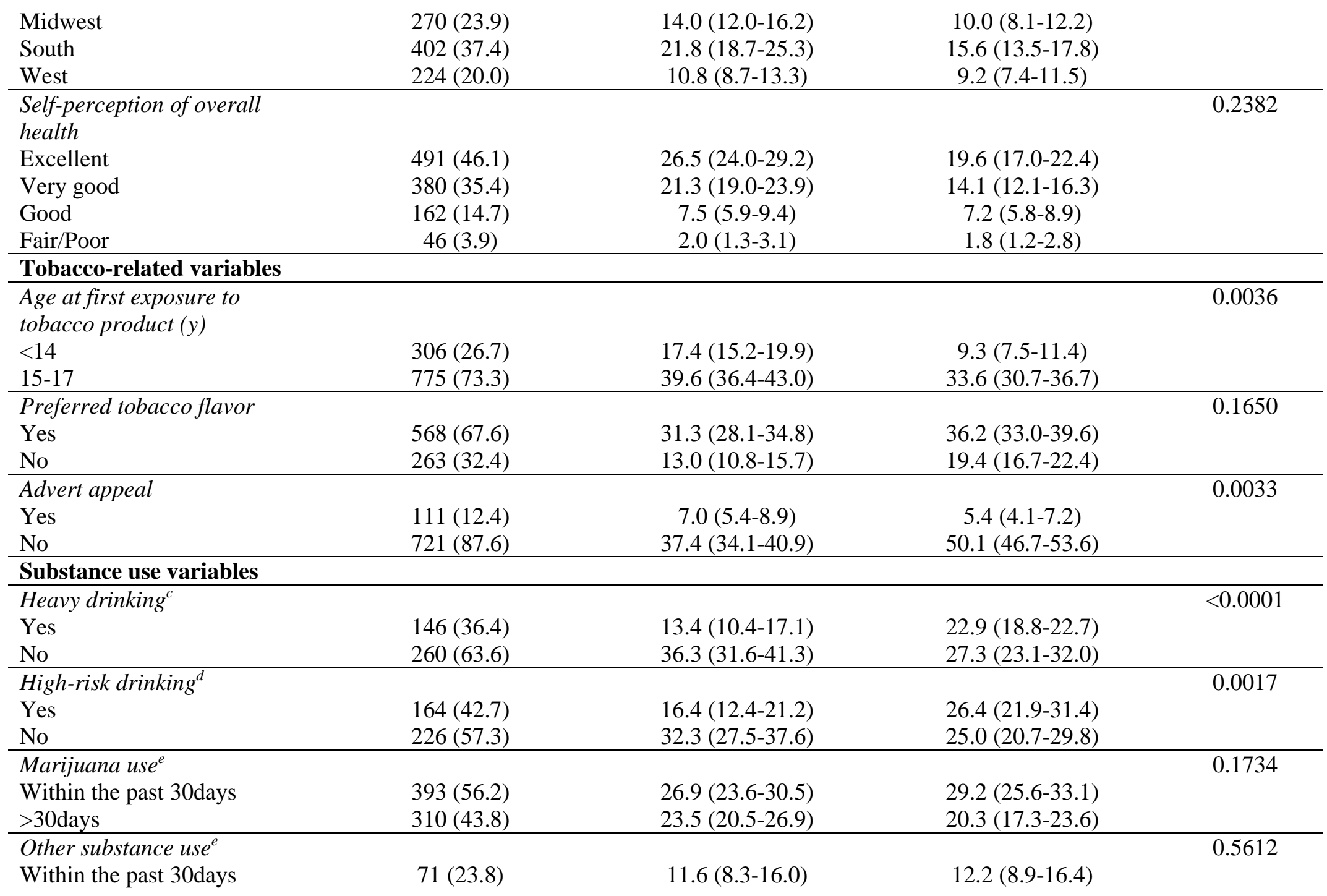


>30days

$227(76.2)$

$34.1(28.6-40.1)$

$42.1(36.1-48.3)$

Note: PATH = Population Assessment of Tobacco and Health, CI = confidence interval. Unweighted sample size and weighted percentages are presented; percentages are weighted to represent youth population. ${ }^{a}$ Other refers to Non-Hispanic American Indian or Alaska Native, Non-Hispanic Asian/Native Hawaiian or Other Pacific Islander and persons with multiple races. ${ }^{b}$ Other refers to college, vocational/tech school, not enrolled, homeschooled, ungraded (schools where students are not assigned to a particular grade). ${ }^{c}$ Answered by respondents who have ever used alcohol and used alcohol in the past 30 days. ${ }^{\mathrm{d}}$ Answered by respondents who have ever used alcohol, used in the past 30 days and drank on one or more days. ${ }^{\mathrm{e}}$ Answered by respondents who have ever used marijuana or other substance use (Ritalin, painkillers, cocaine, methamphetamine, and heroin). 


\begin{tabular}{|c|c|c|c|c|}
\hline \multicolumn{5}{|c|}{ Supplementary table 2 - Characteristics of Tobacco users among Young Adults (18-34 years): PATH Study, 2013- 2014} \\
\hline & $\begin{array}{c}\text { Total, } \\
\text { weighted \% }\end{array}$ & $\begin{array}{c}\text { Mono-tobacco use, } \\
\text { weighted \% (95\% CI) }\end{array}$ & $\begin{array}{c}\text { Poly-tobacco use, } \\
\text { weighted \% (95\% CI) }\end{array}$ & P value \\
\hline Total & $8377(100.0)$ & $52.1(50.8-53.4)$ & $47.9(46.6-49.2)$ & \\
\hline \multicolumn{5}{|l|}{ Sociodemographic variables } \\
\hline Age group $(y)$ & & & & $<0.0001$ \\
\hline $18-24$ & $4784(44.7)$ & $20.5(19.5-21.5)$ & $24.2(23.1-25.3)$ & \\
\hline $25-34$ & $3591(55.3)$ & $31.6(30.2-32.9)$ & $23.7(22.5-25.0)$ & \\
\hline Gender & & & & $<0.0001$ \\
\hline Male & $4788(60.4)$ & $28.4(27.3-29.6)$ & $32.0(30.8-33.3)$ & \\
\hline Female & $3589(39.6)$ & $23.7(22.6-24.8)$ & $15.8(15.0-16.7)$ & \\
\hline Sexual Orientation & & & & 0.0479 \\
\hline Heterosexual & $7356(90.1)$ & $47.3(45.9-48.7)$ & $42.8(41.5-44.1)$ & \\
\hline Lesbian, Gay, Bisexual, Other & $920(9.9)$ & $4.8(4.3-5.4)$ & $5.1(4.4-5.7)$ & \\
\hline Race/Ethnicity ${ }^{a}$ & & & & 0.2175 \\
\hline Non-Hispanic White & $4818(61.9)$ & $32.1(30.8-33.4)$ & $29.8(28.4-31.2)$ & \\
\hline Non-Hispanic Black & $1202(13.3)$ & $6.8(6.2-7.4)$ & $6.5(5.8-7.3)$ & \\
\hline Other & $698(7.5)$ & $3.7(3.1-4.4)$ & $3.8(3.3-4.4)$ & \\
\hline Hispanic & $1596(17.3)$ & $9.5(8.8-10.2)$ & $7.9(7.1-8.7)$ & \\
\hline Education & & & & $<0.0001$ \\
\hline Less than high school or GED & $1924(20.7)$ & $10.5(9.7-11.3)$ & $10.2(9.5-11.0)$ & \\
\hline High school graduate & $2237(26.5)$ & $13.5(12.7-14.4)$ & $13.0(12.0-14.1)$ & \\
\hline Some college or associate's degree & $3279(39.1)$ & $20.0(19.0-21.0)$ & $19.1(18.2-20.1)$ & \\
\hline $\begin{array}{l}\text { Bachelor's degree or advanced } \\
\text { degree }\end{array}$ & $937(13.7)$ & $8.2(7.2-9.2)$ & $5.5(4.9-6.1)$ & \\
\hline Household income $e^{b}$ & & & & 0.0013 \\
\hline$<\$ 25,000$ & $4218(46.5)$ & $23.0(21.8-24.3)$ & $23.5(22.3-24.8)$ & \\
\hline$\$ 25,000-\$ 74,999$ & $2500(32.1)$ & $17.3(16.4-18.3)$ & $14.7(13.8-15.7)$ & \\
\hline$\geq \$ 75,000$ & $997(13.8)$ & $7.8(7.0-8.6)$ & $6.0(5.4-6.7)$ & \\
\hline Not reported & $662(7.6)$ & $4.0(3.5-4.6)$ & $3.6(3.2-4.1)$ & \\
\hline Employment status & & & & 0.0098 \\
\hline
\end{tabular}




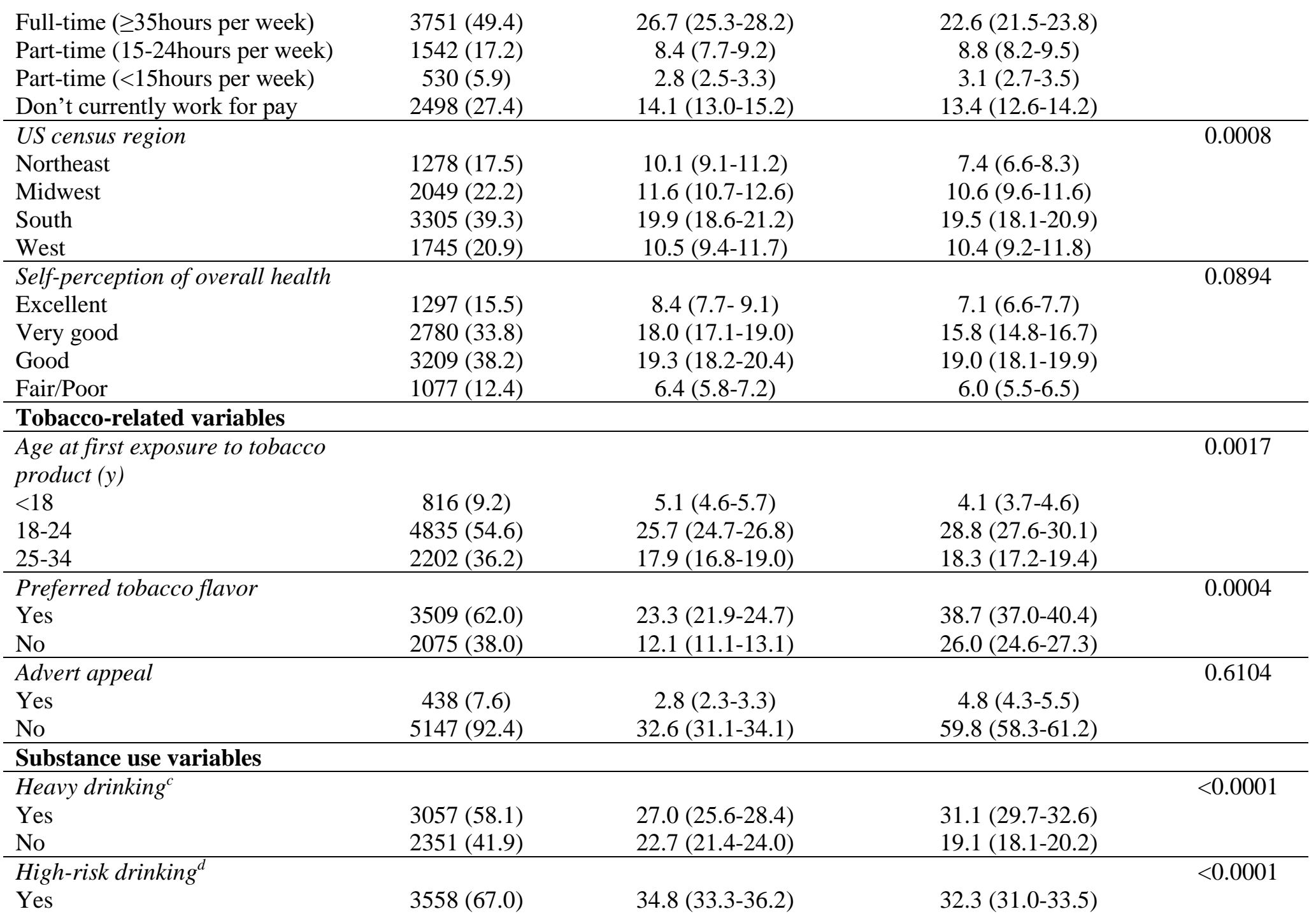




\begin{tabular}{|c|c|c|c|c|}
\hline No & $1808(33.0)$ & $14.9(13.9-16.0)$ & $18.0(16.9-19.2)$ & \\
\hline Marijuana $u s e^{e}$ & & & & $<0.0001$ \\
\hline Within the past 30days & $2454(40.9)$ & $14.7(13.7-15.8)$ & $26.2(24.9-27.4)$ & \\
\hline$>30$ days & & & & \\
\hline Other substance use $e^{e}$ & & & & 0.7874 \\
\hline Within the pas & $317(9.8)$ & $4.3(3.5-5.4)$ & $5.5(4.8-6.4)$ & \\
\hline$>30$ days & $2840(90.2)$ & $40.6(38.4-42.7)$ & $49.6(47.6-51.6)$ & \\
\hline \multicolumn{5}{|c|}{$\begin{array}{l}\text { Note: PATH = Population Assessment of Tobacco and Health, CI = confidence interval. Unweighted sample size and weighted percentages are } \\
\text { presented. } \\
\text { palack persons and young adults (18-24) were oversampled; percentages are weighted to represent young adult populations; Other refers to Non- } \\
\text { Hispanic American Indian or Alaska Native, Non-Hispanic Asian/Native Hawaiian or Other Pacific Islander and persons with multiple races. } \\
\text { bHousehold income includes those who refused to report their income. }{ }^{c} \text { Answered by respondents who have ever used alcohol and used alcohol } \\
\text { in the past } 30 \text { days. }{ }^{d} \text { Answered by respondents who have ever used alcohol, used in the past } 30 \text { days and drank on one or more days. }{ }^{e} \text { Answered } \\
\text { by respondents who have ever used marijuana or other substance use (Ritalin, painkillers, cocaine, methamphetamine, and heroin) }\end{array}$} \\
\hline
\end{tabular}




\title{
Manuscript 2
}

(C) Copyright 2019

\section{E-cigarette trajectories among US youth and adults; results from the Population Assessment of Tobacco and Health Study Waves 1,2,3 (2013-2016)}

\begin{abstract}
Background: The dramatic increase of e-cigarette use among youth in the US has prompted regulatory action to address their spread.

Objective: To address the relative scale of key potentially positive and negative transitions of ecigarettes in the US over a period of 2 years including; for youth 1-trends in e-cigarette uptake among never cigarette smokers; 2) transition from e-cigarette mono use to cigarette smoking; and for adults 3) transition of dual (e-cigarette/cigarette) use to mono or no tobacco use (quitting).

Design: Analysis of longitudinal data from representative population-based samples of US youth (12-17 years) and adults ( $\geq 18$ years) from Waves 1-3 of the Population Assessment of Tobacco and Health (PATH) Study.
\end{abstract}

Setting: PATH Wave 1 was conducted between 2013-2014 (13,621 youth, 32,320 adults); Wave 2 between 2014-2015 (12,172 youth, 28,362 adults); and Wave 3 between 2015-2016 (11,814 youth, 28,148 adults).

Participants: Participants were obtained from Waves 1-3 of PATH for US youth and adults.

Measurements: Weighted prevalence estimates of self-reported current (past 30 days) ecigarette use and cigarette smoking among youth and adults in Waves 1-3.

Results: Between 2013-2016, e-cigarette use in the US increased among youth but not adults. Young e-cigarette users were more likely to be never cigarette smokers compared to older ones. 
Youth results show that among e-cigarette users at each wave the proportion of never cigarette smokers rose from $24.1 \%$ in Wave 1 to $42.6 \%$ in Wave 3 ( $p=0.0001$ for trends). Of youth ecigarette mono users in Wave 1, 34.4\% transitioned to cigarette smoking (10.9\% mono cigarette, $23.5 \%$ dual use) at Wave 3, compared to $45.3 \%$ reporting no tobacco use, and $20.3 \%$ reporting ecigarette mono use.

Adult results show that for e-cigarette dual users in Wave $1,8.8 \%$ transitioned to no tobacco use at Wave 3, 6.2\% continued as mono e-cigarette users, while $85 \%$ either relapsed to cigarettes $(53.5 \%)$ or continued dual use $(31.5 \%)$. Among adult e-cigarette users who never smoked cigarettes at Wave 1,25\% transitioned to cigarette smoking in Wave 3.

Limitation: The question about current e-cigarette use was changed in Wave 3 to include past 30 days use of any ENDS including (e-cigarettes, e-cigars, e-hookahs, e-pipes, hookah pens, personal vaporizers, and vape pens).

Conclusions: In both young and adult current e-cigarette users, there was more relapse, dual-use, and transition to cigarette smoking, as well as e-cigarette uptake among young never cigarette smokers than quitting among adult smokers. This imbalance in the scale of potentially positive and negative transitions related to e-cigarettes in the society needs to be considered carefully when planning regulatory actions for e-cigarettes.

Keywords: Cigarettes, E-cigarettes, Dual use, Harm reduction, Youth, Adults, US, Population, Longitudinal

\section{Introduction}

The recent evidence of the dramatic increase of e-cigarette (a.k.a. electronic nicotine delivery systems, ENDS) use among youth in the US has intensified the debate about their possible contribution to reducing harm from tobacco use in the society, as well as concerns about 
their potential role in smoking uptake (US Department of Health and Human Services 2016; NASEM 2018). Reports based on the National Youth Tobacco Survey (NYTS) show a 78\% increase in e-cigarette use among high school students in 2018 alone. At the same time, sales of Juul e-cigarettes that are particularly popular among youth rose $641 \%$ to dominate the market share of this product (Cullen et al., 2018; King et al., 2018).

A central premise of e-cigarette harm reduction is that, should their use continue to proliferate, they will reduce smoking harms throughout whole populations by enabling cessation and reducing smoking frequency. From this perspective, the potential of e-cigarettes for tobacco control promises an unprecedented reduction in the global burden of disease caused by smoking (Abrams et al., 2018; McNeill et al., 2015; Hajek et al., 2014). These forecasts are based on expectations that the net contribution of e-cigarette use across whole populations will be positive, meaning that the numbers of smokers who quit smoking via e-cigarettes will be larger than the combined numbers of those who relapse back to smoking, keep both smoking and e-cigarettes use (dual users), and previous nonsmokers who commence smoking after first using e-cigarettes (Warner \& Mendez 2018). On the other hand, the increased popularity of e-cigarettes among youth, and their potential to lead to cigarette smoking are raising concerns about their role in expanding the nicotine addiction base among young people and subsequent perpetuation of the tobacco epidemic (Glantz \& Bareham 2018; Soneji et al., 2017; Chapman et al., 2018).

The debate on the impact of e-cigarettes in populations has often been marred by inferring causal or population effects from cross-sectional, ecological or data obtained from limited samples or short follow-ups (Barrington-Trimis et al., 2015; Dutra \& Glantz 2014; US Department of Health and Human Services 2018). The 2018 report on e-cigarettes by the National Academies of Science, Engineering and Medicine (NASEM) emphasized that because the e-cigarette phenomenon is relatively recent, "the majority of studies ... lack sufficient 
duration of follow-up to study the naturalistic cigarette smoking progression sequence"(NASEM 2018). Accordingly, what has been missing is a real-world look at the totality of potentially positive and negative transitions of e-cigarette use in the US, based on representative longitudinal data with sufficient follow up.

In 2011, the NIH and FDA commenced the Population Assessment of Tobacco and Health cohort study (PATH), as the first large research effort since Congress gave FDA the authority to regulate tobacco products in 2009 (US Department of Health and Human Services 2018; Hyland et al., 2017). Studies from PATH Waves 1, and 2 started answering some of the important questions about e-cigarette transition during a 1-year period among US adults (Coleman et al., 2018; Verplaeste et al., 2018). So far, these studies have shown mixed results about the value of e-cigarettes for adult cigarette smokers' cessation. For example, Coleman and colleagues found that the majority of adult dual users in Wave 1 (87.8\%) either continued dualuse or relapsed to cigarette-only smoking at one year follow up, compared to $12.1 \%$ who quit cigarette smoking (Coleman et al., 2018). With the recent availability of Wave 3 data from PATH (October 2018), we have the opportunity to look at an extended follow-up of 2 years and use such data to assess additionally youth uptake of e-cigarettes and its relation to cigarette smoking.

In this analysis, we consider three waves of PATH data for youth and adults, to provide a comparative overview of the real-world evolution of e-cigarette use in relation to cigarette smoking in the US between 2013-2016. Currently, the debate surrounding the regulation of ecigarettes focuses mostly on the size of e-cigarettes' potentially beneficial effects to the society (e.g., adult cessation) vs. their unwarranted effects (e.g., uptake among tobacco naïve adolescents) (Abrams et al., 2018). Therefore, we aimed in this study to answer 3 questions that reflect these outcomes based on the relative scale of key potentially positive and negative transitions of e-cigarettes in the US over a period of 2 years including; for youth 1-trends in e- 
cigarette uptake among never cigarette smokers; 2) transition from e-cigarette mono use to cigarette smoking; and for adults 3) transition of dual (e-cigarette/cigarette) use to mono or no tobacco use (quitting). While our assessment does not imply a direct measurement of harm/benefit differentials between these transitions, it provides what much of the policy and regulatory debate around e-cigarettes have focused on; the relative scale of these transitions in a real-world setting $(2,5)$.

\section{Methods}

\section{Study Sample and Overview}

Data from Waves 1 (2013-2014), 2 (2014-2015) and 3 (2015-2016) of the PATH Study were used in this analysis. The detailed methodology for the PATH Study has been previously described (15). Briefly, the PATH study is a nationally representative sample of 45,971 youth and adults aged $\geq 12$ years old. Youth (12-17 years) and adults ( $\geq 18$ years) were sampled separately using audio computer-assisted self-interview (ACASI), available in English and Spanish. The PATH study employs a multistage sampling design to produce a nationally representative sample of the US population. Adult tobacco users, young adults (aged 18-24 years), and AfricanAmericans were oversampled to make results nationally representative of the general population (US Department of Health and Human Services, 2018). The overall response rate at Wave 1 was $78.4 \%$ for youth and $74.0 \%$ for adults yielding a total of 13,621 youth and 32,320 adult participants. At Wave 2, the response rate was $87.3 \%$ for youth and $83.2 \%$ for adults yielding a total of 12,172 youth and 28,362 adult participants. At Wave 3, the response rate was $83.3 \%$ for youth and $78.4 \%$ for adults yielding a total of 11,814 youth and 28,148 adult participants. In this study, our analysis focused on youth and adults who report current use (past 30 days) of ecigarettes, alone or in combination with cigarettes (dual use) at Wave 1 and had complete followup information at Wave 3 to look at important transitions within 2 years. Survey responses were 
weighted to adjust for nonresponse, varying selection probabilities, and oversampling to reflect national demographics (US Department of Health and Human Services, 2018). The Institutional Review Board of Florida International University approved the study and deemed it exempt.

\section{Study Measures}

Tobacco products use:

Current e-cigarette use was derived from the answers to two questions about; "ever used an e-cigarette" and respondents who answered "yes" were asked; "used an e-cigarette at least once in the past 30 days" for both youth and adults at each wave (Kasza et al., 2017; Chaffee et al., 2018; Dai et al., 2018). This definition was also applied to current cigarette smoking. Ever cigarette smoking was assessed with the question about; "(n)ever smoked a cigarette, even one or two puffs" for youth and adults (Chaffee et al., 2018). Positive and negative responses to this question defined the ever and never cigarette smoking categories used in our analysis. As ecigarette/cigarette is the most common and important combination for the regulatory implications of e-cigarettes (Kasza et al., 2017), dual use was derived from positive responses to both current e-cigarette and cigarette use. To broaden the representativeness of our analysis, given that polytobacco is becoming common among US youth (Osibogun et al., 2018), dual users who reported the use of other tobacco products were still counted towards the dual use category. In Wave 3, the e-cigarette use question was expanded to include other electronic nicotine delivery systems (ENDs, including e-cigarettes, e-cigars, e-hookahs, e-pipes, hookah pens, personal vaporizers, and vape pens), with current use implying the use of any ENDS in the past 30 days (US Department of Health and Human Services, 2018). To avoid confusion and have consistent terminology, we have used the term e-cigarettes throughout and pointed to the possible effect of the change in the e-cigarette question in Wave 3 on our analysis in the limitations section. 


\section{Transitions}

All studied transitions are for current (past 30 days) tobacco use status. The change in the status of e-cigarette use between Waves 1 to 3 was considered for regulatory-important transitions for both e-cigarette mono and dual users (Coleman et al., 2018). For current e-cigarette mono users at Wave 1, we considered the following transitions between Waves 1 and 3;1) transition to dual use, 2) continuing with e-cigarette mono use, 3) transition to cigarette mono use and 4) transition to no use of any tobacco product (quitting). For current dual users at Wave 1 we considered the following transitions between Waves 1 and 3;1) continuing with dual use, 2) transition to e-cigarette mono use, 3) relapse to cigarette mono use, 4) transition to no use of any tobacco product (considered as an indicator of quitting).

\section{Statistical analyses}

We used summaries of weighted prevalence estimates of participants with complete data for current e-cigarette use and cigarette smoking status in the overall population in the 3 Waves separately for both youth and adults. Next, we summarized the age-group distribution of current e-cigarette use by ever cigarette smoking status for youth and adults in the 3 Waves. Furthermore, we calculated the prevalence estimates for e-cigarette mono and dual users among youth and adults identified from Wave 1 and assessed the change in their use status at Wave 3 (Coleman et al., 2018).

The replicate weights provided by the PATH Study for the three Waves were used to obtain unbiased variance estimates using Fay's Method of Balanced Repeated Replication, with the Fay coefficient value of 0.3 , as recommended by the PATH Study team (US Department of Health and Human Services, 2018). Weighted percentages were reported with their corresponding 95\% confidence intervals (CI). Pearson chi-square tests were used to evaluate differences in proportions between ever cigarette and never cigarette smoking by e-cigarette use status for youth 
and adults. We tested the linear trend for the proportions of overall current e-cigarette use, ecigarette use by ever and never cigarette smoking against the general population of the PATH study, and across the 3 Waves using the chi-square test for trends. We also evaluated the differences between identified transitions among youth and adult e-cigarette users using the Pearson chi-square test. All data analyses were performed using STATA 14.2 (Stata Corp, College Station, TX) and a $\mathrm{P}$ value of $<0.05$ was considered statistically significant.

\section{Role of the Funding Source}

Dr. Osibogun is supported by the Dissertation Year Fellowship from Florida International University (FIU) during the time of conducting this study. However, FIU had no role in the study design, analysis or interpretation of the data; preparation, review or approval of the manuscript, or the decision to submit the manuscript for publication. Dr. Maziak is supported by NIH grants R01-DA035160, R01-TW010654, R01-DA042477, and U54MD012393-01 for the FIU-RCMI.

\section{Results}

Overall e-cigarette prevalence and trends among youth and adults

The overall prevalence of current (past 30 days) e-cigarette use among 13,559 youth in Wave 1 was 3.1\% (95\% CI: 2.8-3.5), increasing to 3.6\% (95\% CI: 3.2-4.1) in Wave 2 among $12,059$ youth, and $4.1 \%$ (95\% CI: $3.7-4.7)$ in Wave 3 among 11,546 youth ( $P=0.0008$ for trends)

(Table 1). Among 32,222 US adults in Wave 1, the overall prevalence of current (past 30 days) ecigarette use was 6.7\% (95\% CI: 6.4-7.0), becoming 6.3\% (95\% CI: 5.9-6.6) in Wave 2 among 27,458 adults, and 7.0\% (95\% CI: 6.7-7.3) in Wave 3 among 27,860 adults ( $P=0.44$ for trends)

(Table 2). Below we provide study results according to our study's three main objectives. 
1- Trends of e-cigarette uptake among youth never smokers (2013-2016)

In Wave 1, 24.1\% (95\% CI: 20.1-28.6) of current e-cigarette users were never cigarette smokers, increasing to $35.8 \%$ (95\% CI: $31.1-40.7)$ in Wave 2, and 38.2\% (95\% CI: $32.8-43.9$ ) in Wave 3 ( $P=0.0003$ for trends; data not shown). Since the profile of young e-cigarette smokers is likely to change with time, we compared newly reported e-cigarette smokers at each wave (i.e., did not report e-cigarette use in the previous wave) and found that the proportion of never smokers among new e-cigarette users rose from $24.1 \%$ in Wave 1 to $42.6 \%$ in Wave 3 ( $P=0.0001$ for trends; Figure 1).

2- E-cigarette transitions among US youth (2013-2016)

For e-cigarette mono users in Wave $1(\mathrm{n}=167), 34.4 \%$ transitioned to cigarette smoking (10.9\% mono cigarette, $23.5 \%$ dual use) at Wave 3, compared to $65.6 \%$ reporting no tobacco use (45.3\%), or e-cigarette mono use at Wave $3(20.3 \%)(p<0.0001$; Table 3). This trend differed according to ever cigarette smoking status, whereby among e-cigarette users, never cigarette smokers in Wave 1, 19.9\% transitioned to cigarette smoking ( $7.2 \%$ cigarette, $12.7 \%$ dual use) at Wave 3, compared to $61.4 \%$ transitioning to cigarette smoking ( $24.5 \%$ cigarette, $39.7 \%$ dual use) among e-cigarette, ever cigarette smokers ( $p<0.005$; Figure 2).

Among youth dual users in Wave $1(\mathrm{n}=153), 73.9 \%$ transitioned to either cigarette smoking or dual use in Wave 3, thus can be considered to have been held in smoking 24 months later compared to $26.1 \%$ who have potentially benefitted from e-cigarettes by transitioning to ecigarette mono use or no use of any tobacco product (quitting) (Table 3).

\section{3- Dual use transitions among US adults (2013-2016)}

In Wave 1, 2.3\% (95\% CI: 1.9-2.9) of adult current e-cigarette users were never cigarette smokers, increasing to $2.8 \%$ (95\% CI: $2.3-3.5)$ in Wave 2, and 6.5\% (95\% CI: $5.7-7.5)$ in Wave 3 $(P<0.0001$ for trends; data not shown $)$. 
For adult dual users in Wave $1(\mathrm{n}=2631), 53.5 \%$ relapsed to mono cigarette smoking in Wave 3 , and $31.5 \%$ continued as dual users. Thus, $85 \%$ of adult dual users can be considered to have been held in smoking (dual use or relapse to cigarette smoking) 24 months later compared to $15 \%$ who have potentially benefitted from e-cigarettes by transitioning to e-cigarette mono use or no use of any tobacco product (quitting). For adult e-cigarette mono users at Wave $1(n=608)$, $37.6 \%$ reported no current use of any tobacco product at Wave 3, compared to $62.4 \%$ who either continued with e-cigarettes (49.7\%) or progressed to cigarette smoking (12.7\%) (details in Table 4).

\section{Discussion}

Our analysis of PATH's three waves provides a comprehensive perspective of the evolution of e-cigarette use among youth and adults in the US between 2013-2016. Overall, the study shows that e-cigarette use is increasing among youth but not adults and that younger ecigarette users are becoming more likely to be never than ever cigarette smokers. Adult ecigarette users, by contrast, were mostly cigarette smokers. Looking at e-cigarette transition to cigarette smoking in youth shows that one out of five e-cigarette users, never cigarette smokers in Wave 1 transitioned to cigarette smoking at Wave 3. E-cigarettes transitions in adults show that among dual users in Wave 1, 15\% became current nonsmokers, while $85 \%$ either relapsed to cigarette smoking $(53.5 \%)$ or continued as dual users $(31.5 \%)$ at Wave 3. Below we discuss our results briefly according to the three key questions addressing the relative scale of e-cigarette potentially beneficial vs. harmful transitions among youth and adults in the US between 20132016.

\section{Trends of e-cigarette uptake among youth never smokers (2013-2016)}

One of the main criteria to judge e-cigarettes' potential for harm-reduction is their utility in helping adult smokers quit, but without causing substantial initiation and addiction among 
young never smokers (Maziak 2014). This youth initiation question is acquiring increasing importance as evidence of young e-cigarette smokers being at greater risk of progressing to cigarette smoking compared to non-e-cigarette users are accumulating (Soneji et al., 2017; East et al., 2018). Our analysis offers a dynamic perspective of young e-cigarette users' profile in the US, whereby they are increasingly more likely to be those who have never smoked cigarettes. As

Figure 1 shows, the proportion of never cigarette smokers among young e-cigarette users almost doubled between Waves 1-3 (from $24.1 \%$ to $42.6 \%$ ). This finding contrasts with data from other countries showing a limited scope of e-cigarette uptake among youth never cigarette smokers (Use of e-cigarettes, Great Britain 2014). Thus, in the US e-cigarettes are increasingly attracting cigarette naïve adolescents, who are most vulnerable to the effect of nicotine on their developing brain (NASEM 2018, Barrington-Trimis \& Leventhal 2018), and the consequences of lifelong nicotine addiction (US Department of Health and Human Services, 2012).

\section{E-cigarette transitions among US youth (2013-2016)}

E-cigarettes' potential to lead to cigarette smoking is another important outcome for judging their unwanted effects as a means of harm reduction, especially in youth (Chapman et al., 2018, Chapman 2013). Such potential can be assessed in our analysis by looking at the trajectory of e-cigarette mono use among youth between Waves 1 and 3. This analysis shows that for every adolescent e-cigarette mono user in Wave 1 who became non-tobacco user (quit) in Wave 3, there was one who became a cigarette smoker or dual user. This may not provide a firm answer to the debate about whether young e-cigarette users are predisposed to tobacco/nicotine experimentation rather than at increased risk of smoking because of their e-cigarette use (Barrington-Trimis et al., 2016; Primack et al., 2015; Etter 2018). Of special interest for such debate is the evolution of ecigarette users who have never tried cigarettes before, since this can represent most closely ecigarettes' potential in a real-world setting to recruit youth to cigarette smoking. Our analysis 
shows that amongst cigarette naïve youth, about one out of five current e-cigarette only users end up being current cigarette smokers two years later, signaling the importance of e-cigarettes' potential to lead to cigarette smoking.

\section{Dual use transitions among US adults (2013-2016)}

The potential of e-cigarettes to aid smoking cessation at the population level has focused mostly on whether dual use in adults is a transitional stage towards cigarette quitting or an emerging tobacco use pattern with a distinctive profile (Rahman et al., 2015). Looking at the totality of dual-use trajectories between 2013-2016, our analysis shows that for every one adult who quits cigarette smoking with the help of e-cigarettes there were about 3.6 who relapsed to cigarette smoking, and two continuing as dual users. While smoking cessation methods used in real-world conditions have varying short and long-term effectiveness, claims of e-cigarette superiority in such setting are repeatedly made (Benmarhnia et al., 2018; Bullen et al., 2013; Caponnetto et al., 2013; Tseng et al., 2016). Benmarhnia et al.'s analysis of transitions between Waves 1 and 2 in the PATH data show that $5.6 \%$ of e-cigarette users at Wave 1 were persistently abstinent from all tobacco products at Wave 2 (32). This is compared with rates of $6.1 \%$ for (NRT), 10.2\% for (varenicline), $10.3 \%$ for (bupropion) and $12.5 \%$ for (no aid used) (Benmarhnia et al., 2018).

\section{Limitations}

Our study's main limitation is that between waves, changes were made to the PATH study questionnaire. Specifically, in Wave 3 the questions about e-cigarette use were replaced by a more generic question about the use of any ENDS (including e-cigarettes, e-cigars, e-hookahs, e-pipes, hookah pens, personal vaporizers, and vape pens). However, this is unlikely to have affected our analysis substantially as we focused on the trajectory of e-cigarette users at Wave 1 (baseline) in subsequent waves and having an expanded definition of e-cigarette in Wave 3 will 
not affect our classification of outcomes. Moreover, we focused our analysis on e-

cigarette/cigarette interaction without entertaining other tobacco products combinations in the US (Kasza et al., 2017), since this is the primary interaction shaping the discourse about e-cigarettes' potential to affect morbidity and mortality of cigarettes smoking (NASEM 2018). Finally, we considered only transitions in current use between Waves 1-3, which may not represent prolonged use patterns (e.g., longer no tobacco use is usually needed to establish quitting). However, our main aim in this study is to provide a real-world descriptive picture of common e-cigarette trajectories and their relative scale rather than address the complex nuances of each of those outcomes.

\section{Conclusions}

The comprehensive picture from 3 waves of the PATH about tobacco use evolution among US youth and adults offers a cause for concern for the balance between e-cigarettes beneficial and negative potentials. In both young and adult e-cigarette users, we see more relapse, dual-use, and transition to cigarette smoking, as well as potentially spreading of nicotine addiction among young never-smokers than quitting among adult smokers. While our assessment does not imply a direct measurement of harm differentials between these key e-cigarette transitions, it provides what much of the policy and regulatory debate around e-cigarettes have focused on; their relative scale in a real-world population setting. Accordingly, the imbalance in the scale of potentially positive and negative transitions related to e-cigarettes in the US needs to be considered carefully when planning regulatory actions for e-cigarettes.

\section{References}

Abrams DB, Glasser AM, Pearson JL, Villanti AC, Collins LK, Niaura RS. Harm Minimization and Tobacco Control: Reframing Societal Views of Nicotine Use to Rapidly Save Lives. Annu Rev Public Health. 2018;39:193-213. 
Barrington-Trimis JL, Berhane K, Unger JB, Cruz TB, Huh J, Leventhal AM, et al. Psychosocial Factors Associated With Adolescent Electronic Cigarette and Cigarette Use. Pediatrics. 2015;136(2):308-17.

Barrington-Trimis JL, Urman R, Berhane K, Unger JB, Cruz TB, Pentz MA, et al. E-Cigarettes and Future Cigarette Use. Pediatrics. 2016;138(1).

Barrington-Trimis JL, Leventhal AM. Adolescents' Use of "Pod Mod" E-Cigarettes - Urgent Concerns. N Engl J Med. 2018;379(12):1099-102.

Benmarhnia T, Pierce JP, Leas E, White MM, Strong DR, Noble ML, et al. Can e-Cigarettes and Pharmaceutical Aids Increase Smoking Cessation and Reduce Cigarette Consumption? Findings from a Nationally Representative Cohort of American Smokers. Am J Epidemiol. 2018.

Bullen C, Howe C, Laugesen M, McRobbie H, Parag V, Williman J, et al. Electronic cigarettes for smoking cessation: a randomised controlled trial. Lancet. 2013;382(9905):1629-37.

Caponnetto P, Campagna D, Cibella F, Morjaria JB, Caruso M, Russo C, et al. EffiCiency and Safety of an eLectronic cigAreTte (ECLAT) as tobacco cigarettes substitute: a prospective 12-month randomized control design study. PLoS One. 2013;8(6):e66317.

Chaffee BW, Watkins SL, Glantz SA. Electronic Cigarette Use and Progression From Experimentation to Established Smoking. Pediatrics. 2018;141(4).

Chapman S. Should electronic cigarettes be as freely available as tobacco cigarettes? No. BMJ. 2013;346:f3840.

Chapman S, Bareham D, Maziak W. The Gateway Effect of e-cigarettes; Reflections on main Criticisms. Nicotine Tob Res. 2018.

Coleman B, Rostron B, Johnson SE, Persoskie A, Pearson J, Stanton C, et al. Transitions in electronic cigarette use among adults in the Population Assessment of Tobacco and Health (PATH) Study, Waves 1 and 2 (2013-2015). Tob Control. 2018.

Cullen KA, Ambrose BK, Gentzke AS, Apelberg BJ, Jamal A, King BA. Notes from the Field: Use of Electronic Cigarettes and Any Tobacco Product Among Middle and High School Students - United States, 2011-2018. MMWR Morb Mortal Wkly Rep. 2018;67(45):12767.

Dai H, Catley D, Richter KP, Goggin K, Ellerbeck EF. Electronic Cigarettes and Future Marijuana Use: A Longitudinal Study. Pediatrics. 2018;141(5).

Dutra LM, Glantz SA. Electronic cigarettes and conventional cigarette use among U.S. adolescents: a cross-sectional study. JAMA Pediatr. 2014;168(7):610-7.

East K, Hitchman SC, Bakolis I, Williams S, Cheeseman H, Arnott D, et al. The Association Between Smoking and Electronic Cigarette Use in a Cohort of Young People. J Adolesc Health. 2018;62(5):539-47. 
E-cigarette Use Among Youth and Young Adults: A report of the Surgeon General. Atlanta, GA: US Department of Health and Human Services, Centers for Disease Control and Prevention, National Center for Chronic Disease Prevention and Health Promotion, Office on Smoking and Health; 2016. Available at https://e-cigarettes, surgeongeneral.gov/documents/2016_sgr_full_report_non-508.pdf. Accessed October 2018.

Etter JF. Gateway effects and electronic cigarettes. Addiction. 2018;113(10):1776-83.

Glantz SA, Bareham DW. E-Cigarettes: Use, Effects on Smoking, Risks, and Policy Implications. Annu Rev Public Health. 2018;39:215-35.

Hajek P, Etter JF, Benowitz N, Eissenberg T, McRobbie H. Electronic cigarettes: review of use, content, safety, effects on smokers and potential for harm and benefit. Addiction. 2014;109(11):1801-10.

Hyland A, Ambrose BK, Conway KP, Borek N, Lambert E, Carusi C, et al. Design and methods of the Population Assessment of Tobacco and Health (PATH) Study. Tob Control. 2016.

Kasza KA, Ambrose BK, Conway KP, Borek N, Taylor K, Goniewicz ML, et al. TobaccoProduct Use by Adults and Youths in the United States in 2013 and 2014. N Engl J Med. 2017;376(4):342-53.

King BA, Gammon DG, Marynak KL, Rogers T. Electronic Cigarette Sales in the United States, 2013-2017. JAMA. 2018;320(13):1379-80.

Maziak W. Harm reduction at the crossroads: the case of e-cigarettes. Am J Prev Med. 2014;47(4):505-7.

McNeill A, Brose LS, Calder R, Hitchman SC, Hajek P, McRobbie H. E-cigarettes: an evidence update. A report commissioned by Public Health England. In; 2015. Available at https://assets.publishing.service.gov.uk/government/uploads/system/uploads/attachment_ data/file/733022/Ecigarettes_an_evidence_update_A_report_commissioned_by_Public_ Health_England_FINAL.pdf. Accessed October 2018

National Academies of Sciences, Engineering and Medicine. Public health consequences of ecigarette. Washington, DC: National Academies Press, 2018. Available at https://doi.org/10.17226/24952. Accessed October 2018.

Osibogun O, Taleb ZB, Bahelah R, Salloum RG, Maziak W. Correlates of poly-tobacco use among youth and young adults: Findings from the Population Assessment of Tobacco and Health study, 2013-2014. Drug Alcohol Depend. 2018;187:160-4.

Primack BA, Soneji S, Stoolmiller M, Fine MJ, Sargent JD. Progression to Traditional Cigarette Smoking After Electronic Cigarette Use Among US Adolescents and Young Adults. JAMA Pediatr. 2015;169(11):1018-23.

Rahman MA, Hann N, Wilson A, Mnatzaganian G, Worrall-Carter L. E-cigarettes and smoking cessation: evidence from a systematic review and meta-analysis. PLoS One. 2015;10(3):e0122544.

Soneji S, Barrington-Trimis JL, Wills TA, Leventhal AM, Unger JB, Gibson LA, et al. Association Between Initial Use of e-Cigarettes and Subsequent Cigarette Smoking 
Among Adolescents and Young Adults: A Systematic Review and Meta-analysis. JAMA Pediatr. 2017;171(8):788-97.

Tseng TY, Ostroff JS, Campo A, Gerard M, Kirchner T, Rotrosen J, et al. A Randomized Trial Comparing the Effect of Nicotine Versus Placebo Electronic Cigarettes on Smoking Reduction Among Young Adult Smokers. Nicotine Tob Res. 2016;18(10):1937-43.

US Department of Health and Human Services, 2012. Preventing tobacco use among youth and young adults: A report of the surgeon general. Atlanta, GA: USDHHS, US centers for disease control and prevention, national center for chronic disease prevention and health promotion, office on smoking and health. Available at https://www.surgeongeneral.gov/library/reports/preventing-youth-tobacco-use/fullreport.pdf. Accessed October 2018

United States Department of Health and Human Services. National Institutes of Health. National Institute on Drug Abuse, and United States Department of Health and Human Services. Food and Drug Administration. Center for Tobacco Products. Population Assessment of Tobacco and Health (PATH) Study [United States] Public-Use Files. Ann Arbor, MI: Inter-university Consortium for Political and Social Research [distributor], 2018-05-01. https://doi.org/10.3886/ICPSR36498.v7. Available at https://www.icpsr.umich.edu/icpsrweb/NAHDAP/studies/36498. Accessed October 2018.

Use of electronic cigarettes in Great Britain. In; 2014. Available at https://www.grea.ch/sites/default/files/e-cig_in_great_britain.pdf. Accessed October 2018.

Verplaetse TL, Moore KE, Pittman BP, Roberts W, Oberleitner LM, Peltier MR, et al. Intersection of e-cigarette use and gender on transitions in cigarette smoking status: Findings across waves 1 and 2 of the Population Assessment of Tobacco and Health (PATH) study. Nicotine Tob Res. 2018.

Warner KE, Mendez D. E-cigarettes: Comparing the Possible Risks of Increasing Smoking Initiation with the Potential Benefits of Increasing Smoking Cessation. Nicotine Tob Res. 2018. 
Table 1: Prevalence of current e-cigarette use among US youth (12-17years) by cigarette smoking history: PATH Cohort Study 2013-2016

\begin{tabular}{|c|c|c|c|}
\hline Current E-cigarette use & $\begin{array}{c}\text { Ever Cigarette use, n (\%, } \\
95 \% \mathrm{CI})\end{array}$ & $\begin{array}{c}\text { Never Cigarette use, n }(\%, 95 \% \\
\text { CI })\end{array}$ & Total, n $(\%, 95 \%$ CI $)$ \\
\hline \multicolumn{4}{|c|}{ Wave 1; 2013-2014 (N=13,559) } \\
\hline Yes, n $(\%, 95 \% \mathrm{CI})$ & $321(2.4,2.1-2.7)^{*}$ & $97(0.8,0.6-0.9)^{\ddagger, \S}$ & $418(3.1,2.8-3.5)^{\|}$ \\
\hline \multicolumn{4}{|l|}{ Age, n $(\%, 95 \% \mathrm{CI})$} \\
\hline $12-14$ & $50(64.7,53.6-74.5)^{\dagger}$ & $26(35.3,25.5-46.4)$ & $76(100.0)$ \\
\hline $15-17$ & $271(78.1,72.8-82.5)$ & $71(21.9,175-27.2)$ & $342(100.0)$ \\
\hline \multicolumn{4}{|c|}{ Wave 2; 2014-2015 $(N=12,059)$} \\
\hline Yes, n $(\%, 95 \%$ CI $)$ & $273(2.3,2.0-2.7)$ & $141(1.3,1.1-1.6)$ & $414(3.6,3.2-4.1)$ \\
\hline \multicolumn{4}{|l|}{ Age, n $(\%, 95 \% \mathrm{CI})$} \\
\hline $12-14$ & $53(60.5,47.8-71.9)$ & $35(39.5,28.1-32.3)$ & $88(100.0)$ \\
\hline $15-17$ & $220(65.2,60.0-70.3)$ & $106(34.8,29.7-40.3)$ & $326(100.0)$ \\
\hline \multicolumn{4}{|c|}{ Wave 3; 2015-2016 $(N=11,546)$} \\
\hline Yes, n $(\%, 95 \% \mathrm{CI})$ & $273(2.5,2.2-3.0)$ & $176(1.6,1.3-1.9)$ & $449(4.1,3.7-4.7)$ \\
\hline \multicolumn{4}{|l|}{ Age, n $(\%, 95 \% \mathrm{CI})$} \\
\hline $12-14$ & $50(53.5,42.4-64.4)$ & $39(46.5,35.6-57.6)$ & $89(100.0)$ \\
\hline $15-17$ & $223(63.6,57.3-69.5)$ & $137(36.4,30.5-42.7)$ & $360(100.0)$ \\
\hline
\end{tabular}

Abbreviations: PATH, Population Assessment of Tobacco and Health Study; n, unweighted sample; \%, weighted percentages rounded up to 1 decimal place; $\mathrm{CI}$, confidence interval.

*Indicates significant $(\mathrm{p}<0.05)$ difference between ever and never cigarette smoking among e-cigarette users at each wave

$\dagger$ Indicates significant $(\mathrm{p}<0.05)$ difference between age-groups for ever and never cigarette smoking among e-cigarette users at Wave 1 only

$*$ Indicates significant $(\mathrm{p}<0.05)$ linear trend for the comparison across Waves 1-3 for the proportion of overall e-cigarette never cigarette users among all study participants

$\S$ Indicates significant $(\mathrm{p}<0.05)$ linear trend for the comparison across Waves 1-3 for the proportion of overall never cigarette use among current e-cigarette users 
"Indicates significant $(\mathrm{p}<0.05)$ linear trend for the comparison across Waves 1-3 for the proportion of overall e-cigarette use among all study participants 
Table 2: Prevalence of current e-cigarette use among US adults ( $\geq 18$ years) by cigarette smoking history:

PATH Cohort Study, 2013-2016

\begin{tabular}{|c|c|c|c|}
\hline Current E-cigarette use & Ever Cigarette use, n (\%, $95 \%$ CI $)$ & Never Cigarette use, $\mathrm{n}(\%, 95 \% \mathrm{CI})$ & Total, n $(\%, 95 \%$ CI $)$ \\
\hline \multicolumn{4}{|c|}{ Wave 1; 2013-2014 (N=32,222) } \\
\hline Yes, n $(\%, 95 \% \mathrm{CI})$ & $4308(6.5,6.2-6.8)^{*}, *$ & $119(0.2,0.1-0.2)^{\S, \|}$ & $4427(6.7,6.4-7.0)$ \\
\hline \multicolumn{4}{|l|}{ Age, $\mathrm{n}(\%, 95 \% \mathrm{CI})$} \\
\hline $18-24$ & $1420(93.3,91.5-94.7)^{\dagger}$ & $94(6.7,5.3-8.5)$ & $1514(100.0)$ \\
\hline $25+$ & $2888(99.1,98.6-99.4)$ & $25(0.9,0.6-1.4)$ & $2913(100.0)$ \\
\hline \multicolumn{4}{|c|}{ Wave 2; 2014-2015 $(N=27,458)$} \\
\hline Yes, n $(\%, 95 \% \mathrm{CI})$ & $3262(6.1,5.8-6.5)$ & $117(0.2,0.1-0.2)$ & $3379(6.3,5.9-6.6)$ \\
\hline \multicolumn{4}{|l|}{ Age, n $(\%, 95 \% \mathrm{CI})$} \\
\hline $18-24$ & $1071(90.0,87.3-92.0)$ & $109(10.1,8.0-12.7)$ & $1180(100.0)$ \\
\hline $25+$ & $2191(99.6,99.1-99.8)$ & $8(0.4,0.2-1.0)$ & $2217(100.0)$ \\
\hline \multicolumn{4}{|c|}{ Wave 3; 2015-2016 $(N=27,860)$} \\
\hline Yes, n $(\%, 95 \% \mathrm{CI})$ & $3478(6.6,6.3-6.9)$ & $298(0.5,0.4-0.5)$ & $3776(7.0,6.7-7.3)$ \\
\hline \multicolumn{4}{|l|}{ Age, n $(\%, 95 \% \mathrm{CI})$} \\
\hline $18-24$ & $1347(82.8,80.4-84.9)$ & $268(17.2,15.1-19.6)$ & $1615(100.0)$ \\
\hline $25+$ & $2131(98.2,97.1-98.9)$ & $30(1.8,1.1-2.9)$ & $2161(100.0)$ \\
\hline
\end{tabular}

Abbreviation: PATH, Population Assessment of Tobacco and Health Study; n, unweighted sample, \%, weighted percentages rounded up to 1 decimal place; $\mathrm{CI}$, confidence interval.

* Indicates significant $(\mathrm{p}<0.05)$ difference between ever and never cigarette smoking among e-cigarette users at each wave

$\dagger$ Indicates significant $(\mathrm{p}<0.05)$ difference between age-groups for ever and never cigarette smoking among e-cigarette users at each wave

$\$$ Indicates significant $(\mathrm{p}<0.05)$ linear trend for the comparison across Waves 1-3 for the proportion of overall e-cigarette ever cigarette users among all study participants

$\S$ Indicates significant $(\mathrm{p}<0.05)$ linear trend for the comparison across Waves 1-3 for the proportion of overall e-cigarette never cigarette users among all study participants

"Indicates significant $(\mathrm{p}<0.05)$ linear trend for the comparison across Waves 1-3 for the proportion of overall never cigarette users among current ecigarette users 
Table 3: Transition of current e-cigarette use among US youth (12-17 years) between Waves 1 and 3 of PATH Cohort Study, 2013-2016

\begin{tabular}{|c|c|c|c|c|}
\hline Wave 3 & $\begin{array}{l}\text { E-cigarette dual use } \\
\text { n }(\%, 95 \% \mathrm{CI})\end{array}$ & $\begin{array}{l}\text { E-cigarette mono use } \\
\text { n }(\%, 95 \% \mathrm{CI})\end{array}$ & $\begin{array}{l}\text { Cigarette mono use } \\
\text { n }(\%, 95 \% \mathrm{CI})\end{array}$ & $\begin{array}{l}\text { No tobacco use } \\
\text { n }(\%, 95 \% \text { CI })\end{array}$ \\
\hline Total $(n=320)$ & $103(32.5,27.3-38.3)$ & $47(15.7,12.3-19.8)$ & $69(19.9,15.8-24.8)$ & $\begin{array}{c}101(31.9,26.9- \\
37.4)^{*}\end{array}$ \\
\hline E-cigarette dual use $(n=153)$ & $65(43.3,34.5-52.6)$ & $14(10.1,5.6-17.7)$ & $49(30.6,23.4-38.9)$ & $\begin{array}{c}25(16.0,10.9- \\
22.9)\end{array}$ \\
\hline E-cigarette mono use $(n=167)$ & $38(23.5,17.2-31.2)$ & $33(20.3,15.2-26.6)$ & $20(10.9,7.4-15.8)$ & $\begin{array}{c}76(45.3,37.4- \\
53.5)\end{array}$ \\
\hline \multicolumn{5}{|c|}{$\begin{array}{l}\text { Abbreviations: PATH, Population Assessment of Tobacco and Health; \%, weighted percentage; } 95 \% \text { CI, } 95 \% \text { confidence interval. } \\
\text { Note: Frequencies are unweighted; weighted } \% \text { are row } \% \\
\text { *Indicates differences between groups (e-cigarette dual use, e-cigarette mono use, cigarette mono use and no tobacco use) were significant at p } \\
<0.0001 \text {. }\end{array}$} \\
\hline
\end{tabular}


Table 4: Transition of current e-cigarette use among US adults ( $\geq 18$ years) between Waves 1 and 3 of PATH Cohort Study, 2013-

\begin{tabular}{|c|c|c|c|c|}
\hline Wave 3 & $\begin{array}{l}\text { E-cigarette dual use } \\
\text { n }(\%, 95 \% \mathrm{CI})\end{array}$ & $\begin{array}{c}\text { E-cigarette mono use } \\
\text { n }(\%, 95 \% \text { CI })\end{array}$ & $\begin{array}{c}\text { Cigarette mono use } \\
\text { n }(\%, 95 \% \mathrm{CI})\end{array}$ & $\begin{array}{l}\text { No tobacco use } \\
\text { n }(\%, 95 \% \mathrm{CI})\end{array}$ \\
\hline Total $(n=3239)$ & $924(27.9,26.0-29.8)$ & $363(12.1,10.5-13.8)$ & $1487(45.8,43.8-47.9)$ & $\begin{array}{c}465(14.2,12.9- \\
15.6)^{*}\end{array}$ \\
\hline E-cigarette dual use $(n=2631)$ & $839(31.5,29.4-33.7)$ & $152(6.2,5.1-7.6)$ & $1405(53.5,51.2-55.9)$ & $\begin{array}{c}235(8.8,7.7- \\
9.9) \\
\end{array}$ \\
\hline E-cigarette mono use $(n=608)$ & $85(12.3,9.7-15.3)$ & $211(37.4,32.9-42.2)$ & $82(12.7,10.4-15.4)$ & $\begin{array}{c}230(37.6,33.4- \\
42.1)\end{array}$ \\
\hline
\end{tabular}




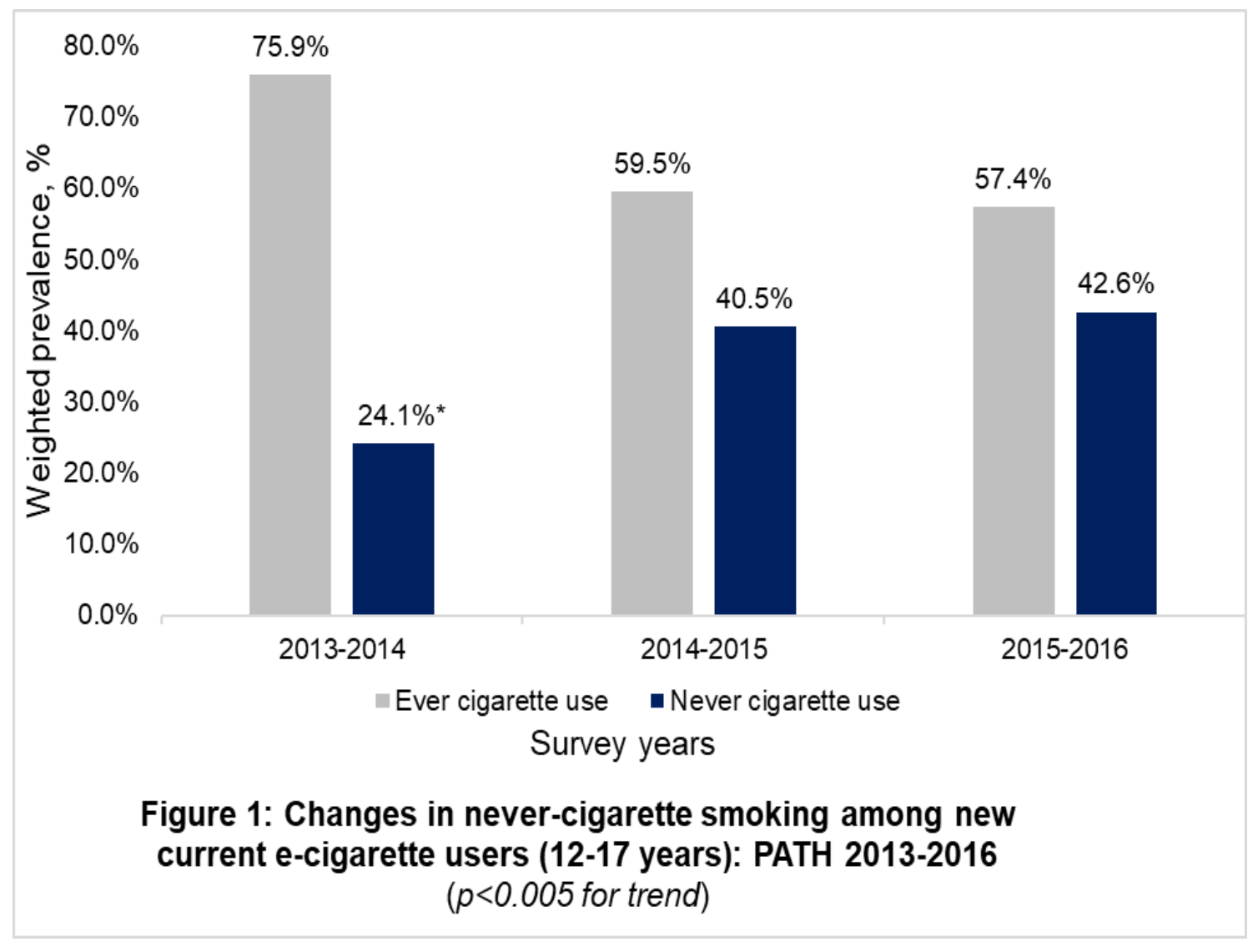

Note: \%, percentages rounded up to 1 decimal place; PATH indicates Population Assessment of Tobacco and Health;

*Indicates significant $(\mathrm{p}<0.005)$ linear trends across Waves 1-3 for never cigarette use among current ecigarette users 


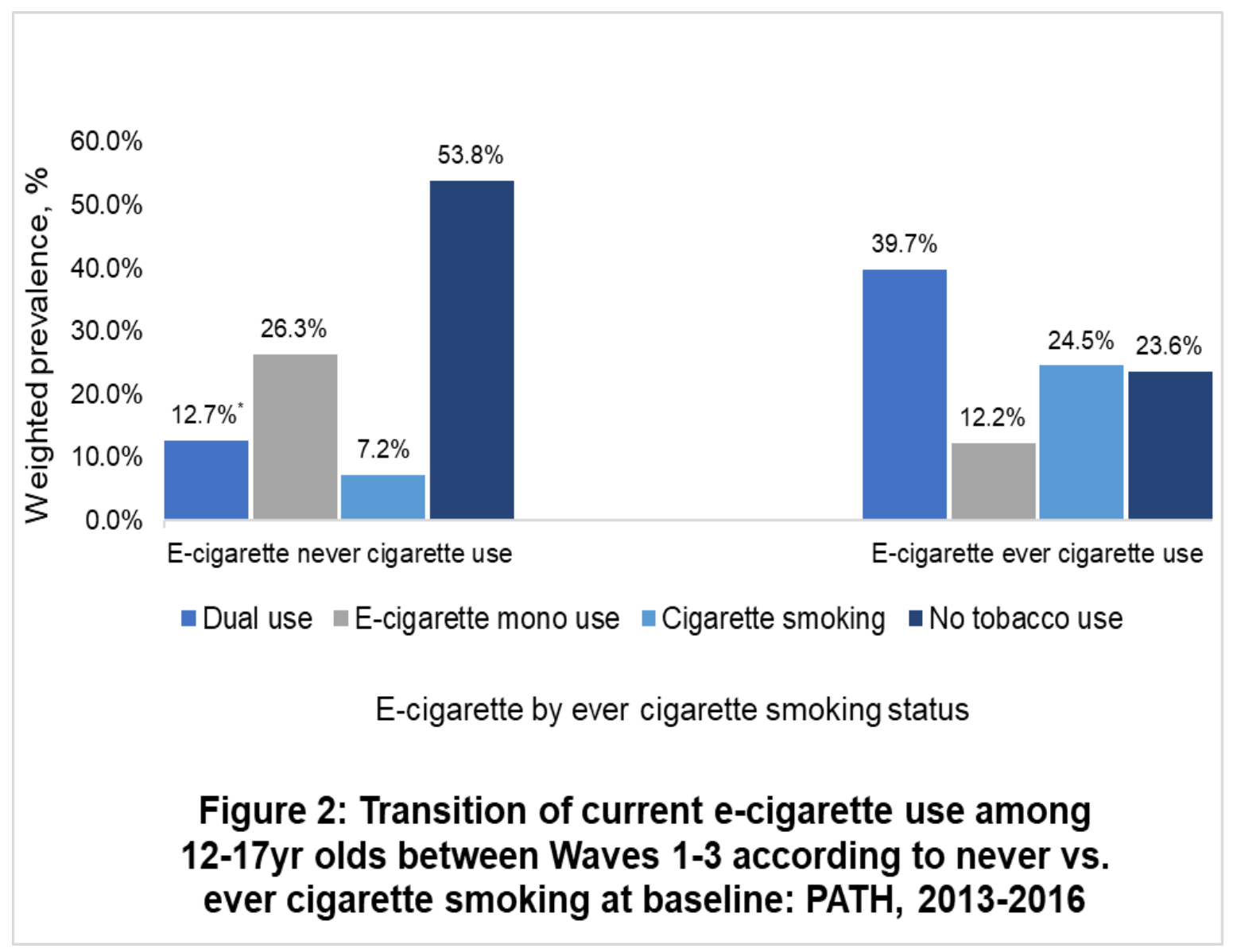

Note: \%, percentages rounded up to 1 decimal place; PATH indicates Population Assessment of Tobacco and Health; * Indicates significant $(\mathrm{p}<0.05)$ difference between dual use at Wave 3 among e-cigarette never cigarette users and e-cigarette ever cigarette users; * Indicates significant $(\mathrm{p}<0.0001)$ difference between cigarette smoking at Wave 3 among e-cigarette never cigarette users and e-cigarette ever cigarette users; * Indicates significant $(\mathrm{p}<0.0001)$ difference between no tobacco use at Wave 3 among e-cigarette never cigarette users and e-cigarette ever cigarette users. 


\title{
Manuscript 3
}

\section{(C) Copyright 2019}

\section{Can e-cigarettes help adult smokers who cannot quit? Results from The Population Assessment of Tobacco and Health Study Waves 1,2,3 (2013-2016)}

\begin{abstract}
Background: We examined the trajectory followed by US adults who are dual ecigarette/cigarette users over two years in relation to nicotine dependence (ND) symptoms, interest in quitting, and history of clinical cardiovascular disease (CVD).

Methods: We used data from the Population Assessment of Tobacco and Health Study (PATH) Waves 1-3 (2013-2016). Adults ( $\geq 18$ years) who reported past 30 days use of both e-cigarettes and cigarettes were identified from Wave 1 and followed for important tobacco use transitions (cessation, harm reduction, and relapse) at two-year follow up (Wave 3). Multinomial logistic regression models were conducted to examine the associations between these transitions and ND symptoms, interest in quitting, and history of CVD.
\end{abstract}

Findings: Among 1,870 adult dual tobacco users at Wave 1, 25.8\% (95\% CI 23·5-28.3) were still dual users 2 years later (Wave 3), 11.9\% (95\% CI 10·5-13.5) reported no current tobacco use (cessation transition), $7 \cdot 0 \%(95 \%$ CI 5.5-8·7) reported e-cigarette mono use (harm reduction transition), and 55.3\% (95\% CI 52-6-58·0) reported cigarette mono use (relapse transition). In the multivariate regression analysis, greater ND severity was associated with lower odds of following

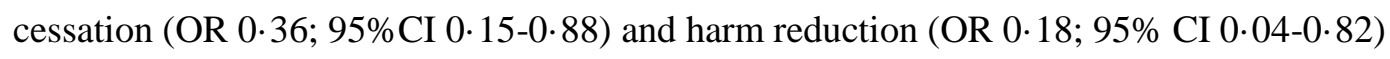
transitions. Interest in quitting and clinical CVD factors were not associated with cessation or harm reduction transitions.

Interpretation: Based on population data with prolonged follow up, e-cigarettes do not seem to offer an advantage for adults who need to quit smoking or reduce their harm. 
Keywords: e-cigarettes, ENDS, nicotine dependence, smoking, quitting, longitudinal

\section{Introduction}

The spread of e-cigarette use in many countries has brought front and center the debate about their place in reducing the burden of tobacco-related disease (NASEM 2018). Two questions arise. The first is what will be the net impact on smoking rates? Thus, if as is claimed, (McNeill et al., 2018) that e-cigarettes might help adult smokers quit, is this counterbalanced by youth initiation? (Warner \& Mendez 2018) Recent findings from the National Youth Tobacco Survey showing a 78\% increase in e-cigarette use among US high school students in 2018 alone (Cullen et al., 2018) have raised concerns about the growing number of tobacco naïve young people taking up e-cigarettes in the US, as a cohort of nicotine-addicted young people may subsequently transition to smoking (Aleyan et al., 2018; Soneji et al., 2017; Chapman et al., 2018).

A second issue is whether e-cigarettes can contribute to tobacco harm reduction (THR). This is based on the premise that adult smokers who cannot do without nicotine may be able to reduce their risk by shifting from conventional cigarettes (Abrams et al., 2018). This assumes that e-cigarettes are less harmful than conventional ones, a view that is widely accepted even if, in the absence of long-term data, it is not possible to say how much (European Respiratory S 2018). It is also contingent on individuals moving to exclusive e-cigarette smoking, as evidence shows that those who use both are exposed to higher levels of some toxins than those who use either on their own (Goniecwicz et al., 2018). From this perspective, advocating e-cigarettes to those suffering from smoking-related diseases but who are unable to quit, such as patients with cardiovascular disease (CVD), could be beneficial if it enables them to transition to sole e-cigarette use or, even better, ultimately to abstain from both. Yet clinicians trying to help such individuals are currently in uncharted territory without any definitive evidence to support their decision-making (Brandon 
et al., 2015; Drummond \& Upson 2014). They also run the risk of exposing their patients to additional risk either by advising the use of a potentially ineffective or even hazardous (Alzahrani et al., 2018) cessation tool, or by withholding what could be a valuable means to help them reduce their harm (NASEM 2018; CDC, Electronic cigarettes, 2018).

What is needed is research on the potential e-cigarettes might have to help adult smokers reduce their harm in a real-world population setting, using appropriate study design and extended follow up (Barrington-Trimis et al., 2015; Dutra \& Glantz 2014). ${ }^{15,16}$ The 2018 report on ecigarettes by the National Academies of Science, Engineering, and Medicine (NASEM) emphasized that because the e-cigarette phenomenon is relatively recent, "the majority of studies ... lack sufficient duration of follow-up to study the naturalistic cigarette smoking progression sequence" (NASEM 2018).

In 2011, the NIH and FDA initiated the Population Assessment of Tobacco and Health study (PATH), as the first population cohort to study tobacco use since Congress gave FDA the authority to regulate tobacco products in 2009 (US Department of Health and Human Services, 2018; Hyland et al. 2017). Studies from PATH Waves 1 and 2 began answering some important questions about e-cigarette transitions during the first year of follow up (Coleman et al., 2018; Verplaetse et al., 2018). For example, Coleman and colleagues found that the majority of adult dual users in Wave $1(87.8 \%)$ either continued dual-use or relapsed to cigarette-only smoking at one year follow up, compared to $12 \cdot 1 \%$ who discontinued cigarette smoking (Coleman et al., 2018). With the recent availability of Wave 3 data from PATH (October 2018), we have the opportunity to look at an extended two-year follow-up of PATH's data to examine a question that is central to the THR debate; can e-cigarettes help adult smokers who are unable to quit reduce their harm. This allows us to answer the key question facing clinicians faced with patients who are heavy smokers. 
In a real-world setting, this question can be addressed by looking at adult dual ecigarette/cigarette users who are nicotine dependent, interested in quitting, and have a clinical condition such as cardiovascular disease (CVD) that warrants their quitting, the transition to sole e-cigarette use or total abstinence, versus relapse to exclusive smoking?

\section{Methods}

\section{Study Sample}

The PATH Study is a collaboration between the FDA and the National Institutes of Health to inform the FDA's regulatory approach to different tobacco products in the US (US Department of Health and Human Services, 2018) PATH is an annual, nationally representative longitudinal study of persons 12 years and older who are residents of households, and noninstitutionalized civilians. Details have been described elsewhere (Hyland et al., 2017). The response rate was $74.0 \%$ at Wave 1 , yielding 32,320 participants, $83 \cdot 2 \%$ at Wave 2 , yielding 28,362 participants and $78.4 \%$ at Wave 3 yielding 28,148 participants. We examine tobacco use among adults who reported current (past 30 days) dual-use of e-cigarette/cigarette at Wave 1 (2013-2014) and had follow-up information at Wave 3 (2015-2016). We examined three main transitions (from Waves 1-3) among these dual users (cessation, harm-reduction, relapse), seeking their associations with the following characteristics at Wave 1;1) ND symptoms, 2) interest in quitting, and 3) clinical CVD factors, in addition to baseline socioeconomic and behavioral factors (Cohn et al., 2015; Loukas et al., 2016). The Institutional Review Board of Florida International University reviewed the study and deemed it exempt. 


\section{Study Measures}

\section{Assessment of tobacco use}

The PATH Study enquires about several tobacco products including cigarettes, ecigarettes, cigars, cigarillos, little-filtered cigar, hookah, and smokeless tobacco. Since combined e-cigarette/cigarette use is currently the most common and important e-cigarette use pattern from a policy and regulatory standpoint, we defined current dual users as those who reported past 30 days (current) use of e-cigarettes and cigarettes in Wave 1, regardless of other tobacco products used. We followed these dual users two years later, defining three main trajectories based on their transitioning to; 1) no current use of any tobacco product (cessation transition); 2) current mono e-cigarette use (harm reduction transition); or 3) current mono cigarette smoking (relapse transition) at Wave 3.

\section{Demographic and behavioral factors}

Demographic variables included age, gender, sexual orientation, race/ethnicity, education, income, employment status, and census region. Age, sexual orientation, race and ethnicity, education, employment, census region, and BMI were categorized as shown in Table 1 (US Department of Health and Human Services, 2018; Cohn et al., 2015; Loukas et al., 2016).

Behavioral factors assessed in Wave 1 included age at first exposure to a tobacco product, duration of tobacco product use, other tobacco use, marijuana use, and alcohol consumption. Age at first exposure to tobacco products was categorized into $<18$, and $\geq 18$ years. Duration of tobacco use was derived by subtracting the age at first exposure to tobacco product from participant's age at Wave 1 and included as a continuous variable. Alcohol consumption and marijuana use were assessed from the questions pertaining to past month drinking and marijuana use categorized into "yes" and "no." 


\section{Nicotine dependence (ND) symptom}

$N D$ assessment was based on several questions asked at Wave 1 for each product reported by participants. Since PATH did not include full scales for ND, but rather a selection of items from different scales (Liu et al., 2017; DiFranza et al., 2002; Heatherton et al., 1991), we opted for items that cover major domains of ND (e.g. craving, withdrawal, latency to smoke upon awakening, smoking heaviness) (Baker et al., 2013), simple to use in our modeling, and have been shown repeatedly to yield good measurement of ND (Baker et al., 2007). These were 1) time to first [product] use after waking up?; 2) do you consider yourself addicted to [product]?; 3) do you ever have strong cravings to smoke or use [product]?; 4) in the past 12 months, did you find it difficult to keep from smoking or using [product] in places where it was prohibited?; 5) have you ever felt like you really needed to use a [product]?; 6) did you cut down on activities that were enjoyable or important to you because [product] was not permitted at activity?; and 7) frequency of tobacco use among current dual users categorized into everyday (regular), vs. someday (not regular) use (US Department of Health and Human Services, 2018). All ND variables were dichotomized into binary scoring as shown in Table 2 (US Department of Health and Human Services, 2018). From these variables, we created a cumulative ND severity variable based on the number of endorsements of the 7 ND items used (range 0-7).

\section{$\underline{\text { Interest in quitting }}$}

We used two items from PATH to assess interest in quitting. The first was interest in quitting (scale of 1-10; with 1, being not interested in quitting and 10, being extremely interested). We categorized this variable into tertiles: 1-3, 4-7 and 8-10. The second was past year quit attempts, measured as the "number of times tried to quit smoking/using tobacco product(s) in the past 12 months." This was categorized into 0 (no quit attempt), and $\geq 1$ (one or more quit attempts) (US Department of Health and Human Services, 2018). 


\section{History of CVD-related illness}

As our aim was to have an example of the potential effect of tobacco-associated clinical conditions on e-cigarette related transitions, we picked reports of the history of CVD and related conditions that are especially relevant to tobacco cessation and harm reduction. They were based on self-reported positive response to the questions asking "Has a doctor, nurse or other health professional ever told you that you have...." for diabetes mellitus (DM), heart attack (myocardial infarction, MI), high blood pressure and high cholesterol (yes, no) (US Department of Health and Human Services, 2018).

\section{Statistical analyses}

We calculated descriptive statistics for the main transitions of dual tobacco use between Waves 1 and 3 (cessation, harm reduction, and relapse). An outcome variable was derived to indicate respondents' tobacco use transition at Wave $3(0=$ continued dual use, $1=$ cessation (no tobacco use), 2 = harm reduction (mono e-cigarette use), 3 = relapse (mono cigarette use). The replicate weights provided by the PATH Study were used to obtain unbiased point and variance estimates using Fay's Method of Balanced Repeated Replication, with the Fay coefficient value of $0 \cdot 3$, as recommended by the PATH Study team (US Department of Health and Human Services, 2018). Weighted percentages for sociodemographic and behavioral factors, ND symptoms, interest in quitting, and history of clinical CVD factors at Wave 1, were reported by with their corresponding 95\% confidence intervals (CI) according to tobacco transitions at Wave 3. Pearson chi-square tests for categorical variables and ANOVA for continuous variables were used to evaluate differences among the tobacco use transitions and demographic and behavioral factors, ND symptoms, interest in quitting and clinical CVD factors respectively (Tables 1,2 \&3).

We applied logistic regression models to test the univariate associations between the demographic, behavioral, ND, interest in quitting and clinical CVD factors at Wave 1 with the 
tobacco use transitions between Waves1-3. We reported unadjusted odds ratios (OR) with their corresponding 95\% CI for variables that had significant results only (Table 4). For the multivariate predictors of main transitions among dual users (cessation, harm reduction, and relapse), we fitted a multinomial regression model, adjusting for variables with inclusion $\mathrm{p}<0 \cdot 2$ from the univariate analysis or those that are theoretically important. Due to modest to moderate correlation and collinearity between individual variables within each domain (e.g., ND) we created the domain summary variables for ND symptoms, interest in quitting and clinical CVD factors. These were categorized according to no endorsement of any ND, no interest in quitting/quit attempt, or no history of CVD factor as "no," and any endorsement of any of domain components as "yes" for each domain (Tables 2,3).

Adjusted ORs with their corresponding 95\% CIs were calculated and reported. Finally, we tested the preplanned two-way interactions between the three domains of ND symptoms, interest in quitting, and history of clinical CVD. Associations were considered statistically significant at the alpha level of 0.05. Analyses were performed using SVY procedures in STATA version $15 \cdot 1$ (StataCorp, College Station, TX).

\section{Role of funding sources}

Dr. Osibogun was supported by the Dissertation year fellowship from Florida International University (FIU) and U54MD012393-01 for the FIU-RCMI during the time of conducting this study. Drs. Bursac and Li are supported by U54MD012393-01 for the FIURCMI. Dr. Maziak is supported by NIH grants R01-DA035160, R01-TW010654, R01DA042477, and U54MD012393-01 for the FIU-RCMI. The funding sources had no role in the study design, analysis or interpretation of the data, writing the manuscript, or the decision to submit the paper for publication. No funding was received to support this manuscript. 


\section{Results}

\section{Transitions of dual use at two year follow up}

Table 1 shows the descriptive statistics of dual use transitions between Waves 1-3 of PATH by main demographic and behavioral factors. Overall, $11.9 \%$ (95\% CI 10.5-13.5) of dual users followed the cessation transition (i.e., to no current use of any tobacco product), $7 \cdot 0 \%$ (95\% CI 5.5-8.7) to the harm reduction transition (i.e., to mono e-cigarette use), 55.3\% (95\% CI 52.658.0) were in the relapse transition (i.e., to mono cigarette use) and $25 \cdot 8 \%$ (95\% CI 23.5-28.3) remained as dual users at two-year follow up.

\section{Dual use transitions according to ND, interest in quitting, and clinical CVD factors}

Overall, the majority of dual users reported at least one ND symptom $(96 \cdot 6 \%, 95 \%$ CI $95 \cdot 7-97 \cdot 4)$ and the most common symptom was addiction to tobacco $(86 \cdot 2 \%, 95 \%$ CI $84 \cdot 0$ $88 \cdot 1)$ (Table 2). In terms of ND severity, 56.7\% (95\% CI 54-1-59·2) reported 4 to 5 ND symptoms. Over half of participants $(57 \cdot 6 \%, 95 \%$ CI 54.6-60.6) had interest in quitting scores of $8-10$, and $83 \cdot 2 \%(95 \%$ CI $80 \cdot 5-85 \cdot 7)$ reported one or more quit attempts in the past year. Participants who reported at least one ND symptom were more likely to report relapse to cigarette smoking $(56 \cdot 7 \%, 95 \%$ CI 53.7-59.7), while those who reported no ND symptoms were more likely to report cessation $(10 \cdot 0 \%, 95 \%$ CI 8.7-11.6) at 2-year follow up ( $p<0 \cdot 0001)$. Dual users who reported an interest in quitting at Wave 1 were less likely to follow the cessation transition $(10 \cdot 5 \%, 95 \% \mathrm{CI} 8 \cdot 7-12 \cdot 5)$ at Wave 3 and more likely to remain as dual users $(28 \cdot 2 \%, 95 \% \mathrm{CI}$ 25.4-31·1) $(p=0.04)$. (Table 2)

Little over a third of participants $(36 \%, 95 \%$ CI 33-1-39.0) overall reported a history of at least one clinical CVD-related factor at Wave 1. The distributions of the clinical conditions across 
the tobacco use transitions were not statistically significant, but those who report at least one condition were less likely to follow the cessation transition $(9 \cdot 1 \%, 95 \%$ CI $7 \cdot 0-11 \cdot 8)$ (Table 3).

\section{Predictors of cessation, harm reduction, and relapse transitions}

In the univariate regression analysis, among dual users at Wave 1, younger age (0.47, 95\% CI 0.30-0.73), and longer duration of tobacco use $(0 \cdot 97,95 \%$ CI $0 \cdot 96-0 \cdot 99)$ were associated with decreased odds of cessation or harm reduction transitions at Wave 3 ( $p<0 \cdot 05$; Table 4). Higher education $(0 \cdot 64,95 \%$ CI $0 \cdot 51-0 \cdot 80)$ was associated with decreased odds of relapse to cigarette smoking, while other tobacco use $(1 \cdot 63,95 \%$ CI $1 \cdot 16-2 \cdot 28)$ and marijuana use $(1 \cdot 71,95 \%$ CI 1.13-2.57) were associated with increased odds of cessation transitions (Table $4)$.

The 3 main domains [ND symptoms $(0 \cdot 08,95 \%$ CI $0 \cdot 03-0 \cdot 18)$, interest in quitting $(0 \cdot 26$, 95\% CI 0.10-0.70), and clinical conditions $(0 \cdot 61,95 \%$ CI $0 \cdot 41-0 \cdot 89)]$, were associated with decreased odds of cessation compared to continuing dual use (Table 4). Similarly, participants who were in the higher categories of ND symptoms severity compared to 0-3 symptoms had a decreased odds of cessation (4-5 symptoms: $0 \cdot 26$, 95\% CI 0·15-0·39; and 6-7 symptoms: $0 \cdot 20$, 95\% CI 0.12-0 35) and harm reduction transitions (4-5 symptoms: $0 \cdot 51,95 \%$ CI $0 \cdot 32-0 \cdot 81$; and 6-7 symptoms: 0·26, 95\% CI 0·12-0.55) (Table 4).

In the final adjusted multivariate model, those who reported the age of first exposure to tobacco product of $<18$ years had a decreased odds of cessation transition $(0 \cdot 45,95 \%$ CI $0 \cdot 21-$ $0 \cdot 97)$ compared to $\geq 18$ years. Also, ND severity of 6-7 symptoms was associated with a decreased odds of cessation $(0 \cdot 36,95 \%$ CI $0 \cdot 15-0 \cdot 88)$ and harm reduction $(0 \cdot 18,95 \%$ CI $0 \cdot 04-$ 0.82) transitions compared to dual use (Table 5). Interest in quitting and clinical CVD factors were not associated with either cessation or harm reduction transitions. The interactions between 
ND symptoms, interest in quitting and clinical CVD factors domains were not statistically significant (all $p>0 \cdot 05)$.

\section{Discussion}

These findings are important because dual e-cigarette/cigarette use has become the most common tobacco use pattern involving e-cigarettes in the US, with $55 \%$ of e-cigarette users also smoking (Sung et al., 2018). We have three main findings, each helping to inform the debate on the potential role of e-cigarettes in tobacco control.

The first is that among adult dual smokers, followed over 2 years in the PATH cohort study, $18.9 \%$ followed either cessation $(11.9 \%)$ or harm reduction (7\%) transitions, compared to $55.3 \%$ relapsing to cigarette use, and $25.8 \%$ continuing dual use. In other words, the majority relapsed and less than one in five transitioned to a less harmful situation. Second, individuals who are highly addicted to nicotine were least likely either to quit or transition to a harm reduction scenario with the use of e-cigarettes. Third, in the univariate analyses, those intending to quit or who have a history of illnesses or conditions increasing their risk of cardiovascular disease were less likely to cease smoking with e-cigarettes, and no more likely than others to transition to harm reduction.

These findings are important because they challenge certain widely aired views. One is that smokers taking up e-cigarettes are beginning a journey to reduced harm or even cessation (Glantz \& BAreham 2018). However, the available evidence has often been marred by selectiveness of samples and outcomes, contradictory evidence, and mostly lacked length of follow-up to answer this question (NASEM 2018; Weaver et al., 2018; Kalkhoran \& Glantz 2016). There are, however, many accounts of individuals who claim benefit in using e-cigarettes

either to quit or reduce their harm by moving exclusively to e-cigarettes (Notley et al., 2018). Our findings confirm that such individuals exist. However, a majority of dual users relapse to 
exclusive cigarette smoking, with a substantial minority remaining dual users. The latter is especially important given concerns that the adverse health effects of continued dual use may be greater than with either on their own (Wang et al., 2018).

Another is that e-cigarettes may be especially useful to those who are highly addicted to nicotine, a group that includes many who have proven resilient to other interventions (Selya et al., 2018). A third is that e-cigarettes may be most effective in those who intend to quit or who are encouraged to do so because of other illnesses. We find no evidence either of these, with those most addicted less likely to transition to reduced harm or cessation.

Our findings are consistent with the few earlier, although smaller studies, with the closest in design an Italian study that included 223 dual users followed over 2 years found that $14.3 \%$ followed the cessation transition, $12.5 \%$ the harm reduction transition, $16.6 \%$ continued dual use, and 57.4\% relapsed (Manzoli et al., 2016). Another study, from the US, included 151 dual users among a larger sample of smokers, but while $43.7 \%$ were still dual users at two years, the other data reported do not allow direct comparison with the present study (Zhuang et al., 2016).

These findings are of direct relevance to clinicians confronted with the dilemma of whether or not to advise their tobacco smoking patients who need to quit but could not to try ecigarettes (Brandon et al., 2015). As noted, the notion that e-cigarettes can be the best option for those who could not or will not quit otherwise has been central in the THR debate (Abrams et al., 2018; Warner 2018). Yet even a dramatic event such as a history of MI was not associated with increased success in using e-cigarettes to quit smoking or reduce harm by substituting cigarettes with e-cigarettes. This is particularly relevant given the emerging evidence that concurrent ecigarette/cigarette use increases the risk of heart disease compared to each individually (Alzahrani et al., 2018). 


\section{Strengths and limitations}

This study has some limitations. As the PATH did not include full scales for ND measurement, we limited our assessment of ND to a subset of available questions (US Department of Health and Human Services, 2018).

Previous research has demonstrated that individual items, several included here (e.g., time of first tobacco product; frequency of use), yield comparable measurements to the full scales (Baker et al., 2007). Second, although this analysis provides useful information on the transition from dual use over two time-points, we did not analyze participants' behaviors between waves. However, our main aim was to track real-world evolution of dual use over an extended period rather than the dynamics of changes occurring during this period or factors influencing them. Third, tobacco use, interest in quitting and history of CVD were based on self-reports. Previous research, however, shows a good correlation between self-report of tobacco use and biomarkers of tobacco exposure, or clinical CVD and medical records (Yuji et al., 2004). Interest in quitting, moreover, was correlated with past year quit attempts $(\mathrm{r}=0.20 ; p<0.0001)$. Finally, since this is a population-based study rather than a cessation trial, it was not possible to apply a definition of cessation based on prolonged abstinence as is used in intervention studies. Using such a definition would have led to even fewer people classified as the cessation or harm reduction transitions. Thus, if anything, our findings exaggerate the probability of cessation. Nevertheless, the major strengths of this study include a representative sample of US adults, longitudinal design and length of follow up, and detailed history of different tobacco products.

\section{Conclusions}

The present study shows that four out of five dual users continue as dual users and cigarette users two years later. Nicotine dependence (ND) severity and early age ( $<18$ years) of first exposure to tobacco were associated with less odds of following a cessation transition at 2- 
year follow up, while interest in quitting, and history of illness were not associated with favorable transitions towards cessation or harm reduction.

Given all the uncertainty about e-cigarette and dual use short- and long-term health effects, our real-world population results cast serious doubt about a central paradigm of THR based on e-cigarettes' potential to help adult smokers who cannot quit otherwise. It seems that, with or without e-cigarettes, cessation and harm reduction success are very challenging in this population.

\section{References}

Abrams DB, Glasser AM, Pearson JL, Villanti AC, Collins LK, Niaura RS. Harm Minimization and Tobacco Control: Reframing Societal Views of Nicotine Use to Rapidly Save Lives. Annu Rev Public Health. 2018;39:193-213.

Aleyan S, Cole A, Qian W, Leatherdale ST. Risky business: a longitudinal study examining cigarette smoking initiation among susceptible and non-susceptible e-cigarette users in Canada. BMJ Open. 2018;8(5):e021080. Published 2018 May 26. doi:10.1136/bmjopen2017-021080.

Alzahrani T, Pena I, Temesgen N, Glantz SA. Association Between Electronic Cigarette Use and Myocardial Infarction. Am J Prev Med. 2018; DOI: 10.1016/j.amepre.2018.05.004.

Baker TB, Piper ME, McCarthy DM, et al., Time to First Cigarette in the Morning as an Index of Ability to Quit Smoking: Implications for Nicotine Dependence. Nicotine Tob Res. 2007;9:S555-S570

Baker TB, Breslau N, Covey L, Shiffman S. DSM Criteria for Tobacco Use Disorder and Tobacco Withdrawal: A Critique and Proposed Revisions for DSM-5. Addiction. 2013; 107:263-275

Barrington-Trimis JL, Berhane K, Unger JB, et al. Psychosocial Factors Associated With Adolescent Electronic Cigarette and Cigarette Use. Pediatrics. 2015;136:308-17.

Brandon TH, Goniewicz ML, Hanna NH, et al. Electronic Nicotine Delivery Systems: A Policy Statement from the American Association for Cancer Research and the American Society of Clinical Oncology. Clinical Cancer Research 2015; DOI: 10.1158/1078-0432.CCR$14-2544$

CDC, Electronic Cigarettes: What's the Bottom Line?, December 3, 2018, https://www.cdc.gov/tobacco/basic information/ecigarettes/pdfs/Electronic-CigarettesInfographic-508.pdf 
Chapman S, Bareham D, Maziak W. The Gateway Effect of e-cigarettes; Reflections on main Criticisms. Nicotine Tob Res. 2018.

Cohn A, Villanti A, Richardson A, Rath JM, et al. The association between alcohol, marijuana use, and new and emerging tobacco products in a young adult population. Addict Behav. 2015;48:79-88.

Coleman B, Rostron B, Johnson SE, et al. Transitions in electronic cigarette use among adults in the Population Assessment of Tobacco and Health (PATH) Study, Waves 1 and 2 (20132015). Tob Control. 2018. doi: 10.1136/tobaccocontrol-2017-054174.

Cullen KA, Ambrose BK, Gentzke AS, Apelberg BJ, Jamal A, King BA. Notes from the Field: Use of Electronic Cigarettes and Any Tobacco Product Among Middle and High School Students - United States, 2011-2018. MMWR Morb Mortal Wkly Rep. 2018;67:1276-7.

DiFranza J, Savageau J, Rigotti N, et al. Development of symptoms of tobacco dependence in youth: 30 month follow up data from the DANDY study. Tob Control 2002;11:228-235.

Drummond MB, Upson D. Electronic cigarettes. Potential harms and benefits. Ann Am Thorac Soc 2014;11:236-42.

Dutra LM, Glantz SA. Electronic cigarettes and conventional cigarette use among U.S. adolescents: a cross-sectional study. JAMA Pediatr 2014;168:610-7.

European Respiratory S. "We have not learned:" ERS leaders respond to BMJ article on the use of e-cigarettes for smoking cessation | European Respiratory Society. 2018. Available at https://www.ersnet.org/the-society/news/we-have-not-learned:-ers-leaders-respond-tobmj-article-on-the-use-of-e-cigarettes-for-smoking-cessation- (accessed 9th December 2018).

Glantz SA, Bareham DW. E-Cigarettes: Use, Effects on Smoking, Risks, and Policy Implications. Annu Rev Public Health 2018;39:215-35

Goniewicz ML, Smith DM, Edwards KC, et al. Comparison of Nicotine and Toxicant Exposure in Users of Electronic Cigarettes and Combustible Cigarettes. JAMA Netw Open. 2018;1:e185937.

Heatherton T, Kozlowski L, Frecker R, Fagerstrom K. The Fagerstrom test for nicotine dependence - a revision of the fagerstrom tolerance questionnaire. British Journal of Addiction 1991;86:1119-27

Hyland A, Ambrose BK, Conway KP, et al. Design and methods of the Population Assessment of Tobacco and Health (PATH) Study. Tob control. 2017;26:371-8. doi:10.1136/tobaccocontrol-2016-052934.

Kalkhoran S, Glantz SA. E-cigarettes and smoking cessation in real-world and clinical settings: a systematic review and meta-analysis. Lancet Respir Med. 2016;4:116-128.

Liu G, Wasserman E, Kong L, Foulds J. A comparison of nicotine dependence among exclusive E-cigarette and cigarette users in the PATH study. Prev Med 2017;104:86-91. 
Loukas A, Chow S, Pasch KE, et al. College Students' Polytobacco Use, Cigarette Cessation, and Dependence. Am J Health Behav 2016;40:514-22.

Manzoli L, Flacco ME, Ferrante M, et al. Cohort study of electronic cigarette use: effectiveness and safety at 24 months. Tob Control. 2016;26:284-292.

McNeill A, Brose LS, Calder R, Bauld L \& Robson D (2018). Evidence review of e-cigarettes and heated tobacco products 2018. A report commissioned by Public Health England. London: Public Health England.

National Academies of Sciences, Engineering and Medicine. Public health consequences of ecigarettes. Washington, DC: National Academies Press, 2018. Available at https://doi.org/10.17226/24952. Accessed October 2018.

Notley C, Ward E, Dawkins L, Holland R. The unique contribution of e-cigarettes for tobacco harm reduction in supporting smoking relapse prevention. Harm Reduct J. 2018;15:31.

Selya AS, Dierker L, Rose JS, Hedeker D, Mermelstein RJ. The Role of Nicotine Dependence in E-cigarettes' Potential for Smoking Reduction. Nicotine Tob Res. 2018;20:1272-77.

Soneji S, Barrington-Trimis JL, Wills TA, et al. Association Between Initial Use of e-Cigarettes and Subsequent Cigarette Smoking Among Adolescents and Young Adults: A Systematic Review and Meta-analysis. JAMA Pediatr. 2017;171(8):788-797.

Sung HY, Wang Y, Yao T, Lightwood J, Max W. Polytobacco Use and Nicotine Dependence Symptoms Among US Adults, 2012-2014. Nicotine Tob Res. 2018;20(suppl_1):S88-S98.

United States Department of Health and Human Services. National Institutes of Health. National Institute on Drug Abuse, and United States Department of Health and Human Services. Food and Drug Administration. Center for Tobacco Products. Population Assessment of Tobacco and Health (PATH) Study [United States] Restricted-Use Files. ICPSR36231v13. Ann Arbor, MI: Inter-university Consortium for Political and Social Research [distributor], 2017-06-19. https://doi.org/10.3886/ICPSR36231.v13. Last accessed December 1, 2018.

Verplaetse TL, Moore KE, Pittman BP, et al. Intersection of e-cigarette use and gender on transitions in cigarette smoking status: Findings across waves 1 and 2 of the Population Assessment of Tobacco and Health (PATH) study. Nicotine Tob Res 2018. doi: $10.1093 /$ ntr/nty 187 .

Wang JB, Olgin JE, Nah G, et al., Cigarette and e-cigarette dual use and risk of cardiopulmnonary symptoms in the Heart eHeart Study. PLoS One. 2018;13:e0198681

Warner KE, Mendez D. E-cigarettes: Comparing the Possible Risks of Increasing Smoking Initiation with the Potential Benefits of Increasing Smoking Cessation. Nicotine Tob Res 2018. doi: 10.1093/ntr/nty062.

Warner KE; How to Think—Not Feel—about Tobacco Harm Reduction, Nicotine Tob Res 2018, nty084, https://doi.org/10.1093/ntr/nty084 
Weaver SR, Huang J, Pechacek TF, Heath JW, Ashley DL, Eriksen MP. Are electronic nicotine delivery systems helping cigarette smokers quit? Evidence from a prospective cohort study of U.S. adult smokers, 2015-2016. PLoS One. 2018. 13: e0198047. https://doi.org/10.1371/journal.pone.0198047.

Yuji O, Urban L, Mahoney D, Jacobsen S, Rodeheffer R. Agreement between self-reported questionnaires and medical record data was substantial for diabetes, hypertension, myocardial infarction and stroke but not for heart failure. J Clin Epidemiol. 2004;57:1096- 103.

Zhuang YL, Cummins SE, Sun JY, Zhu SH. Long-term e-cigarette use and smoking cessation: a longitudinal study with US population. Tob Control. 2016;25:i90-i95 
Tables and figures

Table 1 - Prevalence characteristics of adult ( $\geq 18$ years) dual e-cigarette/cigarette users according to main transitions at 2-year follow-up:

PATH Study, 2013-2016

\begin{tabular}{|c|c|c|c|c|c|c|}
\hline Wave 1 & $\begin{array}{c}\text { Overall } \\
\%,(95 \% \mathrm{CI})\end{array}$ & $\begin{array}{c}\text { Cessation } \\
\%,(95 \% \mathrm{CI})\end{array}$ & $\begin{array}{c}\text { Harm } \\
\text { reduction } \\
\%,(95 \% \mathrm{CI}) \\
\end{array}$ & $\begin{array}{c}\text { Relapse } \\
\%,(95 \% \mathrm{CI})\end{array}$ & $\begin{array}{c}\text { Dual use } \\
\%,(95 \% \mathrm{CI})\end{array}$ & p value \\
\hline Total $(n=1870)$ & $100 \cdot 0$ & $11 \cdot 9(10 \cdot 5-13 \cdot 5)$ & $7 \cdot 0(5 \cdot 5-8 \cdot 7)$ & $55 \cdot 3(52 \cdot 6-58 \cdot 0)$ & $25 \cdot 8(23 \cdot 5-28 \cdot 3)$ & \\
\hline \multicolumn{7}{|l|}{ Demographic factors } \\
\hline Age, years $(n=1870)$ & & & & & & $0 \cdot 0002$ \\
\hline $18-24$ & $17 \cdot 4(15 \cdot 7-19 \cdot 2)$ & $20 \cdot 2(16 \cdot 1-25 \cdot 1)$ & $7 \cdot 2(4 \cdot 8-10 \cdot 6)$ & $49 \cdot 6(43 \cdot 9-55 \cdot 4)$ & $23 \cdot 0(18 \cdot 8-27 \cdot 8)$ & \\
\hline $25-34$ & $26 \cdot 3(23 \cdot 9-29 \cdot 0)$ & $12 \cdot 7(9 \cdot 7-16 \cdot 5)$ & $7 \cdot 1(4 \cdot 8-10 \cdot 4)$ & $52 \cdot 6(47 \cdot 5-57 \cdot 7)$ & $27 \cdot 6(23 \cdot 1-32 \cdot 6)$ & \\
\hline$\geq 35$ & $56 \cdot 3(53 \cdot 1-59 \cdot 5)$ & $9 \cdot 0(7 \cdot 4-10 \cdot 9)$ & $6 \cdot 8(4 \cdot 9-9 \cdot 2)$ & $58 \cdot 4(54 \cdot 7-62 \cdot 0)$ & $25 \cdot 9(23 \cdot 1-28 \cdot 9)$ & \\
\hline Gender $(n=1870)$ & & & & & & $0 \cdot 15$ \\
\hline Male & $45 \cdot 7(43 \cdot 1-48 \cdot 3)$ & $13 \cdot 6(11 \cdot 3-16 \cdot 2)$ & $7.5(5 \cdot 6-10 \cdot 0)$ & $53 \cdot 4(49 \cdot 9-56 \cdot 9)$ & $25 \cdot 5(22 \cdot 3-29 \cdot 0)$ & \\
\hline Female & $54 \cdot 3(51 \cdot 7-56 \cdot 9)$ & $10 \cdot 5(8 \cdot 8-12 \cdot 6)$ & $6 \cdot 4(4 \cdot 9-8 \cdot 4)$ & $57 \cdot 0(53 \cdot 4-60 \cdot 5)$ & $26 \cdot 1(23 \cdot 2-29 \cdot 2)$ & \\
\hline $\begin{array}{l}\text { Sexual orientation } \\
(n=1839)\end{array}$ & & & & & & $0 \cdot 25$ \\
\hline Heterosexual & $91 \cdot 1(89 \cdot 6-92 \cdot 4)$ & $11 \cdot 9(10 \cdot 4-13 \cdot 6)$ & $6 \cdot 7(5 \cdot 2-8 \cdot 5)$ & $56.0(53 \cdot 2-58 \cdot 7)$ & $25 \cdot 4(22 \cdot 9-28 \cdot 2)$ & \\
\hline Lesbian/gay/bisexual/other & $8 \cdot 9(7 \cdot 6-10 \cdot 4)$ & $8 \cdot 7(5 \cdot 4-13 \cdot 8)$ & $8 \cdot 2(4 \cdot 7-14 \cdot 0)$ & $52 \cdot 3(45 \cdot 0-59 \cdot 5)$ & $30 \cdot 8(24 \cdot 8-37 \cdot 6)$ & \\
\hline Non-Hispanic white & $74 \cdot 8(72 \cdot 4-76 \cdot 9)$ & $9 \cdot 9(8 \cdot 5-11 \cdot 5)$ & $7 \cdot 2(5 \cdot 5-9 \cdot 3)$ & $55 \cdot 3(52 \cdot 2-58 \cdot 4)$ & $27 \cdot 6(24 \cdot 8-30 \cdot 5)$ & \\
\hline Non-Hispanic black & $8 \cdot 2(7 \cdot 0-9 \cdot 6)$ & $14 \cdot 7(9 \cdot 6-21 \cdot 9)$ & $6 \cdot 4(2 \cdot 8-14 \cdot 0)$ & $60 \cdot 9(51 \cdot 4-69 \cdot 7)$ & $18 \cdot 0(11 \cdot 5-26 \cdot 9)$ & \\
\hline Hispanic & $11 \cdot 6(10 \cdot 1-13 \cdot 3)$ & $21 \cdot 7(15 \cdot 6-29 \cdot 4)$ & $5 \cdot 4(3 \cdot 2-9 \cdot 0)$ & $50 \cdot 7(43 \cdot 3-58 \cdot 0)$ & $22 \cdot 2(17 \cdot 6-27 \cdot 6)$ & \\
\hline Other & $5 \cdot 4(4 \cdot 4-6 \cdot 7)$ & $14 \cdot 2(7 \cdot 9-24 \cdot 2)$ & $6 \cdot 5(2 \cdot 9-13 \cdot 9)$ & $51 \cdot 9(40 \cdot 7-62 \cdot 9)$ & $27 \cdot 5(18 \cdot 0-39 \cdot 6)$ & \\
\hline Education $(n=1870)^{b}$ & & & & & & $0 \cdot 0012$ \\
\hline$\leq$ High school & $48 \cdot 4(45 \cdot 8-51 \cdot 0)$ & $10 \cdot 2(8 \cdot 4-12 \cdot 4)$ & $6 \cdot 3(4 \cdot 3-9 \cdot 1)$ & $60 \cdot 9(57 \cdot 1-64 \cdot 6)$ & $22 \cdot 5(19 \cdot 7-25 \cdot 7)$ & \\
\hline$\geq$ Some college degree & $51 \cdot 6(49 \cdot 0-54 \cdot 2)$ & $13 \cdot 5(11 \cdot 3-16 \cdot 1)$ & $7 \cdot 5(5 \cdot 7-9 \cdot 8)$ & $50 \cdot 1(46 \cdot 5-53 \cdot 7)$ & $28 \cdot 9(25 \cdot 8-32 \cdot 3)$ & \\
\hline
\end{tabular}




\begin{tabular}{|c|c|c|c|c|c|c|}
\hline \multicolumn{6}{|l|}{$\begin{array}{l}\text { Household income } \\
(n=1737)\end{array}$} & \multirow[t]{4}{*}{$0 \cdot 003$} \\
\hline$<\$ 25,000$ & $47 \cdot 3(44 \cdot 4-50 \cdot 2)$ & $11 \cdot 2(9 \cdot 0-13 \cdot 8)$ & $5 \cdot 3(3 \cdot 6-7 \cdot 7)$ & $57 \cdot 4(53 \cdot 6-61 \cdot 2)$ & $26 \cdot 2(23 \cdot 0-29 \cdot 5)$ & \\
\hline$\$ 25,000$ to $\$ 74,999$ & $38 \cdot 1(35 \cdot 5-40 \cdot 8)$ & $10 \cdot 5(8 \cdot 5-12 \cdot 9)$ & $8 \cdot 1(5 \cdot 9-10 \cdot 9)$ & $56 \cdot 6(52 \cdot 0-61 \cdot 0)$ & $24 \cdot 8(20 \cdot 7-29 \cdot 4)$ & \\
\hline$\geq \$ 75,000$ & $14 \cdot 6(12 \cdot 6-17 \cdot 0)$ & $17 \cdot 8(13 \cdot 1-23 \cdot 6)$ & $9 \cdot 4(5 \cdot 2-16 \cdot 5)$ & $46 \cdot 2(38 \cdot 5-54 \cdot 1)$ & $26 \cdot 6(20 \cdot 8-33 \cdot 4)$ & \\
\hline $\begin{array}{l}\text { Employment status } \\
(n=1864)\end{array}$ & & & & & & $0 \cdot 22$ \\
\hline Full-time & $44 \cdot 9(42 \cdot 1-47 \cdot 7)$ & $12 \cdot 3(10 \cdot 1-14 \cdot 9)$ & $6 \cdot 8(5 \cdot 1-9 \cdot 1)$ & $56 \cdot 6(52 \cdot 7-60 \cdot 4)$ & $24 \cdot 3(20 \cdot 8-28 \cdot 1)$ & \\
\hline $\begin{array}{l}\text { Don't currently work for } \\
\text { pay }\end{array}$ & $37 \cdot 2(34 \cdot 1-40 \cdot 3)$ & $10 \cdot 4(8 \cdot 2-13 \cdot 0)$ & $6 \cdot 0(4 \cdot 2-8 \cdot 5)$ & $56 \cdot 0(52 \cdot 1-59 \cdot 9)$ & $27 \cdot 6(24 \cdot 5-30 \cdot 9)$ & \\
\hline$B M I, k g / m^{2}(n=1823)$ & & & & & & $0 \cdot 31$ \\
\hline$<30 \cdot 0$ & $70 \cdot 3(68 \cdot 0-72 \cdot 4)$ & $12 \cdot 6(10 \cdot 7-14 \cdot 7)$ & $7 \cdot 0(5 \cdot 4-9 \cdot 1)$ & $54.1(51 \cdot 2-57 \cdot 0)$ & $26 \cdot 3(23 \cdot 7-29 \cdot 0)$ & \\
\hline$\geq 30 \cdot 0$ & $29 \cdot 8(27 \cdot 6-32 \cdot 0)$ & $9 \cdot 5(7 \cdot 1-12 \cdot 7)$ & $7 \cdot 2(5 \cdot 0-10 \cdot 3)$ & $58 \cdot 2(53 \cdot 1-63 \cdot 1)$ & $25 \cdot 0(20 \cdot 7-30 \cdot 0)$ & \\
\hline $\begin{array}{l}\text { US Census region } \\
(n=1870)\end{array}$ & & & & & & $0 \cdot 45$ \\
\hline Midwest & $25 \cdot 4(23 \cdot 2-27 \cdot 7)$ & $10 \cdot 1(8 \cdot 3-12 \cdot 3)$ & $5 \cdot 5(3 \cdot 3-8 \cdot 9)$ & $58 \cdot 2(54 \cdot 1-62 \cdot 1)$ & $26 \cdot 3(22 \cdot 4-30 \cdot 6)$ & \\
\hline South & $39 \cdot 9(37 \cdot 1-42 \cdot 8)$ & $11 \cdot 6(9 \cdot 2-14 \cdot 4)$ & $6 \cdot 8(4 \cdot 6-10 \cdot 1)$ & $54 \cdot 6(49 \cdot 1-60 \cdot 0)$ & $27 \cdot 0(22 \cdot 7-31 \cdot 8)$ & \\
\hline West & $20 \cdot 8(18 \cdot 2-23 \cdot 7)$ & $12 \cdot 8(9 \cdot 6-16 \cdot 8)$ & $9 \cdot 2(6 \cdot 5-12 \cdot 8)$ & $52 \cdot 5(47 \cdot 3-57 \cdot 6)$ & $25 \cdot 6(20 \cdot 7-31 \cdot 2)$ & \\
\hline \multicolumn{7}{|l|}{ Behavioral factors } \\
\hline \multicolumn{3}{|c|}{$\begin{array}{l}\text { Age at } 1^{\text {st }} \text { exposure to tobacco product }(y) \\
(n=1870)\end{array}$} & & & & $0 \cdot 0012$ \\
\hline$<18$ & $76 \cdot 5(74 \cdot 4-78 \cdot 4)$ & $10 \cdot 1(8 \cdot 4-12 \cdot 0)$ & $6 \cdot 5(5 \cdot 1-8 \cdot 3)$ & $56 \cdot 5(53 \cdot 3-59 \cdot 6)$ & $26 \cdot 9(24 \cdot 1-29 \cdot 9)$ & \\
\hline$\geq 18$ & $23 \cdot 5(21 \cdot 6-25 \cdot 6)$ & $17 \cdot 9(14 \cdot 3-22 \cdot 2)$ & $8 \cdot 1(5 \cdot 5-12 \cdot 0)$ & $31 \cdot 6(46 \cdot 3-56 \cdot 8)$ & $22 \cdot 4(18 \cdot 1-27 \cdot 4)$ & \\
\hline $\begin{array}{l}\text { Duration of tobacco use } \\
(n=1870)\end{array}$ & & & & & & 0.0005 \\
\hline Mean (SD) & $22 \cdot 2(14 \cdot 6)$ & $16 \cdot 8(14 \cdot 8)$ & $22 \cdot 1(15 \cdot 7)$ & $23 \cdot 0(14 \cdot 1)$ & $23 \cdot 0(14 \cdot 7)$ & \\
\hline $\begin{array}{l}\text { Other tobacco use } \\
(n=1870)\end{array}$ & & & & & & 0.005 \\
\hline Yes & $25 \cdot 6(23 \cdot 0-28 \cdot 4)$ & $16 \cdot 6(13 \cdot 5-20 \cdot 2)$ & $6 \cdot 6(4 \cdot 5-9 \cdot 5)$ & $51 \cdot 4(46 \cdot 9-55 \cdot 9)$ & $25 \cdot 5(21 \cdot 6-29 \cdot 9)$ & \\
\hline No & $74 \cdot 4(71 \cdot 6-77 \cdot 0)$ & $10 \cdot 3(8 \cdot 9-12 \cdot 0)$ & $7 \cdot 0(5 \cdot 4-9 \cdot 1)$ & $56 \cdot 7(53 \cdot 5-59 \cdot 8)$ & $25 \cdot 9(23 \cdot 3-28 \cdot 8)$ & \\
\hline
\end{tabular}


Alcohol use within 30 days $^{c}(n=1616)$

\begin{tabular}{|c|c|c|c|c|c|}
\hline Yes & $67 \cdot 0(63 \cdot 5-70 \cdot 4)$ & $12 \cdot 5(10 \cdot 5-14 \cdot 9)$ & $7 \cdot 1(5 \cdot 4-9 \cdot 2)$ & $55 \cdot 3(51 \cdot 8-58 \cdot 7)$ & $25 \cdot 2(22 \cdot 2-28 \cdot 4)$ \\
\hline No & $33 \cdot 0(29 \cdot 6-36 \cdot 5)$ & $9 \cdot 8(7 \cdot 3-13 \cdot 0)$ & $6 \cdot 4(4 \cdot 2-9 \cdot 5)$ & $54 \cdot 1(49 \cdot 4-58 \cdot 8)$ & $29 \cdot 7(25 \cdot 5-34 \cdot 3)$ \\
\hline Marijuana $^{d}(n=1245)$ & & & & & \\
\hline Yes & $31 \cdot 5(28 \cdot 5-34 \cdot 5)$ & $15.3(12 \cdot 0-19 \cdot 2)$ & $6 \cdot 5(4 \cdot 4-9 \cdot 5)$ & $53 \cdot 5(48 \cdot 4-58 \cdot 5)$ & $24 \cdot 8(20 \cdot 1-30 \cdot 0)$ \\
\hline No & $68 \cdot 5(65 \cdot 5-71 \cdot 5)$ & $10 \cdot 4(8 \cdot 4-13 \cdot 0)$ & $6 \cdot 8(4 \cdot 9-9 \cdot 2)$ & $53 \cdot 9(49 \cdot 9-57 \cdot 8)$ & $29 \cdot 0(25 \cdot 4-32 \cdot 8)$ \\
\hline \multicolumn{6}{|c|}{$\begin{array}{l}\text { Definitions: Cessation indicates no current tobacco use, harm reduction: e-cigarette mono use, relapse: cigarette mono use. Abbreviation: PATH } \\
\text { indicates Population Assessment of Tobacco and Health; CI, confidence intervals; US, United States, BMI, body mass index; SD, standard deviation. } \\
\text { aOther refers to Non-Hispanic American Indian or Alaska Native, Non-Hispanic Asian/Native Hawaiian or Other Pacific Islander and persons with } \\
\text { multiple races. }{ }^{\mathrm{b}} \leq \text { high school denotes less than high school/GED/high school graduate; } \geq \text { some college degree denotes some } \\
\text { college/associate's/bachelor's/advanced degree. }{ }^{\mathrm{c}} \text { Answered by respondents who have ever used alcohol and used alcohol in the past } 30 \text { days. }{ }^{\mathrm{d}} \text { Answered } \\
\text { by respondents who used marijuana in past 30days. Percentages are rounded up to } 1 \text { decimal place. }\end{array}$} \\
\hline
\end{tabular}


Table 2 - Nicotine dependence symptoms and interest in quitting among adult ( $\geq 18$ years) dual e-cigarette/cigarette users according to main transitions at 2-year follow-up: PATH Study, 2013-2016

\begin{tabular}{|c|c|c|c|c|c|c|}
\hline \multicolumn{7}{|c|}{ Tobacco use at 2-year follow-up (Wave 3) } \\
\hline Wave 3 & $\begin{array}{c}\text { Overall, } \\
\%,(95 \% \text { CI })\end{array}$ & $\begin{array}{c}\text { Cessation, } \\
\%,(95 \% \text { CI })\end{array}$ & $\begin{array}{c}\text { Harm reduction, } \\
\%,(95 \% \mathrm{CI})\end{array}$ & $\begin{array}{c}\text { Relapse, } \\
\%,(95 \% \text { CI })\end{array}$ & $\begin{array}{c}\text { Dual use, } \\
\%,(95 \% \text { CI })\end{array}$ & p value \\
\hline \multicolumn{6}{|c|}{ Soon after waking, minutes $(n=1621)$} & $0 \cdot 55$ \\
\hline$<30$ & $83 \cdot 2(81 \cdot 0-85 \cdot 2)$ & $9 \cdot 0(7 \cdot 5-10 \cdot 8)$ & $6 \cdot 4(4 \cdot 8-8 \cdot 4)$ & $58 \cdot 1(54 \cdot 5-61 \cdot 5)$ & $26 \cdot 5(23.6-29 \cdot 7)$ & \\
\hline$\geq 30$ & $16 \cdot 8(14 \cdot 8-19 \cdot 0)$ & $8 \cdot 6(5 \cdot 2-13 \cdot 7)$ & $8 \cdot 6(5 \cdot 7-12 \cdot 8)$ & $54 \cdot 0(46 \cdot 8-61 \cdot 1)$ & $28 \cdot 8(23 \cdot 2-35 \cdot 1)$ & \\
\hline \multicolumn{2}{|c|}{ Addicted to tobacco $(n=1793)$} & \multicolumn{5}{|r|}{$<0 \cdot 0001$} \\
\hline Yes & $86 \cdot 2(84.0-88.1)$ & $8 \cdot 9(7 \cdot 5-10 \cdot 4)$ & $6 \cdot 4(5 \cdot 0-8 \cdot 2)$ & $58 \cdot 0(54 \cdot 8-61 \cdot 1)$ & $26 \cdot 8(24 \cdot 0-29 \cdot 6)$ & \\
\hline No & $13 \cdot 9(11.9-16.0)$ & $26 \cdot 9(21 \cdot 5-33 \cdot 1)$ & $10 \cdot 1(6 \cdot 6-15 \cdot 0)$ & $42 \cdot 2(35 \cdot 7-49 \cdot 0)$ & $20 \cdot 9(15 \cdot 6-27 \cdot 3)$ & \\
\hline \multicolumn{6}{|c|}{ Strong craving for tobacco product $(n=1795)$} & $<0 \cdot 0001$ \\
\hline Yes & $82 \cdot 4(80 \cdot 4-84 \cdot 2)$ & $8 \cdot 4(7 \cdot 0-10 \cdot 1)$ & $6 \cdot 2(4 \cdot 9-8 \cdot 0)$ & $57 \cdot 9(54 \cdot 4-61 \cdot 4)$ & $27 \cdot 4(24 \cdot 6-30 \cdot 5)$ & \\
\hline No & $17 \cdot 6(15 \cdot 8-19 \cdot 6)$ & $25 \cdot 1(20 \cdot 3-30 \cdot 7)$ & $10 \cdot 3(6 \cdot 8-15 \cdot 3)$ & $45 \cdot 9(40 \cdot 0-52 \cdot 0)$ & $18 \cdot 7(14 \cdot 6-23 \cdot 7)$ & \\
\hline \multicolumn{6}{|c|}{ Felt the need to use tobacco $(n=1794)$} & $<0 \cdot 0001$ \\
\hline Yes & $85 \cdot 6(83 \cdot 7-87 \cdot 4)$ & $8 \cdot 9(7 \cdot 5-10 \cdot 5)$ & $6 \cdot 9(5 \cdot 3-8 \cdot 5)$ & $57 \cdot 6(54 \cdot 4-60 \cdot 8)$ & $26 \cdot 8(24 \cdot 0-29 \cdot 8)$ & \\
\hline No & $14 \cdot 4(12 \cdot 6-16 \cdot 3)$ & $26 \cdot 0(20 \cdot 7-32 \cdot 0)$ & $8 \cdot 4(5 \cdot 3-13 \cdot 1)$ & $45 \cdot 1(37 \cdot 9-52 \cdot 4)$ & $20 \cdot 5(15 \cdot 9-26 \cdot 1)$ & \\
\hline \multicolumn{6}{|c|}{ Use tobacco in prohibited places $(n=1795)$} & $0 \cdot 03$ \\
\hline Yes & $28 \cdot 0(25 \cdot 8-30 \cdot 2)$ & $7 \cdot 7(5 \cdot 9-9 \cdot 9)$ & $6 \cdot 3(4 \cdot 2-9 \cdot 5)$ & $59 \cdot 7(54 \cdot 7-64 \cdot 5)$ & $26 \cdot 3(22 \cdot 2-30 \cdot 7)$ & \\
\hline No & $72 \cdot 1(69 \cdot 8-74 \cdot 2)$ & $12 \cdot 8(11 \cdot 1-14 \cdot 7)$ & $7 \cdot 2(5 \cdot 5-9 \cdot 4)$ & $54 \cdot 3(51 \cdot 0-57 \cdot 6)$ & $25 \cdot 8(23 \cdot 0-28 \cdot 7)$ & \\
\hline \multicolumn{6}{|c|}{ Gave up activities $(n=1794)$} & $0 \cdot 97$ \\
\hline Yes & $14 \cdot 3(12 \cdot 7-16 \cdot 0)$ & $10 \cdot 6(7 \cdot 4-14 \cdot 9)$ & $6 \cdot 6(3 \cdot 6-11 \cdot 6)$ & $56 \cdot 5(49 \cdot 6-63 \cdot 5)$ & $26 \cdot 4(20 \cdot 5-33 \cdot 2)$ & \\
\hline No & $85 \cdot 7(84 \cdot 0-87 \cdot 3)$ & $11 \cdot 5(9 \cdot 9-13 \cdot 2)$ & $7 \cdot 0(5 \cdot 5-8 \cdot 9)$ & $55 \cdot 7(52 \cdot 6-58 \cdot 8)$ & $25 \cdot 8(23 \cdot 2-28 \cdot 6)$ & \\
\hline \multicolumn{6}{|c|}{ Frequency of tobacco use $(n=1631)$} & $<0.0001$ \\
\hline Regular & $64 \cdot 4(61 \cdot 7-67 \cdot 1)$ & $14 \cdot 9(12 \cdot 1-18 \cdot 1)$ & $9.9(7 \cdot 4-13 \cdot 1)$ & $64 \cdot 0(60 \cdot 5-67 \cdot 4)$ & $25 \cdot 0(22 \cdot 0-28 \cdot 3)$ & \\
\hline Not regular & $35 \cdot 6(32 \cdot 9-38 \cdot 4)$ & $6 \cdot 0(4 \cdot 7-7 \cdot 7)$ & $5 \cdot 0(3 \cdot 5-6 \cdot 9)$ & $45 \cdot 1(40 \cdot 9-49 \cdot 3)$ & $30 \cdot 2(26 \cdot 4-34 \cdot 3)$ & \\
\hline \multicolumn{6}{|c|}{ ND symptoms severity categories $(n=1796)$} & $<0.0001$ \\
\hline $0-3$ & $23 \cdot 4(21 \cdot 0-25 \cdot 9)$ & $24 \cdot 4(19 \cdot 8-29 \cdot 6)$ & $10 \cdot 5(7 \cdot 4-14 \cdot 6)$ & $44 \cdot 0(38 \cdot 4-49 \cdot 7)$ & $21 \cdot 2(17 \cdot 3-25 \cdot 8)$ & \\
\hline $4-5$ & $56 \cdot 7(54 \cdot 1-59 \cdot 2)$ & $7 \cdot 9(6 \cdot 2-9 \cdot 8)$ & $6 \cdot 9(5 \cdot 2-9 \cdot 2)$ & $57 \cdot 3(53 \cdot 6-61 \cdot 0)$ & $27 \cdot 9(24 \cdot 7-31 \cdot 3)$ & \\
\hline
\end{tabular}




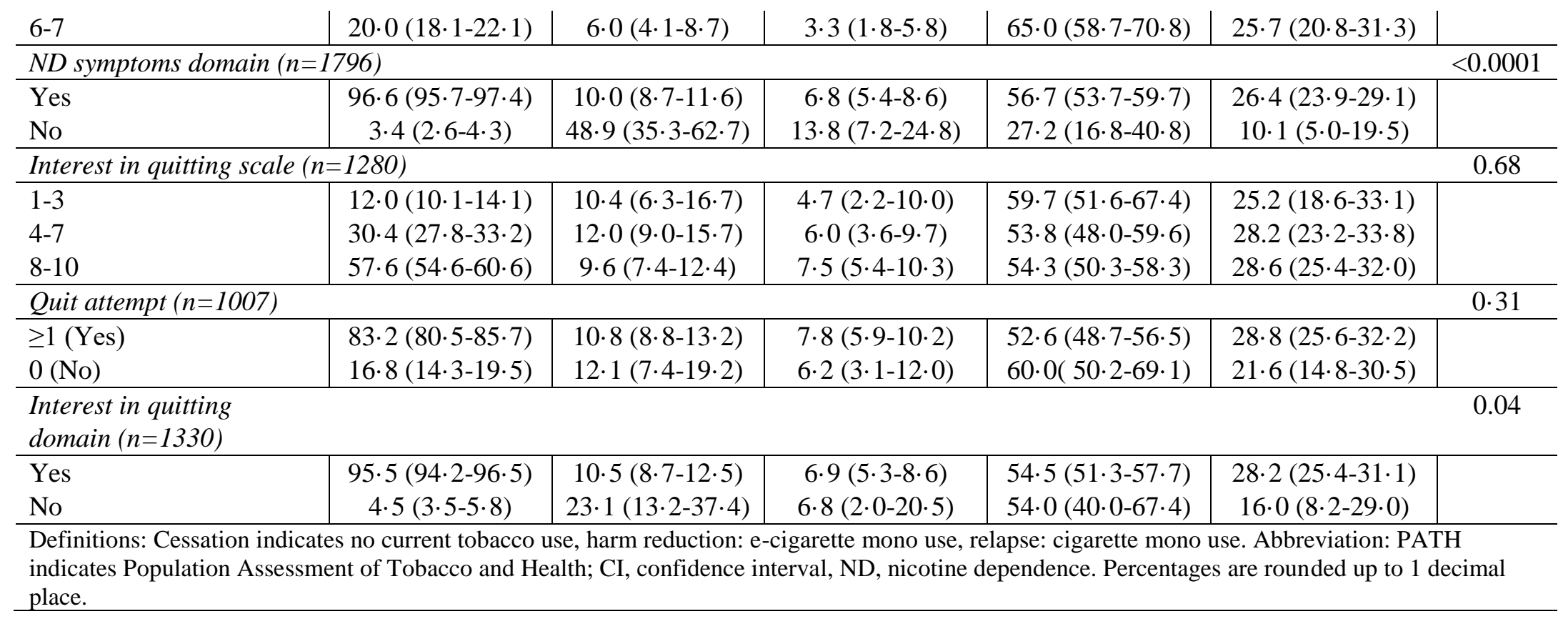




\begin{tabular}{|c|c|c|c|c|c|c|}
\hline \multicolumn{7}{|c|}{ Tobacco use at 2-year follow-up (Wave 3) } \\
\hline Wave 3 & $\begin{array}{c}\text { Overall, } \\
\%,(95 \% \text { CI })\end{array}$ & $\begin{array}{c}\text { Cessation, } \\
\%,(95 \% \mathrm{CI})\end{array}$ & $\begin{array}{c}\text { Harm reduction, } \\
\%,(95 \% \mathrm{CI})\end{array}$ & $\begin{array}{c}\text { Relapse, } \\
\%,(95 \% \text { CI })\end{array}$ & $\begin{array}{c}\text { Dual use, } \\
\%,(95 \% \mathrm{CI})\end{array}$ & p value \\
\hline \multicolumn{6}{|l|}{ Diabetes $(n=1865)$} & $0 \cdot 87$ \\
\hline Yes & $11 \cdot 1(9 \cdot 5-12 \cdot 9)$ & $10 \cdot 9(7 \cdot 0-16 \cdot 5)$ & $8 \cdot 3(4 \cdot 7-14 \cdot 3)$ & $54 \cdot 9(47 \cdot 7-62 \cdot 0)$ & $26 \cdot 0(19 \cdot 9-33 \cdot 1)$ & \\
\hline No & $89 \cdot 0(87 \cdot 1-90 \cdot 5)$ & $12 \cdot 1(10 \cdot 5-13 \cdot 9)$ & $6 \cdot 8(5 \cdot 2-8 \cdot 6)$ & $55 \cdot 3(52 \cdot 5-58 \cdot 1)$ & $25 \cdot 8(23 \cdot 4-28 \cdot 4)$ & \\
\hline \multicolumn{6}{|c|}{ High cholesterol $(n=1865)$} & $0 \cdot 19$ \\
\hline Yes & $18 \cdot 5(16 \cdot 6-20 \cdot 6)$ & $10 \cdot 6(7 \cdot 4-14 \cdot 8)$ & $8 \cdot 6(5 \cdot 3-13 \cdot 5)$ & $51 \cdot 1(44 \cdot 6-57 \cdot 5)$ & $29 \cdot 8(24 \cdot 6-35 \cdot 6)$ & \\
\hline No & $81 \cdot 5(79 \cdot 4-83 \cdot 4)$ & $12 \cdot 2(10 \cdot 6-14 \cdot 1)$ & $6 \cdot 5(5 \cdot 1-8 \cdot 2)$ & $56 \cdot 3(53 \cdot 4-59 \cdot 1)$ & $25 \cdot 0(22 \cdot 6-27 \cdot 6)$ & \\
\hline \multicolumn{6}{|c|}{ Hypertension $(n=1865)$} & $0 \cdot 003$ \\
\hline Yes & $23 \cdot 4(20 \cdot 9-26 \cdot 0)$ & $8 \cdot 4(5 \cdot 9-11 \cdot 7)$ & $5 \cdot 4(3 \cdot 3-8 \cdot 9)$ & $63 \cdot 8(59 \cdot 3-68 \cdot 0)$ & $22 \cdot 5(18 \cdot 6-26 \cdot 9)$ & \\
\hline No & $76 \cdot 6(74 \cdot 0-79 \cdot 1)$ & $13 \cdot 0(11 \cdot 3-14 \cdot 8)$ & $7 \cdot 3(5 \cdot 7-9 \cdot 3)$ & $52 \cdot 8(49 \cdot 6-55 \cdot 9)$ & $27 \cdot 0(24 \cdot 2-29 \cdot 9)$ & \\
\hline \multicolumn{6}{|c|}{ Myocardial infarction $(n=1865)$} & $0 \cdot 84$ \\
\hline Yes & $3 \cdot 3(2 \cdot 5-4 \cdot 3)$ & $8 \cdot 1(2 \cdot 8-21 \cdot 4)$ & $5 \cdot 8(1 \cdot 6-18 \cdot 8)$ & $57 \cdot 3(43 \cdot 2-70 \cdot 3)$ & $28 \cdot 8(17 \cdot 7-43 \cdot 3)$ & \\
\hline No & $96 \cdot 7(95 \cdot 7-97 \cdot 5)$ & $12 \cdot 0(10 \cdot 5-13 \cdot 7)$ & $6 \cdot 9(5 \cdot 5-8 \cdot 7)$ & $55 \cdot 3(52 \cdot 5-58 \cdot 0)$ & $25 \cdot 8(23 \cdot 4-28 \cdot 4)$ & \\
\hline \multicolumn{6}{|c|}{ Clinical factors domain $(n=1869)$} & 0.08 \\
\hline Yes & $36 \cdot 0(33 \cdot 1-39 \cdot 0)$ & $9 \cdot 1(7 \cdot 0-11 \cdot 8)$ & $6 \cdot 8(4 \cdot 7-9 \cdot 7)$ & $54 \cdot 7(51 \cdot 2-58 \cdot 2)$ & $24 \cdot 8(22 \cdot 1-27 \cdot 7)$ & \\
\hline No & $64 \cdot 0(61 \cdot 1-66 \cdot 9)$ & $13 \cdot 5(11 \cdot 6-15 \cdot 6)$ & $7 \cdot 0(5 \cdot 4-9 \cdot 7)$ & $56 \cdot 4(52 \cdot 1-60 \cdot 6)$ & $27 \cdot 7(23 \cdot 8-31 \cdot 9)$ & \\
\hline
\end{tabular}


Table 4 - Univariate predictors of dual use transitions at 2-year follow-up among US adults ( $\geq 18$ years): PATH study, 2013-2016

\begin{tabular}{|c|c|c|c|}
\hline & Cessation & Harm reduction & Relapse \\
\hline & Unadjusted OR (95\% CI) & $\begin{array}{c}\text { Unadjusted OR (95\% } \\
\text { CI) }\end{array}$ & $\begin{array}{l}\text { Unadjusted OR } \\
(95 \% \mathrm{CI})\end{array}$ \\
\hline \multicolumn{4}{|l|}{ Demographic and behavioral factors } \\
\hline \multicolumn{4}{|l|}{ Age, years (ref: $18-24)$} \\
\hline $25-34$ & $0 \cdot 52(0 \cdot 32-0 \cdot 85)$ & $0 \cdot 82(0 \cdot 47-1 \cdot 43)$ & $0 \cdot 88(0 \cdot 61-1 \cdot 27)$ \\
\hline$\geq 35$ & $0 \cdot 40(0 \cdot 26-0 \cdot 61)$ & $0.84(0.49-1.43)$ & $1.05(0 \cdot 76-1 \cdot 44)$ \\
\hline \multicolumn{4}{|l|}{ Education $^{a}$} \\
\hline$\geq$ Some college degree (vs. $\leq$ high school) & $1 \cdot 03(0 \cdot 75-1 \cdot 41)$ & $0 \cdot 92(0 \cdot 55-1 \cdot 54)$ & $0 \cdot 64(0 \cdot 51-0 \cdot 80)$ \\
\hline \multicolumn{4}{|l|}{ US census region (ref: Northeast) } \\
\hline Midwest & $0 \cdot 56(0 \cdot 33-0 \cdot 96)$ & $0 \cdot 71(0 \cdot 28-1 \cdot 76)$ & $0 \cdot 86(0.58-1.26)$ \\
\hline South & $0.63(0 \cdot 36-1 \cdot 08)$ & $0 \cdot 86(0 \cdot 36-2 \cdot 05)$ & $0.78(0 \cdot 52-1 \cdot 18)$ \\
\hline West & $0 \cdot 73(0 \cdot 41-1 \cdot 31)$ & $1 \cdot 22(0 \cdot 51-2 \cdot 93)$ & $0 \cdot 80(0 \cdot 52-1 \cdot 21)$ \\
\hline \multicolumn{4}{|l|}{ Age at $1^{s t}$ exposure to tobacco product, years } \\
\hline$<18$ (vs. $\geq 18)$ & $0 \cdot 47(0 \cdot 30-0 \cdot 73)$ & $0 \cdot 67(0 \cdot 39-1 \cdot 13)$ & $0 \cdot 91(0 \cdot 66-1 \cdot 26)$ \\
\hline Duration of tobacco use & $0.97(0.96-0.99)$ & $1 \cdot 00(0 \cdot 98-1 \cdot 01)$ & $1 \cdot 00(0 \cdot 99-1 \cdot 01)$ \\
\hline \multicolumn{4}{|l|}{ Other tobacco use } \\
\hline Yes (vs. no) & $1 \cdot 63(1 \cdot 16-2 \cdot 28)$ & $0.95(0.59-1.53)$ & $0.92(0 \cdot 71-1 \cdot 20)$ \\
\hline \multicolumn{4}{|l|}{ Marijuana } \\
\hline Yes (vs. no) & $1 \cdot 71(1 \cdot 13-2 \cdot 57)$ & $1 \cdot 13(0 \cdot 63-2 \cdot 03)$ & $1 \cdot 16(0 \cdot 83-1 \cdot 62)$ \\
\hline \multicolumn{4}{|l|}{ ND symptoms } \\
\hline \multicolumn{4}{|l|}{ Addicted to tobacco } \\
\hline Yes (vs. no) & $0 \cdot 26(0 \cdot 16-0 \cdot 41)$ & $0 \cdot 49(0 \cdot 28-0 \cdot 87)$ & $1.07(0.72-1 \cdot 60)$ \\
\hline \multicolumn{4}{|l|}{ Strong cravings for tobacco } \\
\hline Yes (vs. no) & $0 \cdot 23(0 \cdot 15-0 \cdot 36)$ & $0 \cdot 41(0 \cdot 26-0 \cdot 67)$ & $0 \cdot 86(0 \cdot 59-1 \cdot 25)$ \\
\hline Felt the need to use tobacco & & & \\
\hline
\end{tabular}




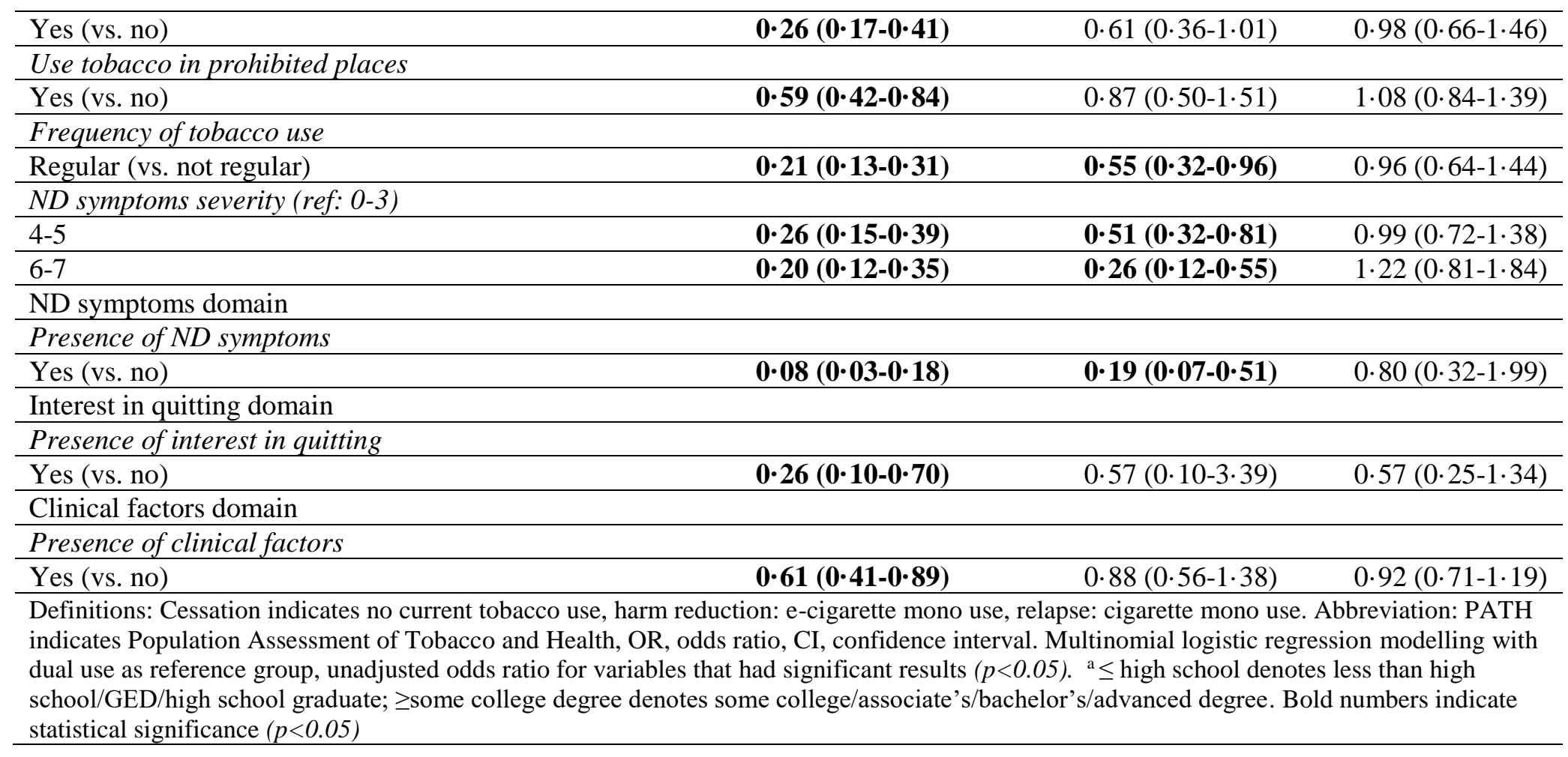


Table 5 - Multivariate predictors of dual use transitions at 2-year follow up among US adults ( $\geq 18$ years):

PATH study, 2013-2016

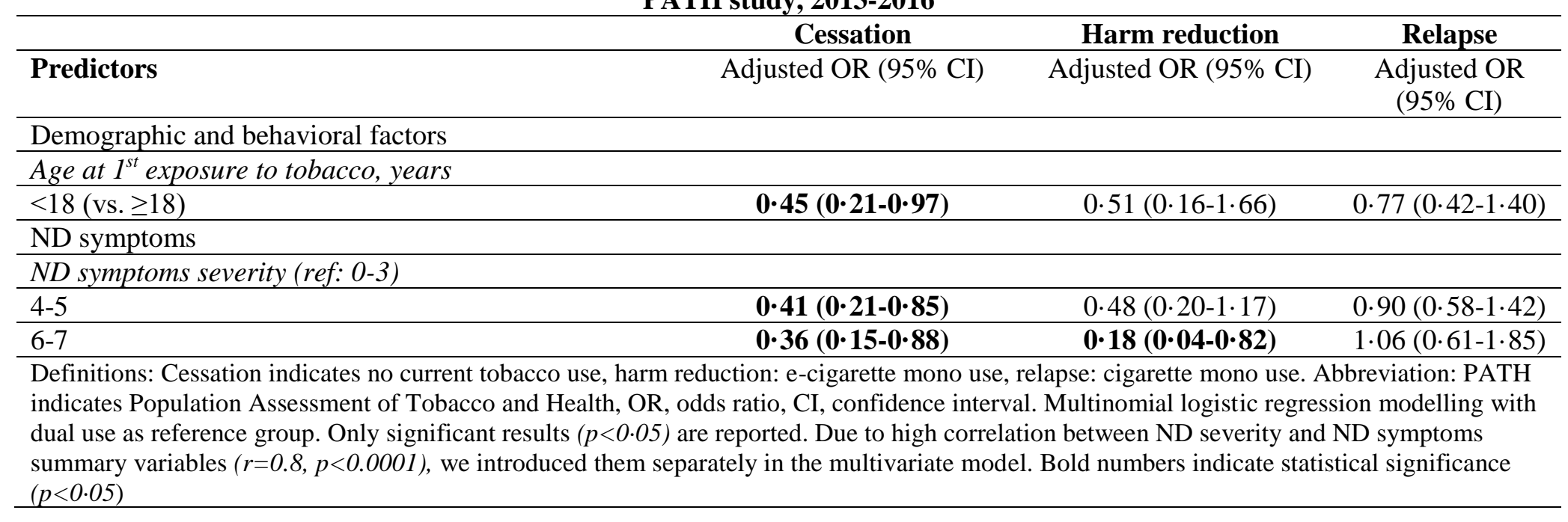




\section{Conclusions}

This dissertation sought to investigate poly-tobacco use in the US given the ever-evolving tobacco landscape with numerous tobacco products that appeal socially to youth and are perceived to be generally less harmful than traditional cigarettes. We estimated the prevalence of poly-tobacco use among youth (12-17 years) and young adults (18-34 years) and also identified correlates of poly-tobacco use in this sub-population of tobacco users. Our findings indicated that approximately $4 \%$ of youth and $18 \%$ of young adults are poly-tobacco users in the general population, with the prevalence much higher among tobacco users. The most common polytobacco combination in both age-groups were cigarettes and e-cigarettes. Additionally, we identified youth heavy drinkers had higher odds of poly-tobacco use compared to mono-tobacco use. Among young adults, males, younger adults (18-24 years), those with lower levels of educational attainment, those residing in the South, heavy drinkers, and marijuana users had statistically significant higher odds of poly-tobacco use compared to mono-tobacco use.

We showed in our second study that young and adult current e-cigarette users, had more relapse, dual-use, and transition to cigarette smoking. Furthermore, there was e-cigarette uptake among young never cigarette smokers than quitting among adult smokers. These findings suggest that e-cigarette use has the possibility of increasing the nicotine addiction base among youth.

Finally, the last study showed that among US adults, four out of five dual (e-cigarette and cigarette) users continue as dual users and cigarette users two years later. Nicotine dependence (ND) severity and early age ( $<18$ years) of first exposure to tobacco were associated with lower odds of following a cessation transition at 2-year follow up, while interest in quitting, and history of illness were not associated with favorable transitions towards cessation or harm reduction. Findings suggestive of the fact that regardless of e-cigarette use, dual users are a challenging group when it comes to quitting cigarettes. 
Collectively, our findings from the three waves of the PATH about tobacco use evolution among US youth and adults offers a cause for concern for the balance between the beneficial and harmful potentials of e-cigarette use in the general population. Our study findings emphasize the need for stricter tobacco regulatory policies, so as to prevent another tobacco epidemic among young people. 


\title{
OLATOKUNBO OSIBOGUN
}

\author{
Born, New York, USA \\ 2003-2010 \\ Bachelor of Medicine, Bachelor of Surgery (M.B.B.S) \\ Igbinedion University Okada \\ Nigeria \\ 2010-2011 \\ Medical Intern \\ Lagos University Teaching Hospital \\ Lagos, Nigeria \\ 2011-2012 \\ Medical Officer \\ Central Bank of Nigeria \\ Lagos, Nigeria \\ $2012-2013$ \\ Master of Public Health (MPH) \\ University of Alabama at Birmingham, \\ Birmingham, Alabama \\ 2015-2017 \\ Doctoral Student \\ Florida International University \\ Miami, Florida \\ 2015-2016 \\ Scholarship recipient \\ Graduate Minority Opportunity Program, \\ Florida International University \\ 2015-2018 \\ Graduate Assistant \\ Florida International University \\ 2018-2019 \\ Dissertation Year Fellowship \\ University Graduate School \\ Florida International University \\ 2017-2019 \\ Doctoral Candidate \\ Florida International University \\ Miami, Florida \\ PUBLICATIONS (Selected)
}

Ogunmoroti O, Osibogun O, McClelland RL, Burke GL, Nasir K, Michos ED. Alcohol and ideal cardiovascular health: The Multi-Ethnic Study of Atherosclerosis. Clin Card. 2018. doi:

10.1002/clc.23125 [Epub ahead of print]

Asfar T, Ben Taleb Z, Osibogun O, Ruano-Herreria EC, Sierra D, Ward KD, Salloum RG, Maziak WM. How Do Waterpipe Smoking Establishments Attract Smokers? Implications for Policy. Subst Use Misuse. 2018. DOI: 10.1080/10826084.2018.1524489 
Osibogun O, Ogunmoroti O, Spatz ES, Burke GL, Michos ED. Is self-rated health associated with ideal cardiovascular health? The Multi-Ethnic Study of Atherosclerosis. Clin Card. 2018. https://doi.org/10.1002/clc.22995

Osibogun O, Ben Taleb Z, Bahelah R, Salloum RG, Maziak W. Correlates of poly-tobacco use among youth and young adults: Findings from the Population Assessment of Tobacco and Health study, 2013-2014. Drug Alcohol Depend. https://doi.org/10.1016/j.drugalcdep.2018.02.024

Osibogun O, Ogunmoroti O, Michos ED, et al. A systematic review of the associations between HIV/HCV coinfection and biomarkers of cardiovascular disease. Rev Med Virol. 2017; e1953. https://doi.org/10.1002/rmv.1953.

Osibogun O, Ogunmoroti O, Michos E, Spatz E, Olubajo B, Nasir K, Madhivanan P, Maziak W. HIV/HCV Co-Infection and the risk of Cardiovascular Disease: A Meta-analysis. J Viral Hepat. 2017;00:1-7.

Osibogun O, Pankey B. Racial Residential Segregation and Poor Health. Am J Public Health. 2017;107:e13

Myers K, Osibogun O, Madhivana P. Errors in Assessing Race and Ethnicity in Clinical Trial Enrollment. J Natl Med Assoc. 2016;108:194

Bahelah R, DiFranza JR, Ward KD, Fouad FM, Eissenberg T, Ben Taleb Z, Jaber R, Osibogun O, Maziak W. (2016). Correlates of nicotine dependence among adolescent waterpipe smokers. Drug Alcohol Depend. 168: 230-238.

Osibogun O, Campa A, Madhivanan P. Literature Review and Meta-Analysis on Micronutrient Fortified Condiments and Noodles: Reduction of Anemia in Children and Adults. Nutrients. 8:240 